\title{
Evaluation of the Visibility of Buoys and Topmarks
}

Belinda L. Collins

Philip A. Sanders

Building and Fire Research Laboratory

Gaithersburg, Maryland 20899

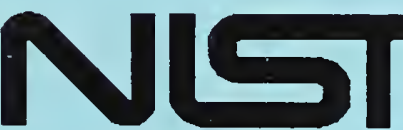

$-\mathrm{QC}$

Inited States Department of Commerce

100 nal Institute of Standards and Technology

.056

4756

1992

C. 2 



\section{Evaluation of the Visibility of Buoys and Topmarks}

\section{Leventraupt}

Belinda L. Collins, Philip A. Sanders

March 1992

Building and Fire Research Laboratory

National Institute of Standards and Technology

Gaithersburg, MD 20899

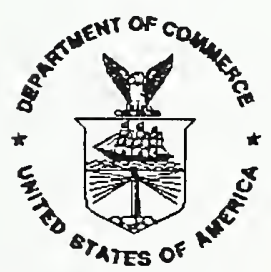

U.S. Department of Commerce

Barbara Hackman Franklin, Secretary

Technology Administration

Robert M. White, Under Secretary for Technology

National Institute of Standards and Technology

John W. Lyons, Director
U.S. Coast Guard

Groton CT 06349 
$$
\text { - }
$$ 
The research literature on the visibility of colors and topmarks used to code information on buoys and other aids to navigation was reviewed. Although several studies suggest that color may be recognizable at greater distances than topmarks, it is difficult to draw conclusions about the relative effectiveness of different topmark, color, and buoy configurations because the researchers used small numbers of observers and tested different aspects of aids to navigation. Consequently, two experiments were conducted to determine the distance at which buoy topmark configurations could be correctly identified for different lighting geometries and background conditions. In experiment 1 , the visibility of buoys and topmarks as separate entities was evaluated for ten different buoy configurations in simulated waterway viewing environments. Four buoys, including safe water, danger, port and starboard, were shown with and without topmarks, while two buoys, north and east, always had topmarks. Front and back lighted buoys were presented against both water and foliage, as well as in a "twilight" condition. In experiment 2 the visibility of buoys with integral topmarks was evaluated for front lighting conditions only. Analysis of the data from both experiments strongly suggests that topmarks did not increase the visibility the buoy configurations studied. It appears that the topmark is too small to be effective beyond $0.8 \mathrm{~km}(0.5$ mile $)$ - near the limit of visual resolution. The data do indicate that color is a critical cue in determining buoy type, with significant differences in buoy detectability between red and green buoys. Front lighting also increased visibility distance significantly. Even under back lighting conditions, however, the presence of a topmark did not increase buoy visibility. While it is possible that training could have improved accuracy, its effects would likely be limited to distances shorter than $0.8 \mathrm{~km}$ ( 0.5 miles).

Keywords: Buoy, color, detection, lighting, mark, navigation aid, shape, topmark, visibility 


\section{Acknowledgements}

The authors would like to thank Rosemary Porterfield and James R. McMahon of the Black Hill Regional Park of the Maryland-National Capital Park and Planning Commission for all their assistance in making their facilities available to us for the photographs of the buoys. This project could not have been completed without their assistance.

In addition, we would like to acknowledge Mr. Robert E. Stachon of the U.S. Coast Guard at Groton for his extremely creative fabrication of the scale model buoys for photography; the participants in the experiments at NIST and Coast Guard Headquarters; Mr. Chuck Mosher for arranging a trip on the Chesapeake Bay to view buoys and safety topmarks; Cmdr. Michael Wroblewski for making the arrangements for the experiment at Coast Guard Headquarters; Mr. Daniel Ciolkolsz and Mr. Mark Helfer for their assistance in the photography; Ms. Carla Ooyen for the photometric measurements on the slides; and Mr. Stefan Leigh for his statistical assistance and insights. Finally, we would like to thank Dr. Marc Mandler for his continuing patience and encouragement throughout the project.

\section{Disclaimer}

Commercial products and trade names are provided in this report for informational purposes only, and do not constitute an endorsement or recommendation by the National Institute of Standards and Technology or the U.S. Coast Guard. 
Table of Contents

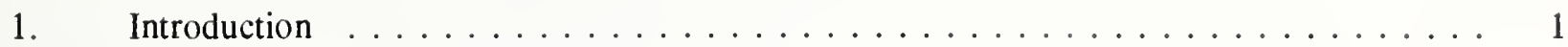

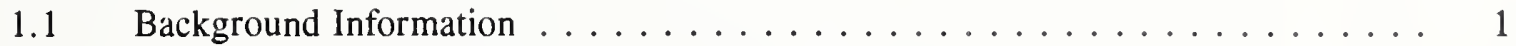

1.2 Specifications for Marks ...................... 1

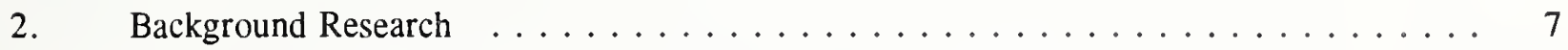

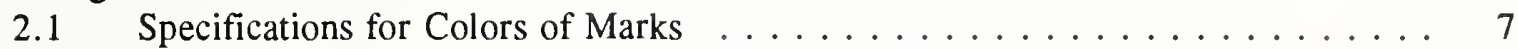

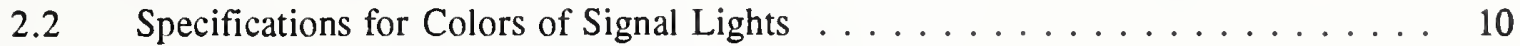

2.3 Background on the Visibility of Markings .................. 11

3. Methodology ............................... 20

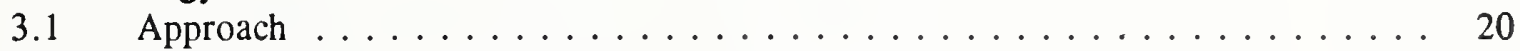

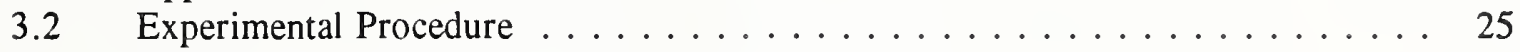

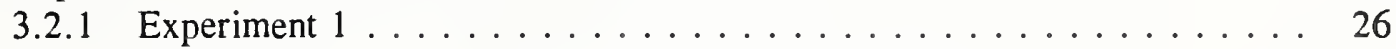

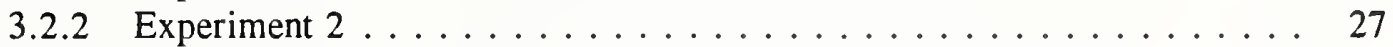

4. $\quad$ Results ................................... . . 29

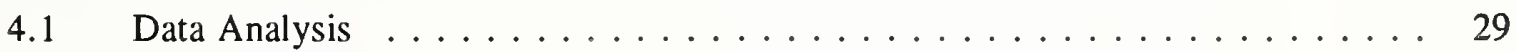

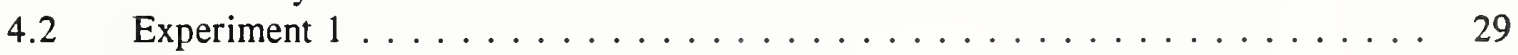

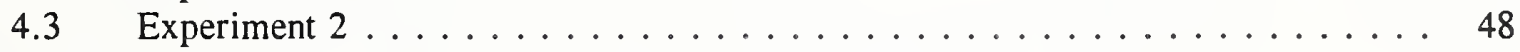

5. Conclusions ............................. 60

6. Bibliography and Additional References of Interest . . . . . . . . . . 62

Appendix A. Instructions to Subjects . . . . . . . . . . . . . . . . . 64

Appendix B. Configuration of Buoys Studied . . . . . . . . . . . . . . 65

Appendix C. Replies to Query about Topmarks . . . . . . . . . . . . . . . . 68 


\section{List of Figures}

Figure 1. Critical Dimensions of Generic Topmark Configurations _ . . . . . . . .

Figure 2. Identification Chart Containing Buoy and Topmark Configurations for

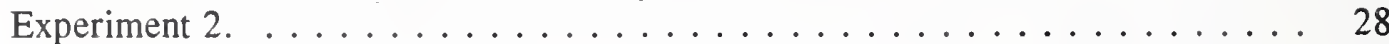

Figure 3. Comparison of Buoy Visibility with and without Topmarks for all Viewing Conditions Studied in Experiment 1................. 31

Figure 4. Comparison of the Effects of the Five Different Environments Studied in

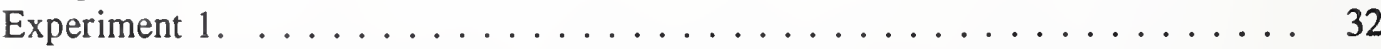

Figure 5. Comparison of the Visibility of the Ten Buoy Types for the Two Front Lighting Conditions in Experiment 1. . . . . . . . . . . . . . . . . 33

Figure 6. Comparison of the Visibility of Different Topmark Types for all Five Environments Combined in Experiment 1................ 35

Figure 7. Visibility Data for Buoy Recognition for the Observers in Experiment 1. . . . . 36

Figure 8. Mean Visibility Distance for each Buoy Type for the Five Environmental and Lighting Conditions Studied in Experiment 1. . . . . . . . . . . . 37

Figure 9. Mean Visibility Distance for each Topmark Type for the Five Environmental and Lighting Conditions Studied in Experiment 1. . . . . . . . . . . . . 38

Figure 10. Comparison of the Mean Visibility Distance for Both Buoys and Topmarks for Front Lighting Conditions in Experiment 1................. 39

Figure 11. Frequency Counts of the Choices Made for Each Buoy Configuration in Experiment 1........................... 41

Figure 12. Mean Ratings of Buoy Visibility for a Viewing Distance Equivalent to $0.18 \mathrm{~km}$ $(0.16$ Miles) in Experiment $1 . \ldots \ldots \ldots \ldots \ldots \ldots \ldots$

Figure 13. Mean Ratings of Buoy Visibility for a Viewing Distance Equivalent to $0.8 \mathrm{~km}$ $(0.50$ Miles $)$ in Experiment $1 . \ldots \ldots \ldots \ldots \ldots \ldots \ldots \ldots$

Figure 14. Comparison of the Visibility of All Buoys With and Without Topmarks in Experiment 2. ......................... 49

Figure 15. Box Plot of Visibility Distance for Different Buoy Configurations for Both Environmental Conditions in Experiment 2................ 50

Figure 16. Comparison of the Visibility of Buoys and Topmarks for the Front Lighting Water and Foliage Conditions in Experiment 2. ............. 51

Figure 17. Visibility of Colors for Buoys Studied in Experiment 2 for Both Environmental

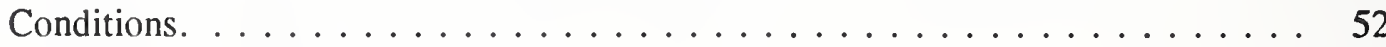

Figure 18. Visibility of Topmarks for Buoys Studied in Experiment 2 for both Environmental Conditions. ..................... 54

Figure 19. Box Plots of Buoy Visibility for Each Subject in Experiment 2. . . . . . . . 55

Figure 20. Mean Rating Data on the Seven-Point Scale for Each Buoy Type in Experiment

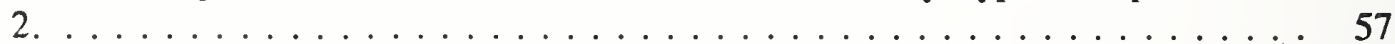

Figure 21. Mean Rating Data as a Function of Viewing Distance for Buoys Containing Red Color in Experiment 2. . . . . . . . . . . . . . . . . . .

Figure 22. Mean Rating Data as a Function of Viewing Distance for Buoys Containing Black or Green Colors in Experiment 2. . . . . . . . . . . . . . . . . 59

Figure B1. Dimensions Used to Determine the Photographic Distances . . . . . . . . . 67 
Table 1. Specifications for Marks (Buoys) $\ldots \ldots \ldots \ldots \ldots \ldots \ldots$

Table 2. Specifications for Topmark Configurations ................ 4

Table 3. IALA (CIE) and ANSI Specifications for Ordinary Surface Colors . . . . . . . 8

Table 4. Matrix for Testing ...................... 21

Table 5. Distances for Photographing Buoys and for Determining Waterway Viewing Distances. . . . . . . . . . . . . . . . . . . . . . 24

Table 6. Percentage of Times that Each Buoy Choice was Selected in Experiment 1. . . . 44

Table 7. Percentage of Times that Each Topmark Choice was Selected in Experiment 1. ............................. 46

Table 8. Percentage of Times that Each Buoy Configuration Was Selected in Experiment

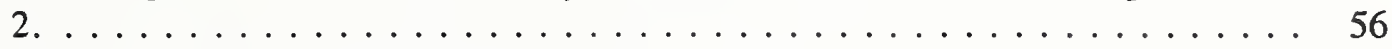

Table B1. Dimensions of Buoy and Topmark Models $\ldots \ldots \ldots \ldots$ 


\section{Introduction}

\subsection{Background Information}

The International Association of Lighthouse Authorities (IALA) recently proposed (1983 a,b) a system of color coded geometrical marks and topmarks (shapes used to code safety and position information) for use on marine buoys to provide coding information during the daytime that would allow mariners to fix their position more precisely and avoid dangers. The IALA identified a series of five marks to provide coded information to mariners. The series includes lateral marks to denote the port and starboard (left and right) sides of marine channels, cardinal marks to denote the location of the deepest water in the area, isolated danger marks to indicate an area of dangerous water which has navigable water all around it, safe water marks to indicate areas of navigable water (such as midchannel or landfall), and special marks to indicate a special area or feature referred to in a chart or other nautical document. These marks are identified by geometrical shape and surface color for daytime use, while at night coding information is provided by the color and rhythm of a flashing light (beacon) located on the buoy. For daytime coding, there are two types of geometrical marks - the buoy itself and the topmark on top of the buoy, with IALA providing specific shapes and colors for use on both the buoy and the topmark.

There is not yet worldwide agreement on the system of marks and topmarks, partly because of an inadequate research base on the effectiveness and visibility of the different marks. Topmarks are not used very extensively in the United States, for example, although specifications for their use are given by the Coast Guard (1991). The cost of introducing topmarks onto the 25,000 floating aids to navigation currently used in U.S. coastal waters is high enough that the Coast Guard requires evidence on their effectiveness before undertaking such an expensive and timeconsuming project.

The present report is designed to review the specifications for markings, explore the technical research base, and present experimental data on the visibility of maritime markings under a variety of plausible marine condition simulations.

\subsection{Specifications for Marks}

In the introduction to the Maritime Buoyage System, the International Association of Lighthouse Authorities (IALA) stated that the significance of a mark by day depends on one or more features - color, shape and topmark (IALA, 1983). These markings are intended to make a buoy conspicuous and to convey navigational information and messages. As a result, the IALA standardized both color and topmarks for marine buoyage and marking systems as aids to navigation.

The IALA recommended the following shapes and colors for buoyage marks:

$\underline{\text { Lateral Marks for Buoys }}$

Port hand

Cylinder (Can) (in Green)

Starboard hand

Cone pointing upward (in Red)

Safe water marks

Sphere (in Red and White Stripes) 
IALA gave the following relative dimensions for the marks:

Cylindrical Cylinder with height between 0.75 and 1.5 its base diameter Conical Cone with a height 0.75 to 1.5 times its base diameter

Spherical Sphere whose apparent height above the water line is more that 0.66 of its diameter

Modified lateral marks are used to indicate the preferred channel at a point where a channel divides. These are identified by a distinctive combination of colors for daytime use (and beacon flash rate for nighttime use). Complete specifications for daytime buoy shape, color, and use are given in Table 1.

The IALA also gave specifications for topmarks (used on top of the marks) to provide additional assistance for a mariner in recognizing the marks listed above. The IALA identified topmarks for six different applications. Specifications for topmarks are presented in Table 2. The IALA (1983 b) stated that the topmark should be at a height above all other parts of the mark and be as large as practical. They noted that having a large structure high above the water line on a buoy may cause damage from wind and problems with mounting, however.

The IALA provided the following guidelines for the relative size of different types of topmarks, as shown in Figure 1 which presents a sketch of the different types of topmarks and their approximate scale:

Cylindrical - The vertical height should be about 1 to 1.5 times the base diameter with a vertical clear space of at least $35 \%$ of the diameter of the cylinder. For a buoy, the diameter of the cylinder base should be at $25-30 \%$ of the diameter of the buoy at the water line.

Conical - The vertical height (base to apex) should be about $90 \%$ of base diameter. Cardinal marks (using double cones) should have a separation distance between cones which is about $50 \%$ of the base diameter. The vertical clear space between the topmark and the rest of the mark should be at least $35 \%$ of the base diameter.

Spherical - For isolated danger marks, the separation distance between the spheres should be about $50 \%$ of their diameter, while the vertical clearance should be about $35 \%$ of the diameter of the sphere. For a buoy the sphere diameter should be at least $20 \%$ of the diameter of the buoy at the waterline.

"X" (Diagonal Cross) - For a buoy, the arms of the "X" should fit diagonally within a square whose side length is about $33 \%$ of the buoy diameter at the waterline. The width of the arms should be about $15 \%$ of the square's side. 
Table 1. Specifications for Marks (Buoys)

\begin{tabular}{|c|c|c|c|c|}
\hline MESSAGE & TYPE & SHAPE & COLOR & TOPMARK \\
\hline PORT & Can & Cylindrical & Green & No Topmark \\
\hline \multirow{2}{*}{$\begin{array}{l}\text { Preferred } \\
\text { Channel }\end{array}$} & Pillar or Spar & Pillar or Spar & Green & Cylinder \\
\hline & $\begin{array}{l}\text { Can, Pillar or } \\
\text { Spar }\end{array}$ & & $\begin{array}{l}\text { Green with Red } \\
\text { Stripes }\end{array}$ & None or Can \\
\hline STARBOARD & Cone & Conical & Red & No Topmark \\
\hline \multirow{2}{*}{$\begin{array}{l}\text { Preferred } \\
\text { Channel }\end{array}$} & Pillar or Spar & Pillar or Spar & Red & Cone \\
\hline & $\begin{array}{l}\text { Cone, Pillar or } \\
\text { Spar }\end{array}$ & & $\begin{array}{l}\text { Red with Green } \\
\text { Stripes }\end{array}$ & None or Cone \\
\hline \multirow[t]{3}{*}{ SAFE WATER } & Sphere & Spherical & $\begin{array}{l}\text { Red and White } \\
\text { Vertical Stripes }\end{array}$ & No Topmark \\
\hline & Pillar & Pillar & $\begin{array}{l}\text { Red and White } \\
\text { Vertical Stripes }\end{array}$ & Sphere \\
\hline & Spar & Spar & $\begin{array}{l}\text { Red and White } \\
\text { Vertical Stripes }\end{array}$ & Sphere \\
\hline \multirow[t]{2}{*}{$\begin{array}{l}\text { ISOLATED } \\
\text { DANGER }\end{array}$} & Pillar & Pillar & $\begin{array}{l}\text { Black with Red } \\
\text { Stripes }\end{array}$ & Double Sphere \\
\hline & Spar & Spar & $\begin{array}{l}\text { Black with Red and } \\
\text { Black Stripes }\end{array}$ & Double Sphere \\
\hline $\begin{array}{l}\text { CARDINAL - } \\
\text { North } \\
\end{array}$ & $\begin{array}{l}\text { Pillar } \\
\text { Spar }\end{array}$ & $\begin{array}{l}\text { Pillar } \\
\text { Spar }\end{array}$ & $\begin{array}{l}\text { Yellow Base, Black } \\
\text { Upright }\end{array}$ & Double Cone \\
\hline East & $\begin{array}{l}\text { Pillar } \\
\text { Spar }\end{array}$ & $\begin{array}{l}\text { Pillar } \\
\text { Spar }\end{array}$ & $\begin{array}{l}\text { Black with Yellow } \\
\text { Stripe }\end{array}$ & Double Cone \\
\hline South & $\begin{array}{l}\text { Pillar } \\
\text { Spar }\end{array}$ & $\begin{array}{l}\text { Pillar } \\
\text { Spar }\end{array}$ & $\begin{array}{l}\text { Black Base, Yellow } \\
\text { Upright }\end{array}$ & Double Cone \\
\hline West & $\begin{array}{l}\text { Pillar } \\
\text { Spar }\end{array}$ & $\begin{array}{l}\text { Pillar } \\
\text { Spar }\end{array}$ & $\begin{array}{l}\text { Yellow with Black } \\
\text { Stripe }\end{array}$ & Double Cone \\
\hline SPECIAL & Optional & Optional & Yellow & Single "X" \\
\hline
\end{tabular}


Table 2. Specifications for Topmark Configurations

\begin{tabular}{||l|l|l|l||}
\hline MESSAGE & SHAPE & CONFIGURATION & COLOR \\
\hline Port & Can & Can & Green \\
\hline Starboard & Cone & $\begin{array}{l}\text { Single Cone Point } \\
\text { Upward }\end{array}$ & Red \\
\hline Safe Water & Sphere & Single Sphere & Red \\
\hline $\begin{array}{l}\text { Isolated } \\
\text { Danger }\end{array}$ & Double Sphere & $\begin{array}{l}\text { Two Spheres On Top } \\
\text { of Each Other }\end{array}$ & Black \\
\hline $\begin{array}{c}\text { Cardinal - } \\
\text { North }\end{array}$ & Double Cone & $\begin{array}{l}\text { Two Cones } \\
\text { Points Upward }\end{array}$ & Black \\
\hline East & Double Cone & $\begin{array}{l}\text { Two Cones } \\
\text { Base to Base }\end{array}$ & Black \\
\hline South & Double Cone & $\begin{array}{l}\text { Two Cones } \\
\text { Points Downward }\end{array}$ & Black \\
\hline North & Double Cone & $\begin{array}{l}\text { Two Cones } \\
\text { Point to Point }\end{array}$ & Black \\
\hline Special & Single "X" & Single "X" & Yellow \\
\hline
\end{tabular}



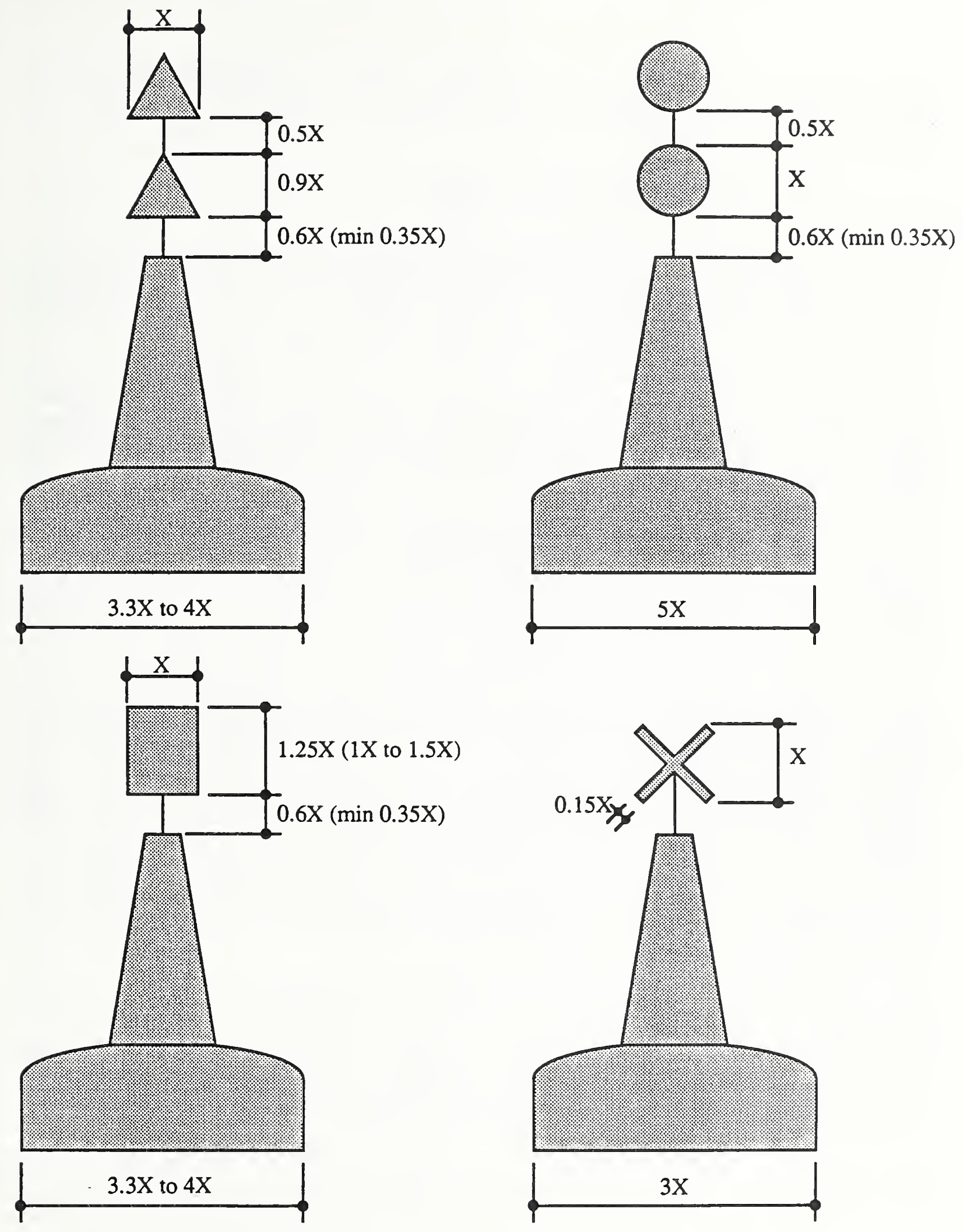

Figure 1. Critical Dimensions of Generic Topmark Configurations (from p.14 IALA 1983b). 
Color in North and South America, as well as Japan, N. Korea, and the Philippines, reverses European practice of red for port and green for starboard. Thus, for the United States, the following conventions apply for lateral marks:

\section{Port hand (Left hand) marks - Green \\ Starboard (Right hand) marks - Red}

The IALA also specifies the use of yellow, white, and black for particular applications, with the same specifications used throughout the world. The Association noted that black may be used as a contrast color for yellow and white backgrounds as well as on bright fluorescent green or red. White or yellow symbols may be used on black, red, or green backgrounds.

Color on markings is typically achieved by paint, although through-colored plastics, fiberglass, and adhesive sheeting are also used. While fluorescence may be desirable for visibility, significant (and rapid) durability problems can occur as a result of degradation by ultraviolet radiation from the sun. The IALA also noted that the combination of colors in a marine environment may cause unexpected problems because of fouling due to marine growth. This is particularly true for horizontal bands which may be confused with "false" black bands created by marine growth. At low tides the false band can appear very large, while the true band can disappear completely at high tide. The IALA commented that in these cases the topmark is very valuable in providing navigation information.

The IALA stated that although the recognition range of a topmark will depend on a number of factors, it can be estimated as being about 500 times the height of the sphere, cylinder, or cone. The recognition range for the " $\mathrm{X}$ " topmark will be much lower due to its smaller surface area. (The IALA stated that such special marking is useful for close quarters identification.) The IALA stated that although a very large topmark should be readily identified, problems with weight, wind resistance, and instability are likely to increase with size. As a result, the whole assembly must be as light in weight as possible because the topmarks are high above the waterline. A number of materials can be used to reduce weight in buoy construction, including plastic, glass reinforced plastic, light metal (and wood), and perforated aluminum alloy. The U.S. Coast Guard has also expressed some concern about possible difficulties in placing large, potentially unwieldy structures with current buoy tenders.

In the guidelines, the IALA also provided guidance for beacon colors and flash patterns for use at night, radar characteristics, and retroreflector materials and films - all of which are used for greater detectability at night. Since these are not characteristics of the marks or topmarks themselves nor do they relate to the daytime recognition of such marks, they will not be addressed in the experimental portion of the present report. 


\section{Background Research}

\subsection{Specifications for Colors of Marks}

The IALA (1980) provided recommendations for surface colors used as visual signals and as aids to navigation. They defined a surface color as a color belonging to a surface. It may be one of four types: ordinary colors (such as ordinary paint or opaque plastics); fluorescent (or luminescent) colors; transilluminated colors; and retroreflective colors. All colors are specified in terms of chromaticity and luminance factors ${ }^{1}$ defined by the Commission International de l'Eclairage (CIE). The IALA and CIE specifications for surface colors are the same.

Blaise (1968) and Blaise and Pétry (1969) provided background information on the specifications of colors used in maritime signaling. The initial discussions by Blaise (1968) reviewed the fundamentals of the CIE colorimetric system including the development of the system and the CIE parameters used to define colors including those used for aids to navigation. Specifically, colors are often described in terms of hue, saturation, and luminosity (brightness). Blaise and Pétry (1969) define luminosity as corresponding "to a more or less intense sensation of received light "(p.7). These characteristics are transformed by the CIE system into a trio of numbers, which include a pair of chromaticity coordinates $(x, y)$ and a luminance factor, which are functions of each other and locate the specific color within the CIE color space. If luminosity (or the luminance factor) is missing, the color can still be localized in terms of its chromaticity or hue and saturation. Blaise also explained the mathematical derivation of the current CIE x,y coordinates and the notation used to define surface colors in terms of a chromaticity diagram.

The IALA and CIE specifications for ordinary surface colors are presented in table 3. Specifications are given for the illuminant $D_{65}$, with an illumination geometry of $45^{\circ}$ in which the color is illuminated at an angle of $45^{\circ}$ to the normal of the surface and measured in the normal direction. (The illuminants used to measure chromaticity as well as the viewing geometry are standardized by the CIE to reduce measurement uncertainty and avoid reflections). The American National Standards Institute (ANSI) Standard Safety Color Code for Marking Physical Hazards (Z535.1, 1992) also provides specifications for ordinary, fluorescent and retroreflective colors. These colors are widely recognized by regulatory bodies in the United States, such as OSHA, DOT, and others. Of importance is the fact that the ANSI Z535.1 specifications differ from those recommended by IALA and the CIE, particularly in the green region, because of a desire to make the green and red colors more discriminable by color defective observers who comprise some $8-10 \%$ of the male population. The Z535 specifications for ordinary safety colors are also given at the bottom of table 3. The IALA did caution that "with the exception of the purple boundary of RED, the specifications have not been designed to assist people with severely defective colour vision, most of whom will have great difficulty in distinguishing between Red and Green" (p.15). IALA stated that although a minimum value of only 0.07 is specified for the luminance factor for red, significantly higher values are possible, with values greater than 0.10 being preferable. (The IALA specifications for luminance factors for surface colors range from 0.03 for matte black to 0.75 for white.)

1 Measure of the lightness of a color relative to that of a pure white diffusing surface under the same illuminant (IALA, 1980). 
Table 3. IALA (CIE) and ANSI Specifications for Ordinary Surface Colors

Table 3a. CIE and IALA Specifications for Ordinary Surface Colors

\begin{tabular}{|c|c|c|c|c|c|c|c|c|}
\hline \multirow[t]{2}{*}{ Color } & \multicolumn{2}{|c|}{1} & \multicolumn{2}{|c|}{2} & \multicolumn{2}{|c|}{3} & \multicolumn{2}{|c|}{4} \\
\hline & $\mathrm{x}$ & & $x$ & & $\mathrm{x}$ & & $\mathrm{x}$ & \\
\hline Red & 0.690 & 0.310 & 0.595 & 0.315 & 0.569 & 0.341 & 0.655 & 0.345 \\
\hline Orange & 0.610 & 0.390 & 0.535 & 0.375 & 0.506 & 0.404 & 0.570 & 0.429 \\
\hline Yellow & 0.522 & 0.477 & 0.470 & 0.440 & 0.427 & 0.483 & 0.465 & 0.534 \\
\hline Green & 0.313 & 0.682 & 0.313 & 0.453 & 0.238 & 0.402 & 0.004 & 0.632 \\
\hline Blue & 0.078 & 0.171 & 0.196 & 0.250 & 0.225 & 0.184 & 0.137 & 0.038 \\
\hline White & 0.350 & 0.360 & 0.300 & 0.310 & 0.290 & 0.320 & 0.340 & 0.370 \\
\hline Black & 0.385 & 0.355 & 0.300 & 0.270 & 0.260 & 0.310 & 0.345 & 0.395 \\
\hline
\end{tabular}

Table 3b. ANSI Z535.1 Specifications for Ordinary Colors

\begin{tabular}{|l|l|l|l|l||}
\hline Color Name & Tolerances & \multicolumn{1}{|c|}{$x$} & \multicolumn{1}{|c||}{$y$} & \multicolumn{1}{|c|}{$Y(\%)$} \\
\hline Red & Standard & 0.5959 & 0.3269 & 12.00 \\
\hline Orange & Standard & 0.5510 & 0.4214 & 30.05 \\
\hline Yellow & Standard & 0.4562 & 0.4788 & 59.10 \\
\hline Green & Standard & 0.2110 & 0.4120 & 12.00 \\
\hline Blue & Standard & 0.1690 & 0.1744 & 9.00 \\
\hline
\end{tabular}


Although the chromaticity region specified for red is quite practical for reds with glossy surfaces or fluorescent pigments, this region is more difficult to achieve for matte or semi-matte surfaces. In addition, glossy materials may deteriorate beyond specification if they lose their gloss. IALA noted that the likelihood of accurate identification for orange colors is lower than for either yellow or red, with probable confusions with yellow or red, particularly if the color area subtends only a small visual angle. As a result, orange cannot serve as a satisfactory additional color in a coding system that uses both red and yellow. Yet, "orange is probably the best ordinary color for conspicuity against the sea, and it should preferably be reserved for those objects for which detection in the water is more important than recognition of their colors" (IALA, 1980, p.5). Fluorescent orange or red orange colors can provide the highest conspicuity and are widely used for life jackets and other safety materials which require accurate and rapid recognition. The IALA noted that as far as yellow and white surface colors are concerned, they are not discriminable as separate colors at small visual angles. As a result, they should not be used as separate colors to be distinguished in a coding system. In addition, white is unlikely to be recognized or even detected at sea. Using either yellow or white as critical, unique signal colors appears unwise, although both are extensively used in combination with other colors.

Although ordinary green is not usually an effective color at sea, fluorescent green is a possibility since it is much more recognizable. Ordinary blue is also an ineffective color for maritime use, except at short distances. The IALA recommended using luminance values above the minimum recommended factor of 0.07 whenever blue is used alone. The IALA commented that when either blue or green is used alone as the background color for a sign, its luminance factor can be reduced significantly to enhance contrast with the sign message. Such darker colors are not acceptable for use as unique signal colors, however. Finally, the IALA recommended a maximum luminance factor of 0.03 for ordinary glossy black, although 0.04 may be used for matte or semi-matte surfaces.

The IALA noted that surface color appearance can be influenced by the presence of other colors so that any signal color should be checked at a distance. Surface colors also deteriorate on exposure to external conditions and so must be checked periodically for compliance with the chromaticity specifications. Fluorescent colors in particular can undergo rapid changes in chromaticity and luminance factor (especially if not protected with special protective surfaces). Furthermore, fluorescent and ordinary colors may deteriorate at different rates causing unexpected dissimilarities in appearance.

The IALA standard states that symbols and alphanumeric characters should contrast with their background. The IALA states that using colors of contrasting luminances (such as yellow and black) is usually more advantageous than contrasting hues (such as red and green). The ratio of luminances should be as large as is possible (e.g. white and black, or red and white). They recommended black with yellow, and white with red, green or blue for maximum contrast. In conclusion the IALA recommended that the ordinary colors for use as maritime signals be white, black, red, yellow, blue and green, with orange reserved for special purposes when high conspicuity is desired. It also provided color limits for chromaticity and luminance factor for each signal color. Fluorescent color recommendations include red, green, and yellow, with orange again being reserved for special high conspicuity situations. 


\subsection{Specifications for Colors of Signal Lights}

The use of color as a code for navigational aids is not restricted to surface color. A number of researchers have evaluated the choice of colors for lights, largely in terms of the amount of information to be conveyed. Thus Halsey (1959a) used a color naming experiment to evaluate the discriminability of 50 samples of green, blue, purple and white colors. She wished to determine the chromaticity boundaries for maximally discriminable signal lights. Reducing illuminance decreased the accuracy of color identification, especially for desaturated greens, blues and purples, with frequent confusions between violet and blue. Whites were often confused with yellows but not with blues or greens. Increasing viewing distance increased subject variability and tended to shift the appearance of the colors toward green. Halsey recommended that blue and purple lights should not be used in the same coding system. In a second experiment, examining the effects of removing purple as a color choice on the accuracy of identifying marine signal lights, Halsey (1959b) found that blue lights were identified much more accurately.

In their discussions, Blaise (1968) and Blaise and Pétry (1969) also establish a few perceptual phenomena which have implications for color discrimination under degraded viewing conditions. First, they observe that two equally bright and spectrally pure (monochromatic) colors do not appear to be equally saturated. Thus a pure yellow appears much less saturated than a pure red. In fact, across the spectrum of equally bright color samples, red, green and violet colors will appear maximally saturated while blue will appear less saturated and yellow even more so, a finding demonstrated by Burns, Smith, Pokorny and Elsner (1982). Differences in the saturation of spectrally pure hues is an important consideration in the selection and specification of colors for signal color codes.

Blaise and Pétry note further that under photopic conditions the eye has about a $1^{\circ}$ field of detail vision. Below about $10^{-2} \mathrm{~cd} / \mathrm{m}^{2}$, sensations of hue and saturation disappear and only luminosity remains. The peak of the spectral luminous efficiency curves shifts from $555 \mathrm{~nm}$ to about 505 $\mathrm{nm}$ as the overall luminance decreases to scotopic levels. At the same time, the Purkinje effect occurs in which reds become less visible (or luminous) and blues relatively more luminous. Under scotopic viewing conditions, lights of very low intensity can be detected (as long as the adaptation or background luminance remains low).

When Blaise and Pétry (1969) reviewed information on the colors of signals and shapes of marks, they commented that the three golden rules for safety in signalling include: reliable and proper operation, adequate information to the intended user, and accurate identification without likelihood of confusion. They also noted that distance is likely to affect color perception such that colored flashes of light can appear colorless, and cited an accident in 1953 in which a steamer was wrecked because an alternate green and white flashing light was confused with a white flashing light.

Finally, Blaise and Pétry discussed the CIE recommendations for colors used in signaling and marine use, which included a three color system for general use. This system includes red, yellow/white, and green. For traffic signalling, the intermediate color is yellow, while for marine use the intermediate color is white. In a four-color system, both yellow and white are used - but only if they are shown simultaneously (in adjacent locations), or successively, or if 
the color need not be recognized until of an appreciable size or if it is a secondary signal. In that case, the use of a bluish-white is recommended. In a five-color system, blue is the fifth color, but reserved for use only at short distances. While purple or violet is the sixth possible color, it is also discriminated accurately only at short distances as Halsey $(1959 \mathrm{a}, \mathrm{b})$ pointed out.

Blaise and Pétry provided the following uses for colored lights in maritime signalling:

Violet - Distances less than $1 \mathrm{~km}$ in maritime roadsteads

Bluish white Oceanographic buoys (xenon arc lamps used)

Green Marine lights, starboard of ships, entries and exits of waterway locks

Yellow Beacons at marine aviation bases

Red Marine light to port, entries and exits of waterway locks

White Numerous uses - must be rhythmic for distinction from ordinary lights.

Both distance and fog can alter the appearance of colored lights - such that whites can appear more yellow (or even orange), while greens can appear grey (or white) and blues can appear white. "Only red and violet lights maintain their hue down to the visual threshold and so to their limit of range (in the case of violet, this limit rarely exceeds $2 \mathrm{~km}$ )" (Blaise and Pétry, 1969 , p. 15) Blaise and Pétry point out further that interposing a colored filter between the white light and the observer will decrease the intensity of the light by varying amounts depending on the transmissivity of the filter. Thus red filters can decrease the light intensity by a factor of 0.01 to 0.3 , with red plastic decreasing it by 0.24 , green plastic filters will decrease the light intensity by about 0.20 , while other colored filters have different degrees of reduction.

Because shore lights such as advertising, roadway, warning and vehicular movement can also create problems for mariners, there is an official agreement in France that marine and aviation lights flash at different rates. Signal lights during the day are less useful because of the high ambient light levels, although some success has been achieved by mounting the lights on dark backgrounds. To be visible by day, light intensity may need to be some 100 to 10,000 times greater than at night. Although glare from oncoming headlights is frequently a problem for nighttime highway use, it is less of a problem at sea (providing their illuminance on the eye remains less than 0.1 lux).

\subsection{Background on the Visibility of Markings}

The documents reviewed above contained information on specifications for safety colors and research on marine color visibility. The effectiveness of specialized colors and symbols for providing visible daytime cues about position and the location of hazards and safe water was assessed in the studies to be described below. Several researchers actually evaluated the performance of colors and topmarks in marine applications. Their data provide important information on the relative performance of each type of coding.

In the article discussed above, Blaise and Pétry (1969) state that shape recognition may be somewhat independent of illumination and background contrast. They suggest that alphanumeric characters can be identified at a distance equal to about 500 times their height, while simpler geometric shapes, such as circles, triangles, or squares, can be identified at about 1000 times their height. Color recognition, however, is very dependent on external illumination, as well 
as the saturation and luminance factor of the color itself. Thus fluorescent reds can be distinguished at a "distance of more than five thousand times the side of the square which carries them. Green and blue cannot be distinguished from one another beyond that distance at which the shape of the square bearing them may be recognized. Yellow is influenced by neighboring colors to such an extent that in order to ensure its recognition one must surround it by black" (p. 21). Blaise and Pétry note that color and shape have been used to convey redundant information. "The conical shape is associated with the color black; the can shape with the color red. This redundancy is useful to ensure safety of navigation. One may often distinguish the color when the shape is not perceptible, particularly under direct lighting. On the other hand, in against-the-light conditions, the shape will often be recognized before the color" (p. 22).

In a lengthy article, Blaise (1971) discusses geometrical marks as aids to marine navigation, noting that such marks are seen only by natural light - which varies tremendously as a function of time of day, season, weather, cloud cover, and background characteristics. Two extreme cases are presented - clear sky and uniform overcast sky with formulas for predicting both. Zenith sky luminance ranges from 100 to $10,000 \mathrm{~cd} / \mathrm{m}^{2}$ for an overcast sky and exceed 20,000 $\mathrm{cd} / \mathrm{m}^{2}$ for a clear sky. Blaise notes that "In uniformly overcast weather and on a dark background, a vertical white panel has practically the same luminance and the same color as the sky near the horizon. If the ground is perfectly white, under snow, for example, the luminance of the panel is doubled"(p. 4). In clear weather the same panel, lit directly by the sun has a luminance which is about four times that of the sky near the horizon. This luminance is almost independent of the height of the sun with actual measured ratios ranging from about 2.8 to 5.6. If the panel is viewed against the light, the luminance ratio varies from about 0.05 to about 0.65 . This "luminance is only a fraction of that of the sky near the horizon in the direction of observation, and this luminance is found to be sensitive to the lighter or darker color of the ground, and diminishes greatly in relative value as the sun sinks toward the horizon. In the case of a white ground, the ratio between the luminance of the sky and that of the panel changes from about 2 with the sun at a height of about $70^{\circ}$ to values of about 10 near sunset; with a dark ground this ratio changes in the same conditions from 5 to about 20" (Blaise, 1971, p.5).

Site variables against which the geometrical mark is likely to be viewed are also likely to affect its visibility, according to Blaise. Marks can be obscured by terrain irregularities, buildings, vehicles, vegetation, or other marks. The background itself can also have an influence - a mark located at the top of a cliff will stand out against the sky whereas one at the bottom of the same cliff will be lost in the background detail. "The background against which it appears may be subject to wide variations, not only because the objects from which it is made up depend on the direction of observation, which is itself a function of the bearing and elevation of the mark with respect to the observer, but also because these objects assume different luminances and colors according to the natural lighting" (Blaise, 1971, p.16). Built-up areas cause the greatest problems for distinguishing the mark from its background.

Scattering and fog can reduce or eliminate the visibility of marks. Fog affects object visibility in two ways. First it reduces the luminous flux from an object located at a distance " $X$ " by the ratio $0.05^{\mathrm{X} / \mathrm{V}}$ with " $\mathrm{V}$ " defined as the meteorological visibility. Second, it superimposes a luminance "practically equal to that of the sky in the direction of observation, reduced in the ratio $\left[1-(0.05)^{\mathrm{XV}}\right]$. The luminance and the color of an object therefore approach those of the sky 
as the distance increases" (Blaise, 1971, p.7). Blaise states that "if an object has a contrast $C(O)$ against the sky when viewed at short distance, it will have, at a distance " $X$ ", the contrast $C(X)$ given by:

$$
C(X)=(0.05)^{X / V} C(0)
$$

When the object is seen not against the sky itself but against a background landscape directly behind it, the same law holds good for the 'contrast relative to the sky' $C$ ' $(X)$. This contrast is equal to the difference in luminance of the object and the background divided by the sky luminance" (p.7). There are certain instances when fog may actually improve object visibility a dark object may be more visible against a foggy coast than a dark coast.

Accurate visual perception requires adequate size and contrast in both luminance and color for the mark against its background (Blaise, 1971). Shape, color and position are important cues for identification. Visibility depends in part on the apparent diameter of the object. Thus for small diameters below one milliradian (subtending visual angles of about $3.4 \mathrm{~min}$ ), visibility is a product of contrast and solid angle subtended by the object. For larger objects, just discernible contrast is independent of apparent diameter. One can assume that the just discernible contrast against the sky, $\mathrm{C}(\mathrm{X})$, is 0.05 which gives the following equation:

$$
\mathrm{X}=\mathrm{V}(1+(\log \mathrm{C}(0) / 1.3))
$$

where

$$
\begin{aligned}
& X=\text { visual range (distance to the object) } \\
& V=\text { meteorological visibility, and } \\
& C(O)=\text { contrast at short distance (intrinsic contrast). }
\end{aligned}
$$

The size of objects of small diameter can be described by the mean side of the object defined as the side of the square which has the same area as the object projected on a plane which is perpendicular to the observation direction. If " $\mathrm{d}$ " is the mean side in meters and $\mathrm{X}$ is the distance of observation in kilometers, the solid angle subtended by the object is about $\mathrm{d}^{2} / \mathrm{X}^{2} 10^{-6}$ steradians and the visual range is expressed as:

$$
K=C(0)(0.05)^{X / v} d^{2} / X^{2}
$$

where $\mathrm{K}=0.038$ and $\mathrm{V}$ and $\mathrm{X}$ are given in kilometers. Blaise provides nomograms of visibility as well as corrections for the level of sky luminance, although he notes that this correction is negligible in most normal situations.

Accurate identification of objects is a more complicated process than simple perception, according to Blaise. Despite being conditioned by the data available as well as the variety of choices, an observer must recognize shapes, colors, environment, and characteristic marks or features:

"Here we are faced with a multiplicity of effects which are difficult to separate and have only rarely been the subject of systematic study. It may be remarked that out of a selection of simple forms - circle, square, equilateral triangle - all black on a white background, it is 
possible to recognize the triangle when its side subtends an angle of $0.9 \mathrm{mrd}(3.1$ '), and the square and the circle when the side or diameter subtends an angle of $1.2 \mathrm{mrd}$ (4.1'). Black capital letters on a white ground, with vertical strokes of a width of about one-fifth of the height are distinguished when their height subtends an angle of $2 \mathrm{mrd}$ (6.88')" (Blaise, 1971, p. 10).

Blaise (1971) also reports experimental data on color and shape recognition from a distance. In his experiment, he applied bright colors to squares that were $5 \mathrm{~cm}$ on a side. Colors included: red, fluorescent red, white, black, blue, fluorescent green, and yellow. Shape recognition consisted of identifying one of two positions - horizontal and vertical sides, or diagonal sides (e.g. squares vs. diamonds). Tests were made outside on a baseline $(250 \mathrm{~m})$ running east to west with all varieties of natural lighting. Two backgrounds were used - the sky and a black screen. A total of 39 observers made 124 sets of observations. The results were graphed in terms of the frequency of color or shape recognition as a function of observation distance for both lighting conditions (direct or back) and backgrounds (sky or black screen). The curves for shape recognition do not differ greatly as a function of lighting or background (contrast) suggesting that visual acuity is the determining factor for shape recognition with a median value of about $65 \mathrm{~m}$ (equivalent to a visual angle of 2.64'). The results for color, however, varied greatly and were sensitive to lighting and background conditions. Blaise found that while most colors were recognizable at the same distances as the shape, others were recognizable at greater distances. Use of a black background yielded very positive results, except for black objects. Yellow, in particular, was readily perceived against the black. The use of back lighting, on the other hand markedly reduced all color recognition, with the greatest impact on the reds. Nonetheless, red was the most satisfactory color, with the longest identification range and the fewest confusions with other colors. The fluorescent reds were recognized with more than $90 \%$ accuracy at 250 m (equivalent to a visual angle of 0.69 '). Numerous confusions occurred for white, which was frequently termed yellow when seen against the sky or confused with yellow, green or blue under dim lighting conditions. As noted earlier, black disappeared completely against black backgrounds, although it was quite visible under other conditions. Other colors, however, when seen against the light with the sky as the background, tended to be confused with black. This was especially true for red. Blue and green were recognized accurately at the same distance as the shape on which they were located. Beyond this distance they were confused with one another. Blaise attributes these results to foveal tritanopia - the absence of blue receptors in the very center of the visual field (or fovea). The results indicated that yellow is often confused with white, particularly beyond the distance for shape recognition and when seen against the light. In fact, fluorescent yellow was particularly confused with white. Blaise comments that the relationships described above hold for compact shapes and colors but that elongated shapes might be better under some conditions.

Blaise (1971) presents a method for determining recognition distance - at least for red. "The recognition of the hue depends on the ratio of the light reaching us from the object to that from the sky, which determines our state of visual adaptation for objects close to the horizon" (p.16). An exposure index $\xi$ can be defined as the ratio of the luminance for white surfaces (substituted for the colored surfaces) to the sky luminance in the direction of the observation. "This index is equal to the contrast against the sky of the white surface, augmented by unity if the surface is lighter than the sky; it is equal to the difference between unity and this contrast if the white surface is darker than the sky" (p.16). Blaise also introduces the concept of a color index $\tau$ 
which depends on the object color and which is proportional to the luminance factor for constant chromaticity and illuminant. The color exposure index $\gamma$ is the product of the exposure index $\xi$ and the color index $\tau$, and can be used to calculate color recognition by substituting it for contrast relative to the sky $\mathrm{C}(\mathrm{O})$. Thus, for red, Blaise calculates three different color indices ranging from 0.7 for a fluorescent red to 0.16 for ordinary red. These indices can be substituted in visibility nomograms developed to calculate visibility for a given distance and meteorological condition.

Blaise also discusses principles to be applied to the design of navigational marks, noting that they should be located so that they are not obscured, and that consideration should be given to the natural and man-made features in the surrounding environment. As far as shape is concerned, a slender, high, narrow shape will be the most effective, and allow the mark to be seen against the sky (as on a lighthouse). He did not discuss the various shapes proposed specifically for topmarks, however. White marks will give good visibility in clear weather if the lighting is frontal or lateral. If it is lit from behind, the white mark will appear dark in contrast with the light sky. Dark marks always show up well against the light, but have less visibility range than a well-lit white mark. Furthermore, they may be especially difficult to detect against a dark coast.

Blaise comments that while hue is a valuable tool for identification, it is useful only under good illumination conditions. "We must restrict ourselves to a very small range of well-defined hues, and provide an optimal compromise between saturation and lightness" (Blaise, 1971, p.19). Red is the only color extensively used for seamarks because it can be identified at a greater range than other colors, and occurs relatively rarely in nature. When seen against the light, it is often confused with black (because of the lack of long wavelength light in the shadows). Blaise suggests increasing the luminance factor for traditional surface reds from 0.07 to 0.13 or 0.14 . Fluorescent reds have apparent luminance factors as high as 0.35 to 0.50 . Green, yellow, blue, and purple are used more infrequently because of confusions. Green and blue are confused with the sky and sea, yellow is confused with white, and purple has a low intrinsic luminance factor. Yellow can be recognized easily only when framed in black. While two color marks allow one to take advantage of the complementary effects of the two colors, the use of complicated patterns is not effective for objects viewed at a distance. Yet, two color marks can be very effective when used for backgrounds that will be either dark or light at different times. Finally, Blaise notes that when two marks are used, they should not be spaced too close together. "In the cases studied - a circle, or a rectangle of height twice its width - the greatest sensitivity is obtained for a separation equal to target height"(p.21).

Walraven (1978) extended the assessment of the visibility of different geometric shapes and colors for marking buoys to the combined lateral and cardinal marking system in a study in the Netherlands. He evaluated the visibility of five different topmarks - the four cardinal marks consisting of four different types of pairs of black cones - and the isolated danger mark consisting of two black spheres, one mounted above the other.

One of Walraven's concerns was the shape of the mark - in this case determined by the angle of the apex (or top) of the mark. He selected three angles for study $-40^{\circ}, 60^{\circ}$, and $90^{\circ}$. Total surface area was held constant. He presented the topmarks as slides using three sets with the different angles. Slides were projected through a rear-projection screen illuminated from the 
front. The total luminance was about $800 \mathrm{~cd} / \mathrm{m}^{2}$. The slides themselves occupied an area of 10 x $15 \mathrm{~cm}$ (for a topmark cone height of $8 \mathrm{~mm}$ ) in a surrounding field of $100 \times 100 \mathrm{~cm}$. Slides were viewed at four distances $-9,11,13.5$, and $16 \mathrm{~m}$. Only five subjects participated. Their task was to identify the mark.

Walraven analyzed the number of times that each topmark was identified both as itself and confused with one of the four other marks. Topmarks with an apex angle of $60^{\circ}$ were identified correctly most frequently (at a percentage of $60 \%$ vs $53 \%$ for $90^{\circ}$ and $48 \%$ for $40^{\circ}$ ). Walraven's analysis also indicates the potential for several major confusions. Thus the double sphere for isolated danger was identified more frequently (at twice the rate) as east when the apex angle was $40^{\circ}$. Similarly, south was confused with the double sphere at about equal frequency for this apex angle. These particular confusions disappeared for the apex angle of $60^{\circ}$, although new confusions emerged between the danger mark and the north mark. These confusions persisted for the apex angle of $90^{\circ}$. In addition, south and north were confused somewhat for this angle. Of interest, the mark for east was identified correctly the most frequently, regardless of angle, followed by the mark for west. These two marks were the only ones which were identified correctly more than $50 \%$ of the time; regardless of apex angle. At $60^{\circ}$, both marks were identified correctly $80 \%$ of the time. If distance were reduced to $9 \mathrm{~m}$, identification frequency went up to $90 \%$. Walraven comments that the identification distance would translate into an effective viewing distance of $700 \mathrm{~m}$ (for observers with good eyesight). Walraven next studied separation distance between the two portions of the topmarks for the $60^{\circ}$ apex angle. Analysis of the results indicated that a separation of $66 \%$ cone height came reasonably close to the maximum possible detection distance. As a result, Walraven concludes that an apex angle of $60^{\circ}$ and a separation distance of $66 \%$ cone height is practicable.

Walraven then considered the effectiveness of different colors, with particular emphasis on green. He suggested that for a color to be accurately identified, it should have a high reflection value. Yet, to be detected against the sea (generally of higher brightness), green should be as dark as possible to maximize contrast. Walraven quoted reflectance values for the sea as being about $25 \%$ with a range of 15 to $35 \%$. The greens he considered varied from 11.2 to $16.2 \%$ in reflection value. When a darker green object is viewed against the sea, its color tends toward black and becomes almost unrecognizable. Walraven suggested that the incompatibility between demands for object detection and color recognition is almost insurmountable for green. Walraven's data suggest that the darkest (11\%) green object could be visible at about $27 \mathrm{~m}$ if the background were $40 \%$ but that its color would be detected as such at only between $1-4 \mathrm{~m}$. Choice of green thus becomes a compromise between object and color recognition. Because red is more conspicuous than green - particularly against a green-shaded sea, perhaps the best that can be hoped for green is a perception of "not red". As a result, Walraven recommends a darker green to maximize contrast with the sky and sea. Using color division on buoys does not appear particularly fruitful since they are visible at such short distances. He does, however, suggest widening the vertical red stripes by about $20 \%$ to avoid bleeding from the white (and a pink appearance to the red). From a distance these stripes actually appear somewhat symmetrical. A similar change for yellow and black is not recommended because of the poor perceptibility of yellow at a distance.

Walraven concludes his review by indicating that the apex angle for cardinal marks should be $60^{\circ}$ and that double marks should be separated by a distance equal to $66 \%$ of cone height. Use 
of an orangeish red is recommended, where orange is not part of the coding system, because of its greater conspicuity. Similarly a darker green is recommended for contrast with light colored backgrounds such as sea and sky. While its color recognition will be poor, Walraven suggests that this would not be such a problem since it would not be confused with red - the only real alternative coding color. Finally he recommends widening the red stripes in the vertically banded mark to be about $20 \%$ greater than the white stripes.

In 1981, the Japanese Association for Preventing Marine Accidents (JAPMA), conducted an assessment of the colors and topmarks proposed for the international maritime buoyage system in a series of land and sea tests. In the land tests, the visibility of colored boards were assessed; while in the sea tests, the visibility of different color configurations and topmarks were evaluated. A total of 30 observers, all members of the association, participated.

In the color comparison test, two samples each of yellow and green, and three samples of red, were assessed for visibility along with faded samples which had been aged for 1 and 2 years (except the three red samples which were only aged for one year). Chromaticity of all color samples was also measured for comparison with the IALA specifications. Visual comparisons of the different samples were made at three different distances $-300 \mathrm{~m}, 500 \mathrm{~m}$, and $800 \mathrm{~m}$ (equivalent to visual angles subtending 20.97', 12.58' and 7.86') in both the morning (face light) and afternoon (back light). Observers assessed the adequacy of these colors and stated how recognizable they were.

Visual comparisons were also made for a set of two-color marks. These included: green with a broad horizontal red band (primary channel to port); red with a green horizontal band (starboard); black with a yellow horizontal band (eastward); yellow with a black horizontal band (westward); black with one or more horizontal red bands (isolated danger mark); and red and white vertical stripes (safe water). The optimum band width was assessed in terms of topmark height. Band width was divided either in thirds or in a mixture of thirds and quarters. The isolated danger markings were divided into fifths (black and red alternating) or sixths and fourths (black and red alternating with red being broader). Observers viewed the different color configurations for moving buoys from a shore position. For the color recognition task, the observer's task was to compare the different colors - both new and faded with a color name (red, yellow, or green) and determine the "best one". Second, each color was assessed on a five point scale from bad to very good. Third, general observations were made for each color. The same procedure was followed for the two-color panels; the two-colour buoys and the topmarks.

The final portion of the evaluation involved an assessment of topmark shape and color when mounted on buoys and viewed from different distances. Shapes included a red cone for starboard; green cylinder for port; red sphere for safe water; yellow " $\mathrm{X}$ " for special situations; two black cones with bases together for east; two black cones with points together for west; and two black spheres for isolated danger. Measurements of the colored panel, the sky and sea luminance were taken along with the illuminance of the panel surface. These measures indicated that background luminance was quite high, and ranged between 4000 and 5000 nits (or cd/m $)$ depending on whether the sky, the horizon or the sea was being assessed, while the luminance of the color panels and topmarks was between 80 and 1000 nits - or only about one fifth that of the background. These data indicate that the objects would be seen only as fairly dark objects against a bright background, even when the sun was behind the observer. Chromaticity of the 
paints did not match the planned values in all cases, particularly the red paints, with the faded paints being generally outside the color tolerance limits.

Evaluation of the color recognition data indicates significant effects due to the lighting condition. Red and yellow were all identified more accurately in the back lighting condition, where the red with the highest chroma was evaluated most positively. The "faded" red samples, with one exception, became markedly less visible with front lighting, indicating that the decline in chroma due to the lighting impaired their detectability. In the yellow series, one of the paints was more visible, although neither was as "visible" as the red paint. Both yellow samples were more recognizable in back light. One of the green set, the darker of the two, was more detectable in front light, while the other, a brighter green, was more recognizable in back light. The report concludes that brighter green can be distinguished better against a bright background. The greens and yellows, tested in the unfaded condition, fell within the IALA guidelines; the reds were outside, although the "best" red was only slightly outside.

Evaluation of the data for recognition of the color configurations for the cardinal and isolated danger marks reveals that size of the horizontal band played an important role in their recognizability. Thus the use of a proportionally smaller band for the yellow and black horizontal bands for the center of the east and west markings tended to be more effective. Observers indicated that the wider yellow mark for East was more difficult to recognize at a distance of $800 \mathrm{~m}$. The worst performance was obtained for the wide black west mark where the black overwhelmed the yellow marking, particularly when the background luminance was high. Performance for this mark was especially poor at $800 \mathrm{~m}$. Assessment of the different color configurations proposed for the isolated danger mark indicates that the configuration in which the reds and blacks were of equal width was generally preferred. Because use of two red bands (and three black bands) was less detectable at $800 \mathrm{~m}$, the report suggests that use of a simpler color configuration leads to better recognition of the mark from a distance.

Analysis of the data on the recognizability of the colors and shapes of topmarks for lateral, safe water, and special marks indicates serious problems with the recognizability of these shapes even at $500 \mathrm{~m}$. At $300 \mathrm{~m}$ the green square, red triangle, and red sphere were all distinguished readily, while only the cross shape of the yellow cross could be distinguished. By $500 \mathrm{~m}$, while the red and green colors were recognized accurately, their shapes were not. No component of the yellow cross could be recognized at this distance. At $800 \mathrm{~m}$, no color or shape could be recognized correctly. Unfortunately no size specifications were given for the target panels to relate these data to the visual angle subtended by the color patches. The JAPMA report states that the poor recognition data for topmarks pose a serious problem for implementation of the IALA recommendations if these marks are to be distinguished at a distance. It suggests that for detection at $800 \mathrm{~m}$ the topmarks (square, triangle, and sphere) should be at least 1.67 - times larger than the versions tested. No modifications of size will increase the visibility of the yellow cross, since the yellow itself is not conspicuous (nor is the cross shape).

Analysis of the data for the cardinal and isolated danger marks - two black triangles and two round topmarks - indicates that the color (black) could be distinguished at $500 \mathrm{~m}$ (visual angle

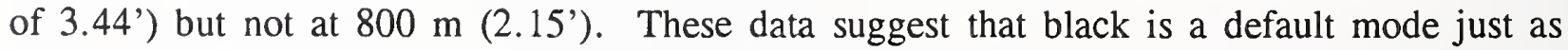
Walraven had found. In other words the color is identified as "not red". The shape of the topmarks could not be identified at $500 \mathrm{~m}$, with only the round shape being distinguished at 300 
Walraven had found. In other words the color is identified as "not red". The shape of the topmarks could not be identified at $500 \mathrm{~m}$, with only the round shape being distinguished at 300 $\mathrm{m}\left(5.73^{\prime}\right)$. When the four topmarks were presented randomly in a supplemental assessment, only $30 \%$ of the observers could identify them at $800 \mathrm{~m}$. (No information is given on how this particular assessment was conducted or how many subjects participated.)

"The results of the tests on topmarks for lateral and isolated danger marks all suggest that it would be difficult to recognize the shapes of the topmarks of the present size from a far distance" (JAPMA, 1981, p. 37). As a result, the marks should be made larger - perhaps by two-thirds. Inspection of the data reveal that no topmark shape was recognized as such at $500 \mathrm{~m}$ while all colors, except yellow, were recognized at the same distance for a back lighting condition. Neither shape nor color was recognized accurately at $800 \mathrm{~m}$.

The tests conducted by JAPMA are difficult to interpret since the procedure is not specified in all cases. The tables suggest that different numbers of subjects viewed each condition - or that some subjects viewed a condition more than once. Few data are given on "front" lighting so that it is difficult to determine the effects of lighting geometry. In addition, although the tables indicate that it rained on at least one afternoon, the effect on the data is not discussed in the text. A clearer presentation of the procedure and results would solidify the contention that colors are detectable at greater distances regardless of the lighting than shapes.

The preceding review of the literature suggests the likelihood of problems in identifying topmarks from a distance. It also suggests that color is likely to be a more effective cue than shape for maritime signal applications, particularly for front lighting conditions. None of the studies reviewed, however, evaluated the effects of color and geometrical configuration systematically for the gamut of topmarks proposed by IALA. 


\section{Methodology}

\subsection{Approach}

The purpose of the present investigation was to compare the effectiveness of buoys with and without topmarks in providing mariners with critical navigational information for a variety of viewing conditions. Of particular interest was an assessment of whether the presence of a topmark would increase the distance at which a buoy could be detected and identified. A secondary question was a determination of the effects of different lighting geometries, such as front lighting or back lighting, on visibility as well as of the kind of background against which the buoys are viewed, such as foliage or water. To answer these questions, we conducted a simulation study in which distance to detect buoys and buoy topmark combinations was determined as a function of buoy, topmark and color characteristics, as well as different lighting and background parameters.

Ideally, this experiment would have been done on actual waterways with actual buoys but since the number of buoys with topmarks is extremely limited in U.S. coastal waters and because the lighting and environmental conditions would have been impossible to control, the viewing conditions were simulated by photographing scale model buoys $\left(25.4 \mathrm{~mm}=0.305 \mathrm{~m}\right.$ or $\left.1^{\prime \prime}=1^{\prime}\right)$ floating on a 204ha (505 acre) lake. These slides were then presented to observers for visual evaluation. Ten different buoy configurations were selected for evaluation. Four buoys were presented with and without topmarks (for a total of eight configurations). These included safe water, danger, port, and starboard. Two other configurations, the cardinal marks, North and East, were assessed only with topmarks. All buoys were painted in the appropriate colors. The configurations tested are shown in table 4.

To relate the simulation to actual waterways with full scale buoys, the viewing angles in the simulation and the dimensions of full scale buoys were used to calculate actual waterway viewing distances for an $2.4 \mathrm{~m}$ ( $8 \mathrm{ft}$ ) buoy. These distances were then simulated during the photography. A total of 13 slides were taken for each buoy, simulating viewing distances ranging from 0.16 to $4.2 \mathrm{~km}$ ( 0.1 to 2.6 miles). The buoys in the slides at the furthest distance simulated a visual angle of only 1.9 minutes of arc. All of these values are shown in Table 5. Each of the ten buoy configurations was photographed in specified distance increments (to approximate viewing distances around 1-5' visual angle for the buoy and for the topmark). All the photographs in a given series were taken as rapidly as possible outdoors at specified times of the day under sunny conditions. The lighting conditions simulated both front and back lighting against two environmental conditions - water and foliage - meaning that four viewing conditions were studied. The color and size of the model buoys were calibrated according to preset specifications, with the color for the slide film being assessed against actual topmark material using a chromameter before the final photographs were taken. Calibration material was assessed for both color and luminance. The following general procedure was followed. Three different scale model buoys, painted in two color schemes, were photographed at specified distances. The buoys were scaled according to the specifications given in Appendix B. 
Table 4. Matrix for Testing

\begin{tabular}{|c|c|c|c|c|c|c|}
\hline & \multicolumn{2}{|c|}{ Buoys and Topmarks } & \multicolumn{4}{|c|}{ Viewing Conditions } \\
\hline \multirow{2}{*}{$\begin{array}{l}\text { Message } \\
\text { Safe Water }^{2}\end{array}$} & \multirow{2}{*}{$\begin{array}{l}\begin{array}{l}\text { Buoy } \\
\text { Color }\end{array} \\
\begin{array}{l}\text { Red \& } \\
\text { White }\end{array}\end{array}$} & \multirow{2}{*}{$\begin{array}{l}\text { Topmark } \\
\text { Shape } \\
\text { One Red Ball }\end{array}$} & \multicolumn{2}{|c|}{$\begin{array}{l}\text { Lighting } \\
\text { Condition }\end{array}$} & \multicolumn{2}{|c|}{$\begin{array}{l}\text { Background } \\
\text { Environment }\end{array}$} \\
\hline & & & Front & $\begin{array}{l}\text { Back, } \\
\text { Twilight }\end{array}$ & Water & Foliage \\
\hline Danger $^{2}$ & $\begin{array}{l}\text { Red \& } \\
\text { Black }\end{array}$ & $\begin{array}{l}\text { Two Black } \\
\text { Balls }\end{array}$ & Front & $\begin{array}{l}\text { Back, } \\
\text { Twilight }\end{array}$ & Water & Foliage \\
\hline Starboard ${ }^{2}$ & Green & Can & Front & $\begin{array}{l}\text { Back, } \\
\text { Twilight }\end{array}$ & Water & Foliage \\
\hline Port $^{2}$ & Red & Nun & Front & $\begin{array}{l}\text { Back, } \\
\text { Twilight }\end{array}$ & Water & Foliage \\
\hline North ${ }^{3}$ & $\begin{array}{l}\text { Black \& } \\
\text { Yellow }\end{array}$ & $\begin{array}{l}\text { Two Black } \\
\text { Triangles - } \\
\text { Points Up }\end{array}$ & Front & $\begin{array}{l}\text { Back, } \\
\text { Twilight }\end{array}$ & Water & Foliage \\
\hline East $^{3}$ & $\begin{array}{l}\text { Black \& } \\
\text { Yellow }\end{array}$ & $\begin{array}{l}\text { Two Black } \\
\text { Triangles - } \\
\text { Bases } \\
\text { Together }\end{array}$ & Front & $\begin{array}{l}\text { Back, } \\
\text { Twilight }\end{array}$ & Water & Foliage \\
\hline
\end{tabular}

${ }^{2}$ Tested with and without the topmark

${ }^{3}$ Tested only with the appropriate topmark 
The photographic process was more involved than placing the buoys at distances the naked eye would interpret as subtending corresponding visual angles. Rather, it required the development of a predictive tool which would determine the camera-to-buoy, or photographic, distance required for producing a projected image that would subtend a given visual angle for prescribed viewing and projection distances while accounting for the intervening lenses of the photographic and projection systems.

A diagram of the photographic/projection/viewing condition (see figure B1) demonstrates that the photographic distance can be determined by tracing the image size of the buoy through the geometric optics system. If we know what the size of the projected image needs to be at a given projector distance, the ratio of those two values will equal the ratio of the image on the slide to the focal length of the projector lens (the distance from the slide to the lens where the light rays converge). This expression is given as:

$\mathrm{H}_{\text {proj }}=\mathrm{H}_{\text {slide }}$
-----
$\mathrm{D}_{\text {proj }} \quad \mathrm{F}_{\text {proj }}$

where

$\mathrm{H}_{\text {proj }}=$ Height of the projected image required to subtend a given angle

$\mathrm{D}_{\text {proj }}=$ Distance from the projector to the screen

$\mathrm{H}_{\text {slide }}=$ Height of the image on the slide

$\mathrm{F}_{\text {proj }}=$ Focal length of the projector's lens.

Similarly, the ratio of the size of the image on the slide (now the undeveloped film) to the focal length of the camera will equal the ratio of the critical buoy dimension (overall model height or topmark dimension) to the photographic dimension:

$$
\begin{aligned}
& \mathrm{H}_{\text {slide }}=\mathrm{H}_{\text {buoy }} \\
& \hdashline------ \\
& \mathrm{F}_{\text {camera }} \quad \mathrm{D}_{\text {camera }}
\end{aligned}
$$

where

$\mathrm{H}_{\text {slide }}=$ Height of the image on the slide (film)

$\mathrm{F}_{\text {camera }}=$ Focal length of the camera's lens

$\mathrm{H}_{\text {buoy }}=$ Critical buoy or topmark dimension

$\mathrm{D}_{\text {camera }}=$ Distance from the camera to the buoy. 
Equations 1 and 2 can be combined to express the distance from the camera to the buoy as a function of the focal lengths of both the camera's and projector's lenses, the critical buoy dimension, the height of the projected image of that critical dimension required to subtend a given visual angle, and the projection distance. This is given as:

$$
\mathrm{D}_{\text {camera }}=\frac{\mathrm{H}_{\text {buoy }} \mathrm{F}_{\text {camera }} \mathrm{D}_{\text {proj }}}{-\mathrm{F}_{\text {proj }} \mathrm{H}_{\text {proj }}}
$$

However, recalling that the expression for determining the visual angle subtended by an image is

$$
\begin{gathered}
\mathrm{VA}= \\
-3438 \mathrm{H}_{\text {proj }} \\
-\mathrm{D}_{\text {image }}
\end{gathered}
$$

where

VA $=$ Visual Angle in minutes of arc

$\mathrm{H}_{\text {proj }}=$ Height of image

$D_{\text {image }}=$ Distance from viewer to image,

equation 3 can be rewritten as

$$
\begin{gathered}
\mathrm{D}_{\text {camera }}=3438 \mathrm{H}_{\text {buoy }} \mathrm{F}_{\text {camera }} \mathrm{D}_{\text {proj }} \\
-\mathrm{F}_{\text {proj }} \text { VA D } \mathrm{D}_{\text {image }}
\end{gathered}
$$

Using this equation with

$$
\begin{aligned}
& F_{\text {camera }}=28 \mathrm{~mm} \\
& D_{\text {proj }}=3.65 \mathrm{~m} \\
& F_{\text {proj }}=133 \mathrm{~mm} \\
& D_{\text {image }}=3.05 \mathrm{~m}
\end{aligned}
$$

and the visual angles from Table 5 , the photographic distances, $D_{\text {camera }}$, were determined and rounded off. With the rounded $D_{\text {camera }}$ values, the actual visual angles to be simulated were computed. Further, to relate the simulated situation to waterways with full scale buoys, the viewing angles in the simulation and the dimensions of full scale buoys were used to calculate actual waterway viewing distances. All of these values are shown in Table 5. 
Table 5. Distances for Photographing Buoys and for Determining Waterway Viewing Distances.

\begin{tabular}{|c|c|c|c|c|c|c|c|c|c|}
\hline \multirow{2}{*}{\multicolumn{2}{|c|}{$\begin{array}{l}\text { Desired Visual } \\
\text { Angle } \\
\text { Minutes of Arc }\end{array}$}} & \multirow{2}{*}{\multicolumn{2}{|c|}{$\begin{array}{l}\text { Desired } \\
\text { Photographic } \\
\text { Distance } \\
\text { Feet }\end{array}$}} & \multicolumn{2}{|c|}{$\begin{array}{l}\text { Rounded } \\
\text { Photographic } \\
\text { Distance }\end{array}$} & \multicolumn{2}{|c|}{ Actual Visual Angle } & \multicolumn{2}{|c|}{$\begin{array}{l}\text { Waterway } \\
\text { Viewing Distance }\end{array}$} \\
\hline & & & & \multirow{2}{*}{$\begin{array}{l}\text { Feet } \\
\text { Buoy }\end{array}$} & \multirow{2}{*}{$\begin{array}{l}\begin{array}{l}\text { Kilo- } \\
\text { meters }\end{array} \\
\text { Buoy }\end{array}$} & \multicolumn{2}{|c|}{ Minutes of Arc } & \multirow{2}{*}{$\begin{array}{l}\text { Feet } \\
\text { Buoy } \\
\end{array}$} & \multirow{2}{*}{$\begin{array}{l}\begin{array}{l}\text { Kilo- } \\
\text { meters }\end{array} \\
\text { Buoy }\end{array}$} \\
\hline Buoy $^{4}$ & Topmark & Buoy & Topmark & & & Buoy & Topmark & & \\
\hline 2.0 & & 288.01 & & 290 & 88.4 & 1.99 & & 2.62 & 4.22 \\
\hline 3.0 & & 192.01 & & 190 & 57.9 & 3.03 & & 1.72 & 2.77 \\
\hline 4.0 & & 144.00 & & 145 & 61.8 & 3.97 & & 1.31 & 2.10 \\
\hline 5.0 & & 115.21 & & 115 & 35.1 & 5.01 & & 1.04 & 1.67 \\
\hline 7.0 & & 82.29 & & 82 & 25.0 & 7.02 & & 0.74 & 1.19 \\
\hline 8.5 & & 67.77 & & 68 & 20.7 & 8.47 & & 0.62 & 1.00 \\
\hline 10.0 & 1.0 & 57.60 & 54.28 & 56 & 17.1 & 10.29 & 0.97 & 0.51 & 0.82 \\
\hline 15.0 & 1.5 & 38.40 & 36.19 & 38 & 11.6 & 15.16 & 1.43 & 0.34 & 0.55 \\
\hline 20.0 & 2.0 & 28.80 & 27.14 & 27 & 8.2 & 21.33 & 2.01 & 0.24 & 0.39 \\
\hline 32.0 & 3.0 & 18.00 & 18.09 & 18 & 5.5 & 32.00 & 3.02 & 0.16 & 0.26 \\
\hline 40.0 & 4.0 & 14.40 & 13.57 & 14 & 4.3 & 41.14 & 3.88 & 0.12 & 0.19 \\
\hline 50.0 & 5.0 & 11.52 & 10.86 & 11 & 3.4 & 52.37 & 4.93 & 0.10 & 0.16 \\
\hline 64.0 & 6.0 & 9.00 & 9.05 & 9 & 2.7 & 64.00 & 6.03 & 0.08 & 0.13 \\
\hline
\end{tabular}

${ }^{4} 203 \mathrm{~mm}$ (8in) buoy photographed with $19 \mathrm{~mm}(0.75 \mathrm{in})$ topmark to simulate $2.4 \mathrm{~m}(8 \mathrm{ft})$ buoy. 
During the photography session, different $203 \mathrm{~mm}$ (8-in) scale model buoys with and without topmarks were photographed at 13 specified distances from 2.7 to $88.4 \mathrm{~m}$ ( 9 to $290 \mathrm{ft}$ ). A pulley device allowed the buoys to be located at the predetermined distances. The pulley device consisted of a float with a screw-eye anchored in the lake at an approximate distance of 152.4 $\mathrm{m}(500 \mathrm{ft}$ ) from the camera (substantially further than the maximum $88.4 \mathrm{~m}(290 \mathrm{ft}$ ) photographic distance to minimize the visibility of the floatation device) and two spools of monofilament line located beside the camera. One spool of monofilament line was calibrated with the 13 photographic distances and attached to the front of the buoy. The second spool of monofilament line was run out to the floatation device, through the screw-eye and back to the buoy where it was connected to the back side. By reeling one spool or the other, the buoy would approach or retreat from the camera. The camera was located on the edge of a dock and about $203 \mathrm{~mm}$ (8 in) above water level.

The SLR camera (Nikon F-3) with a $28 \mathrm{~mm}$ lens was adjusted with two requirements: 1) to maintain the largest depth of field possible; 2 ) to properly expose the film based on the camera's internal light meter. The camera also contained a data information back which imprinted a number on each slide at the time of exposure. These numbers were used for image identification by the experimenter during the experiment.

Five viewing conditions were photographed, including two lighting conditions, back and front lighting, two environmental, foliage and water environments, and a fifth condition combining very low lighting levels with back lighting and water. The lighting conditions were intended to determine if the direction of lighting would affect the visibility of the buoys while the environmental conditions were intended to see if the presence or absence of foliage and foliage would similarly affect visibility. The fifth condition occurred for a set of underexposed slides in the back lighting/water combination in which the overall luminance closely resembled a twilight situation. Ten buoy configurations were photographed for each viewing condition. The configurations were port, starboard, safe-water and danger, both with and without topmarks, in addition to two of the cardinal directions, north and east, with topmarks, as given in table 4 . Each of the ten buoy configurations was photographed at the thirteen distances for each of the viewing combinations before moving on to the next buoy. Because atmospheric conditions can alter viewing conditions from day to day and because we wished to compare the effectiveness of buoys within a given viewing condition, all ten buoys were photographed consecutively over a time span of about three hours under each lighting and viewing condition. The times for buoy photography were the three hours on either side of solar noon. As shown in table 5 , a total of 13 slides were taken for each buoy simulating viewing distances of 0.2 to $4.2 \mathrm{~km}(0.1$ to 2.6 miles). The buoys in the slides at the furthest distance simulated a visual angle of only 1.9 minute of arc.

\subsection{Experimental Procedure}

Two experiments were performed to assess the visibility of buoys and topmarks. In both, a series of slides was shown to a set of observers. The slides simulated typical topmark/buoy configurations as shown in table 3. The first experiment was done at the National Institute of Standards and Technology using a total of 17 naive observers. The purpose of this experiment was to determine the distance at which buoys and topmarks were identified for five lighting 
conditions. The second was done at Coast Guard Headquarters using a total of 10 trained observers. The purpose of this experiment was to explore the effects of color and topmarks. The goal of the evaluation was to determine the distance at which topmarks and buoys are identified both individually and together, as well as to determine if there were any situation in which a buoy is identified at a greater distance because it has a topmark.

\subsubsection{Experiment 1}

In experiment 1 , the visibility of 10 buoy configurations with and without topmarks was assessed for five lighting and environmental conditions by 17 observers. The experimental design was a completely crossed (full factorial) design with three factors (Buoy Configuration (10) $\mathrm{x}$ Viewing Condition (5) x Observer (17)). The ten buoy configurations result from presenting four buoys both with and without topmarks and two buoys only with topmarks. The five viewing conditions were created by combining two lighting conditions with two environmental conditions and adding an underexposed condition (to simulate very low light levels). During the experiment, a total of about 650 photographs were presented in a semi-random order. To obtain this order, all slides were first organized according to photographic distance regardless of buoy type and viewing condition. Then they were completely randomized for each of the 13 distances. Finally, the thirteen groups of distance dependent slides were presented randomly to the observer, thus limiting learning effects.

The 17 observers were screened for visual acuity with a Snellen Chart and for color deficiencies with a set of pseudo-isochromatic charts. Corrective lenses were worn by 12 subjects in the form of contacts or glasses. Volunteers with tinted lenses were not accepted for participation. Volunteers ranged in age from 22 years to 56 years with a mean age of 36.5 ; one observer was mildly color defective. Observers generally had little sailing or navigation experience. After the vision screening, subjects were presented with two charts to be used for buoy and topmark identification and asked to read one page of written instructions (given in Appendix B.) The first chart contained ten buoy configurations without topmarks -- the six presented during the experiment and four distractors. The distractors were intended to serve as a check on guessing and to evaluate possible confusions. Of the four distractors, three were legitimate IALA configurations that we chose not to test, while the fourth was solid black. The black buoy was included in an attempt to reduce guessing because many of the backlighted buoys appeared black. Thus, the black buoy would be a legitimate option to the subjects. Furthermore, until recently the Coast Guard used black for port buoys. The second chart contained only topmark configurations -- the six used in the study and four distractors. For the topmarks, the four distractors included a red danger, a black safety, a south cardinal, and an inverted nun. Again, the distractors were chosen to represent what could be legitimate choices based on the appearance of the topmarks in the "genuine" slides. Neither identification chart presented topmarks on top of buoys but both presented buoys and topmarks in correct and incorrect colors.

Once subjects became familiar with the possible buoy and topmark choices, the room lights were turned off with the exception of a small desk light located behind the subject. The desk light provided an ambient illumination in the room of about 2 lux at the projection screen and 15-30 lux on the identification charts. During this five minute adaptation period, the experimenter verbally stated the color, and in the case of topmarks, shape choices on both the buoy and topmark identification charts as a reminder of what the choices looked like under low light 
levels. The adaptation period also included a short slide presentation to familiarize the subjects with the experimental stimuli. The first part of the familiarization included about 15 slides of randomly chosen buoys at the $2.7 \mathrm{~m}(9-\mathrm{ft})$ photographic distance. This allowed the subjects to see what the buoys look like under the various front and back lighting conditions. During this time, the subjects were encouraged to verbally identify by code which buoy they were viewing as well as any topmarks. The experimenter corrected any gross misinterpretations by asking the subject: "Are you sure that's what you see?" In each case, this suggestion was enough to get subjects to reconsider their choice and correct their observation. The second part of the presentation included five slides chosen to represent the range of buoy sizes that subjects could expect, as well as potentially misleading size cues provided by the foliage at the lake. During the experiment, subjects maintained a viewing distance of $3 \mathrm{~m}(10 \mathrm{ft})$ from the projection screen. During the adaptation period, the projected size of the target buoy was checked using a calibration slide and ruled measure. In this way, all subjects saw buoys which subtended the same visual angle. Screen luminance ranged from $1 \mathrm{~cd} / \mathrm{m}^{2}$ to $85 \mathrm{~cd} / \mathrm{m}^{2}$ with about $15-30 \mathrm{lux}$ at the observer's position (a level high enough to allow them to see the identification charts). The viewing distance was controlled so that the visual angle subtended by each buoy combination could be determined precisely and related back to realistic viewing distances.

Beginning with the first slide, subjects were asked to indicate whether they could see a buoy and, if so, if it had a topmark. Observers were instructed that the experiment involved a determination of the visibility of different proposed markings for Coast Guard buoys. For each of the 650 slides, subjects were asked: "Do you see a buoy?"; "If so, which one?"; "Does it have a topmark?"; "If so, which one?" Thus, their task was to indicate when they could identify a buoy and/or topmark and match it against the configurations shown on the two charts. For

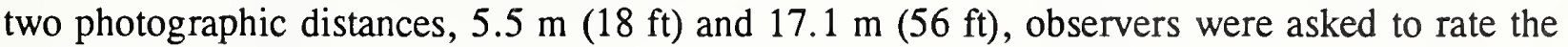
"visibility" of the buoy configuration using a scale of 1 to 7 where 7 meant "very visible". These distances translate into visual angles of 32' for the buoy and 3' 'for the topmark for the $5.5 \mathrm{~m}(18 \mathrm{ft})$ distance, and 10' for the buoy and 1' for the topmark for the $17.1 \mathrm{~m}(56 \mathrm{ft})$ distance. The experimental session lasted between two and three hours to view the 650 slides with a time limit of about $5 \mathrm{sec}$ per slide.

\subsubsection{Experiment 2}

A similar procedure was followed for experiment 2. In this experiment a total of 10 observers participated at the Coast Guard Headquarters in Washington D.C. Most of these observers $(90 \%)$ were familiar with aids to navigation and had first-hand experience on the water. The procedure was changed to focus on the visibility of the combined buoy-topmark configurations and their colors using only the two front lighting conditions with water and foliage. Otherwise, similar lighting conditions were maintained for the screen and general ambient lighting. Observers were given only one identification chart, shown in figure 2, containing the six buoy configurations studied plus the four distractors - all with topmarks. In this chart, all buoys were shown with an appropriate topmark (unlike experiment 1 where topmarks and buoys were depicted separately). Subjects were told that they would see the buoys with and without topmarks. The slides using front lighting from experiment 1 were used again, for a total of 260 slides. All 260 slides were randomized so that an observer saw buoys at different distances in no particular order. Observers again indicated when they saw a buoy and could match it against the identification chart. 


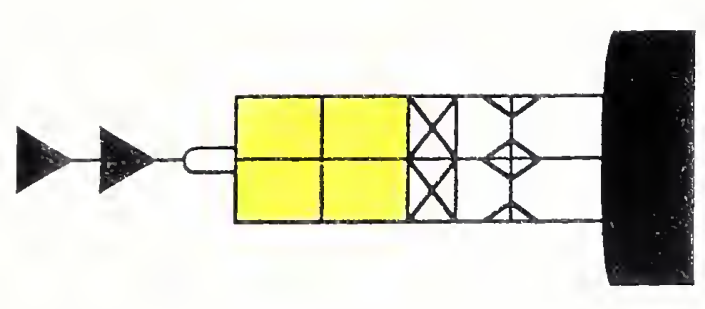

傗
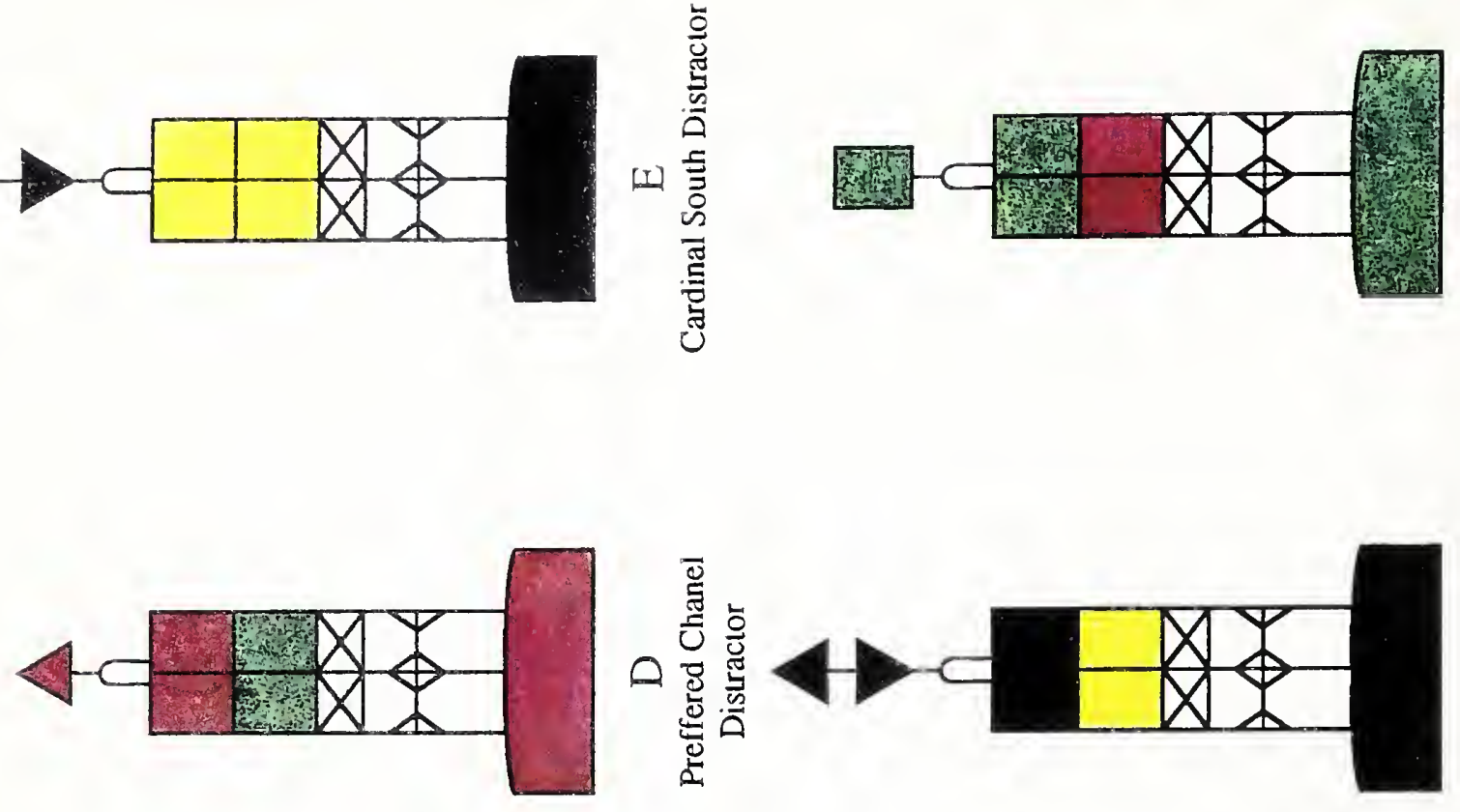

In

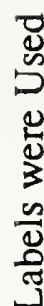

量

ป气

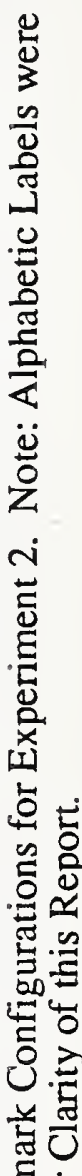

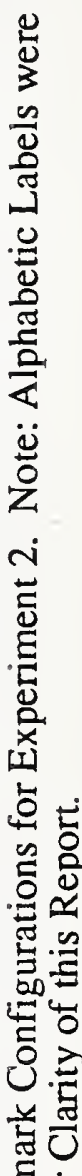

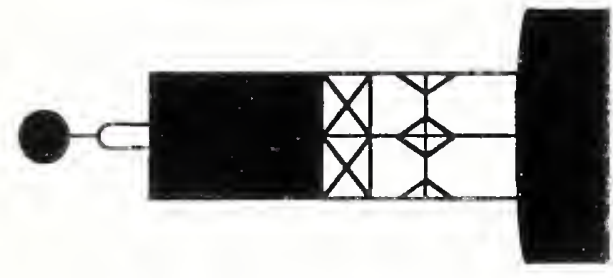

U

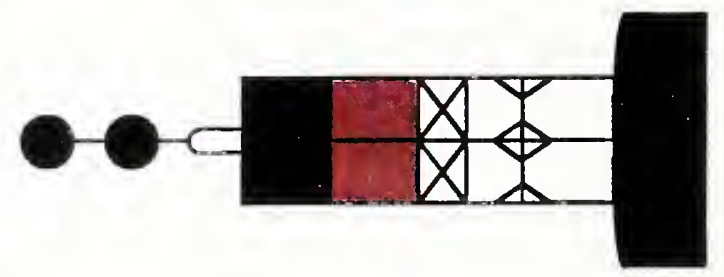

工总

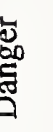

i

:

家

흥혀

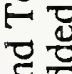

总要

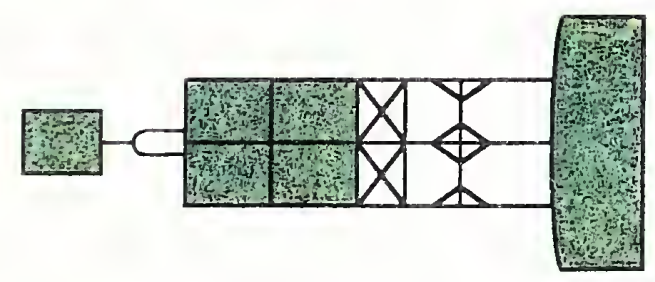

$m$ 년

它这

○

青

苋苍范

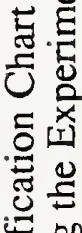

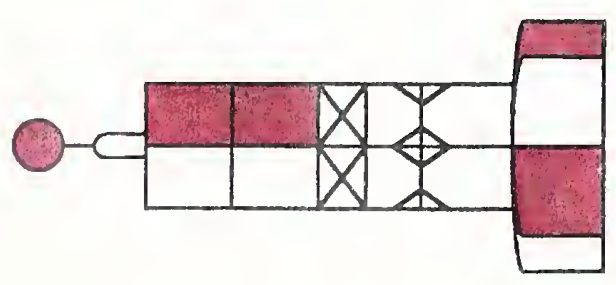

$<\frac{\text { ये }}{3}$

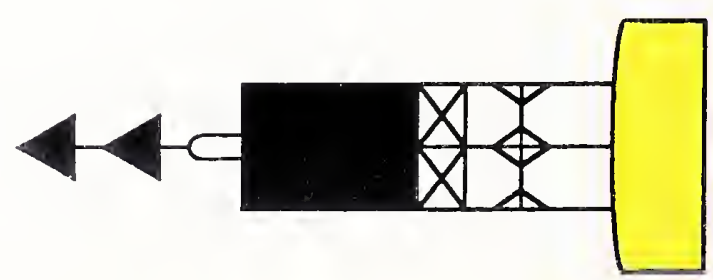

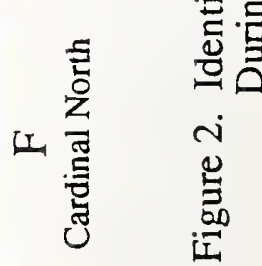


Observers also indicated if they saw a topmark, although they were not asked to identify its configuration separately (as they had been in experiment 1). Unlike experiment 1 they also identified the color of the buoy, and rated each buoy for visibility using the 7-point scale. In experiment 2, observers ranged in age from 20 to 64 with a mean age of 41.3. All observers reported normal vision. These observers generally had extensive navigation and sailing experience.

\section{Results}

\subsection{Data Analysis}

Detection, identification, and rating data for each slide were entered into a commercially available spreadsheet program. Rating data were summed for each buoy at the thirteen distances. To determine identification data, a procedure for selecting a threshold distance at which a buoy was last identified correctly was developed and applied to the data. Basically, a "threshold" was considered to exist at the last distance at which a subject made a correct match. If a subject made two correct matches in a row, the last match (greatest distance) was selected. Because of difficulties in determining the threshold distance when subjects changed their mind more than once, the following set of rules was developed:

1. For the last two consecutive matches in a row, the longest distance was selected.

2. If only one match was made, for a given buoy configuration, the chosen default distance was the shortest distance on the assumption that the match may well have been a guess.

3. If three matches were made, each separated by one or more No's, the middle match was selected as the distance.

4. If two matches were made, separated by two or more No's, the distance selected was the No closest to the first match - thereby giving the subject credit for seeing somewhat more than the first distance, but not as much as the second distance.

The statistics and graphical analyses presented in sections 4.2 and 4.3 were performed on the threshold distances using Dataplot, a statistical graphics analysis computer program developed at NIST (Filliben, 1981). The threshold distances were determined by converting the visual angle subtended by the projected buoy slide to an equivalent distance in kilometers (or miles) assuming a standard $2.4 \mathrm{~m}(8-\mathrm{ft})$ buoy.

\subsection{Experiment 1}

As described above, the visibility of ten different buoys was assessed for five viewing conditions. Four of the buoys, including safe water, danger, port and starboard were shown with and without topmarks, while two buoys, the cardinal marks north and east, always had topmarks. Thus, the results for the four buoys can be compared to determine the effect of topmarks on visibility distance. In addition the effects of different lighting and environmental conditions can be compared as well. 
Figure 3 compares the visibility (distance at which a buoy was identified correctly) for the four buoys with and without topmarks for the five viewing conditions studied. The analysis includes a comparison of safe water, danger, port, and starboard, all with and without topmarks. The cardinal marks were not included in this analysis since these were not tested without topmarks. This figure (and subsequent figures) is in the form of a box plot in which the middle $\mathrm{x}$ represents the median (the data point for which half the data are larger and half are smaller), the box represents the midrange (or interquartile range into which 25 to $75 \%$ of the data fall, and the vertical lines with $x$ 's represent the extremes (minimum and maximum) of the data range. As noted above, this figure was generated using Dataplot (Filliben, 1981). The plot provides an overview of the entire data set, rather than just a single summary value, such as the mean. As figure 3 demonstrates the median value and midrange value for buoys with and without topmarks are virtually identical, suggesting that there is no difference in visibility between buoys with topmarks and those without. An analysis of variance on these data confirms that there is no significant difference between the two data sets $(p<.1)$, indicating that the presence of a topmark did not increase the visibility of the buoy.

Figure 4 compares the effects of the five different viewing environments on buoy visibility. This box plot reveals a marked improvement in visibility for the two front lighting conditions. Again, an analysis of variance for the five viewing conditions was statistically significant $(p<.0001)$, attributable to the superior performance for the two front lighting conditions. There was, however, virtually no difference between the two front lighting conditions, or between the three back lighting conditions, including twilight.

Figure 5 compares the visibility of the ten different buoy types for the two front lighting conditions. In this plot, data are broken out separately for buoys with and without topmarks, with those having topmarks labeled with a "TM" at the end of their label. Examination of this box plot reveals that performance was best for the starboard buoy (labeled as Stbd and StbTM) and the north buoy (labeled as NthTM) followed by the safe water buoy (Saf and SafTM). Both the starboard and safe water marks had red color on them, while the North cardinal mark had a distinctive yellow base. Performance was poorest for the port buoys (labeled as Prt and PrtTM) and the East cardinal mark (labeled as EasTM). Performance for the two danger buoys (labeled as Dgr and DgrTM) was intermediate. A two-way analysis of variance on the factors of buoy type and environment type demonstrated significant differences $(p<.0001)$ in visibility among the ten buoy types but not between the two types of environments (water versus foliage) for the front lighting condition. 


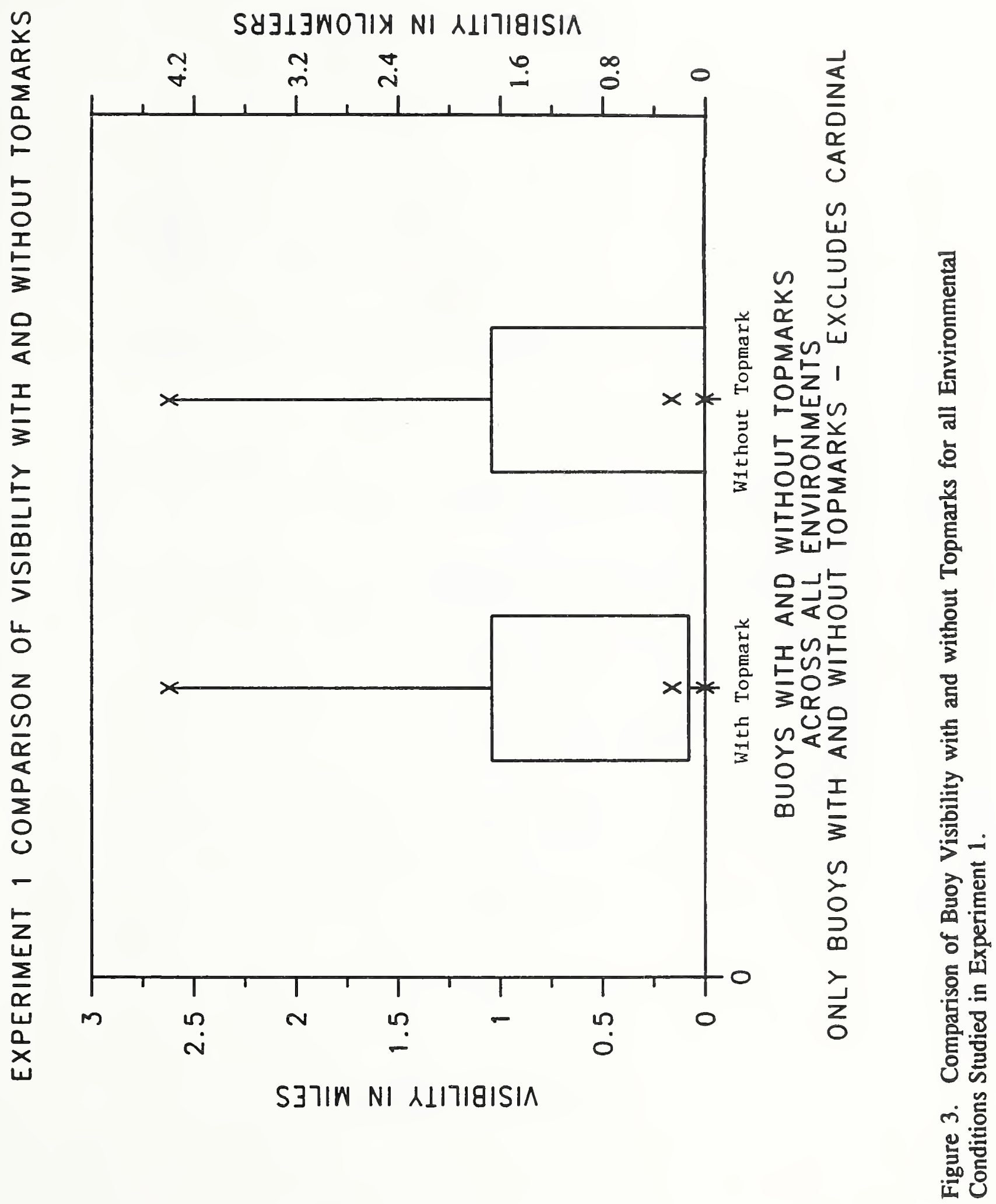




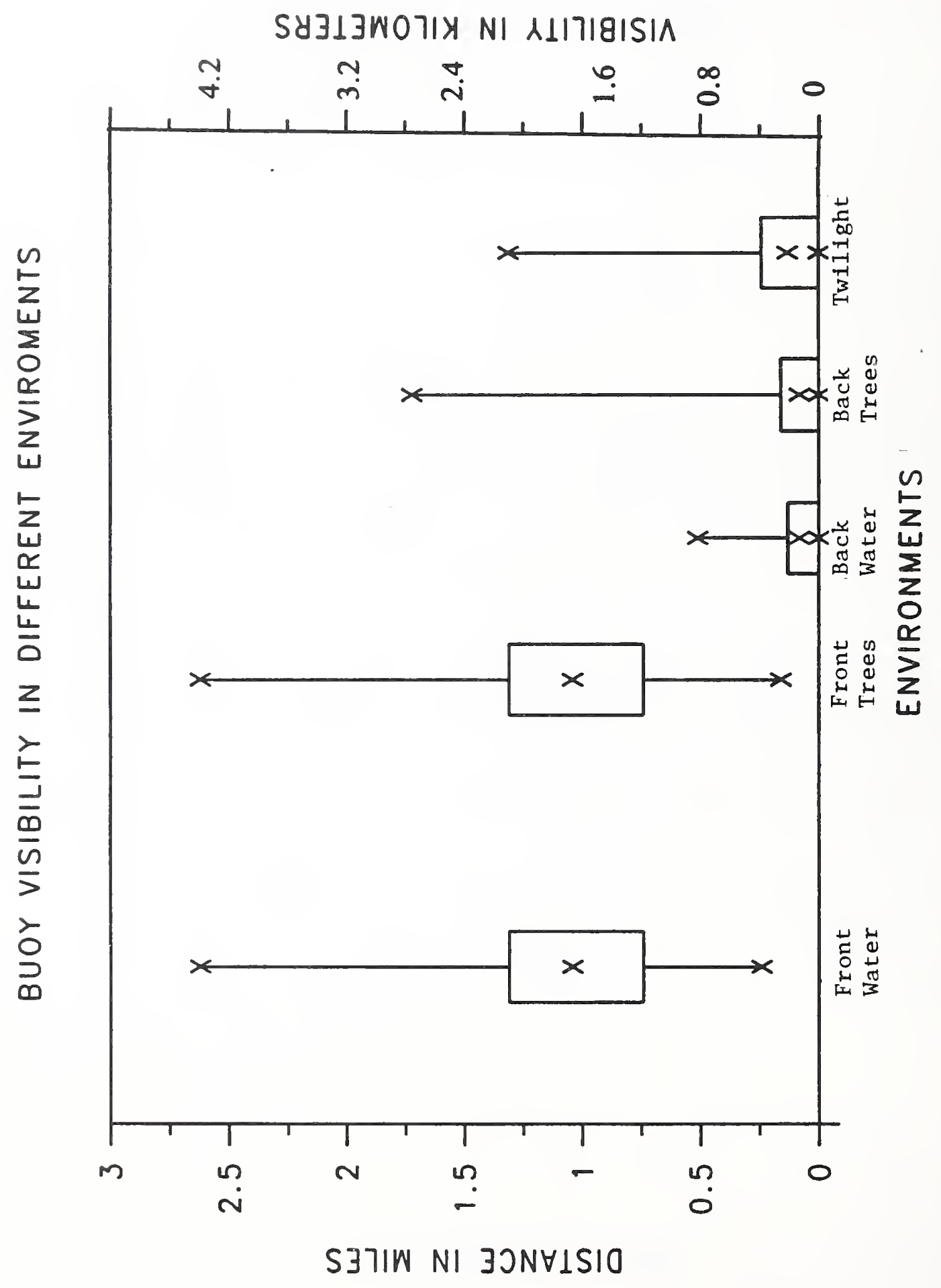

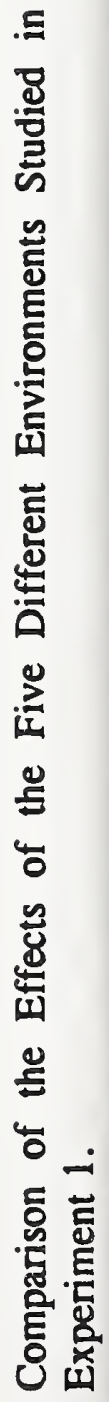




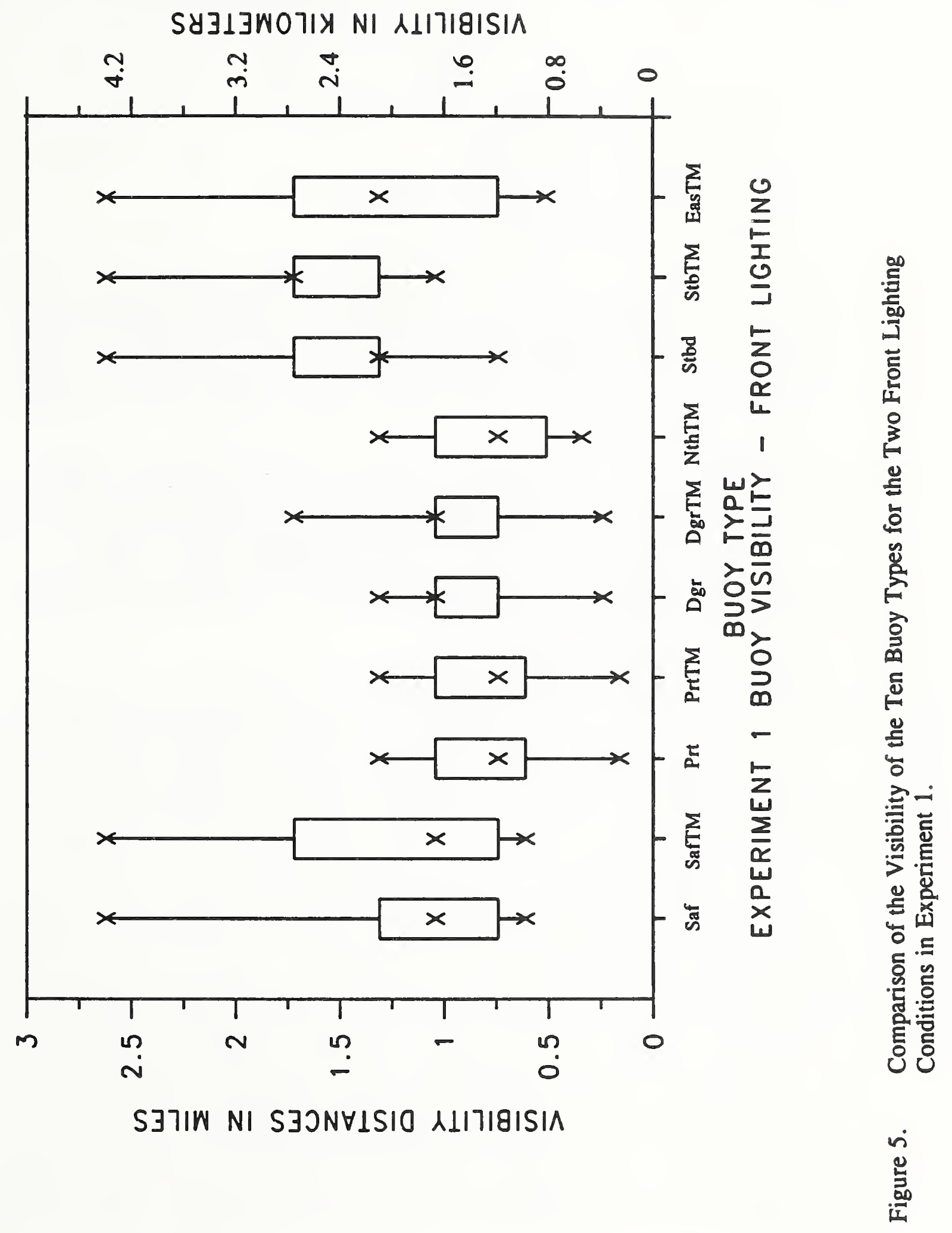


Figure 6 presents data on the visibility of the different topmark types. In experiment 1, subjects matched the buoy and the topmark against two standard matching sets containing examples of ten buoys or topmarks. Figure 6 plots topmark visibility for all lighting and viewing conditions combined. In these figures, topmark visibility is plotted as a function of topmark type, as follows:

North $=$ two black triangles pointing up
Safe Water = one red sphere
Starboard $=$ one red nun (cone)
Port $=$ one green can (cylinder)
East $=$ two black triangles, bases together
Danger = two black spheres

An analysis of variance of the visibility of different topmark types was significant $(p<.01)$. These comparisons suggest that the green cylinder (can) used to indicate port was the most "visible" topmark, followed by the two red spheres used to indicate danger. (Because the can was the only topmark with this shape, guessing may have been easier.) The visibility of the other four marks was roughly comparable, with median visibilities below $0.5 \mathrm{~km}$ ( 0.3 miles).

Figure 7 plots the visibility data for the 17 individual subjects for buoy visibility for the front lighting conditions only. An analysis of variance indicated significant differences $(p<.01)$ in performance among the subjects, attributable partly to the poorer performance of subjects 5,8 , 11,13 , and 15. (These subjects tended to have poorer visual acuity. Subject 11 also failed the color vision test.) By comparison, the performance of subjects 3, 6, 7, 9, 14 and 16 was above the norm. The variability among subjects should only have increased the variability in the mean visibility data, not the direction of the results.

Figures 8 and 9 present another way of examining the data from experiment 1 . In these two figures, the mean visibility distance for buoys (Figure 8) and for topmarks (Figure 9) is plotted as a function of buoy and topmark type for the five different viewing conditions. These plots provide a convenient summary of the results discussed above. Figure 8 makes it clear that the (red) starboard buoys were visible at the greatest distances, beyond $1.6 \mathrm{~km}(1 \mathrm{mile})$ for front lighting conditions. In addition the use of back lighting and twilight conditions reduced the effective visibility distance for both buoys and topmarks below $0.8 \mathrm{~km}(0.5$ mile). Examination of the mean visibility distances for buoys and for topmarks under back lighting conditions revealed no significant difference, according to a Wilcoxon matched-pairs signed-rank test. Figure 9 indicates that the green can topmark for the port buoy was the most visible for front lighting conditions (probably because of its uniqueness). This figure also demonstrates much less effect of lighting geometry with relatively similar results for both back and front lighting. This likely occurred because the topmarks were probably identified by geometrical shape rather than color. As a result, the visual angle they subtended determined their detection distance. In Figure 10, the mean visibility data for each buoy and topmark are plotted to provide a direct comparison of their visibility for the front lighting condition only. This figure makes it clear that the buoys were visible at significantly greater distances than topmarks. Inspection of this figure also confirms that the visibility of the starboard and danger topmarks was slightly greater than for the other topmarks, although the visibility of the buoys was somewhat lower than the other buoys. 
SУ313W07II NI A1IרI8ISIA

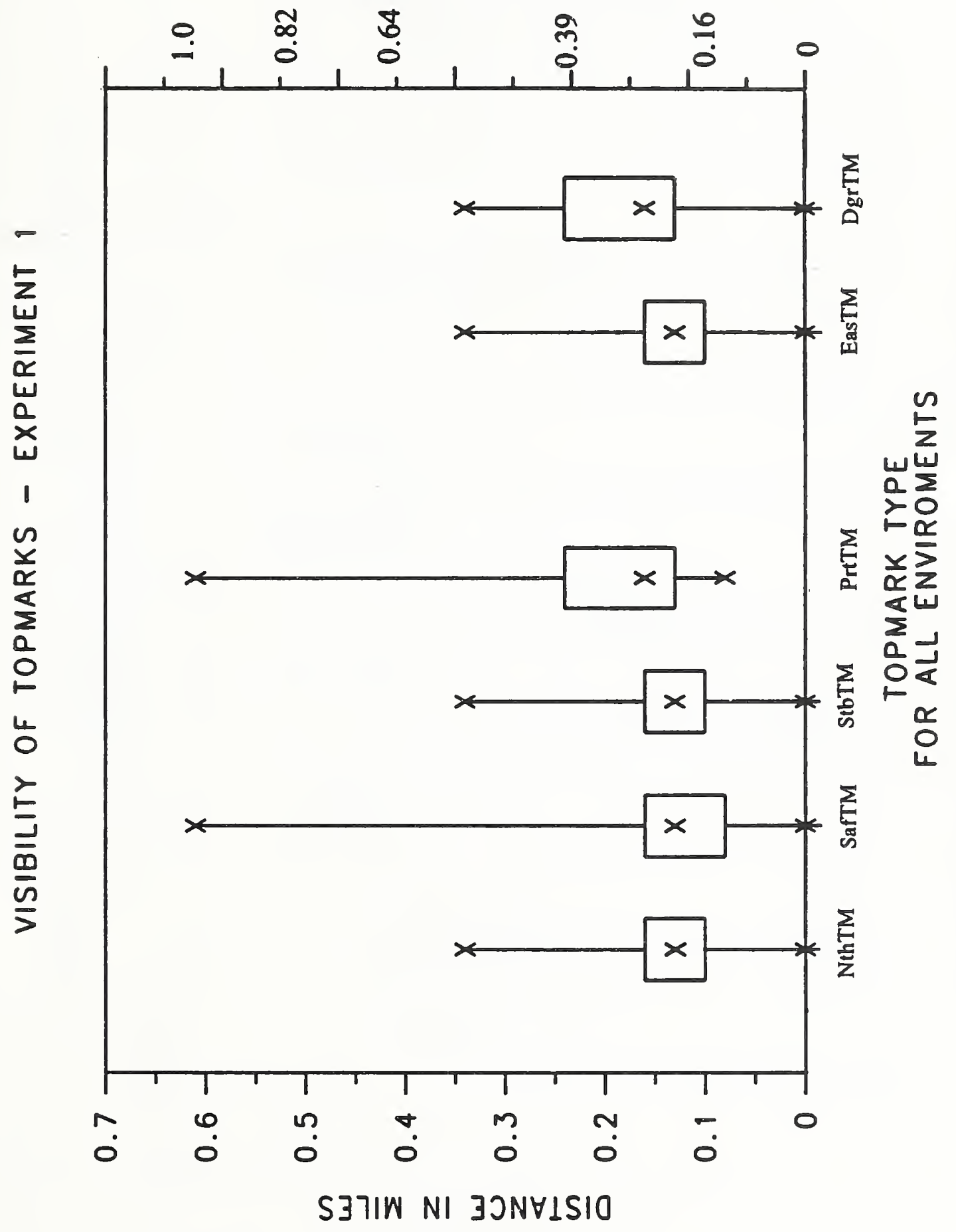

$\sum_{1}^{0}$

라

온

है

选

․․ㄹㄹㄹ

를 또

드도

$>8$

을

$-0$

들

$\frac{0}{3}$ 


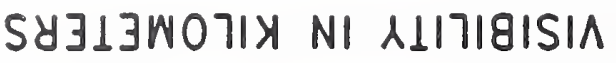

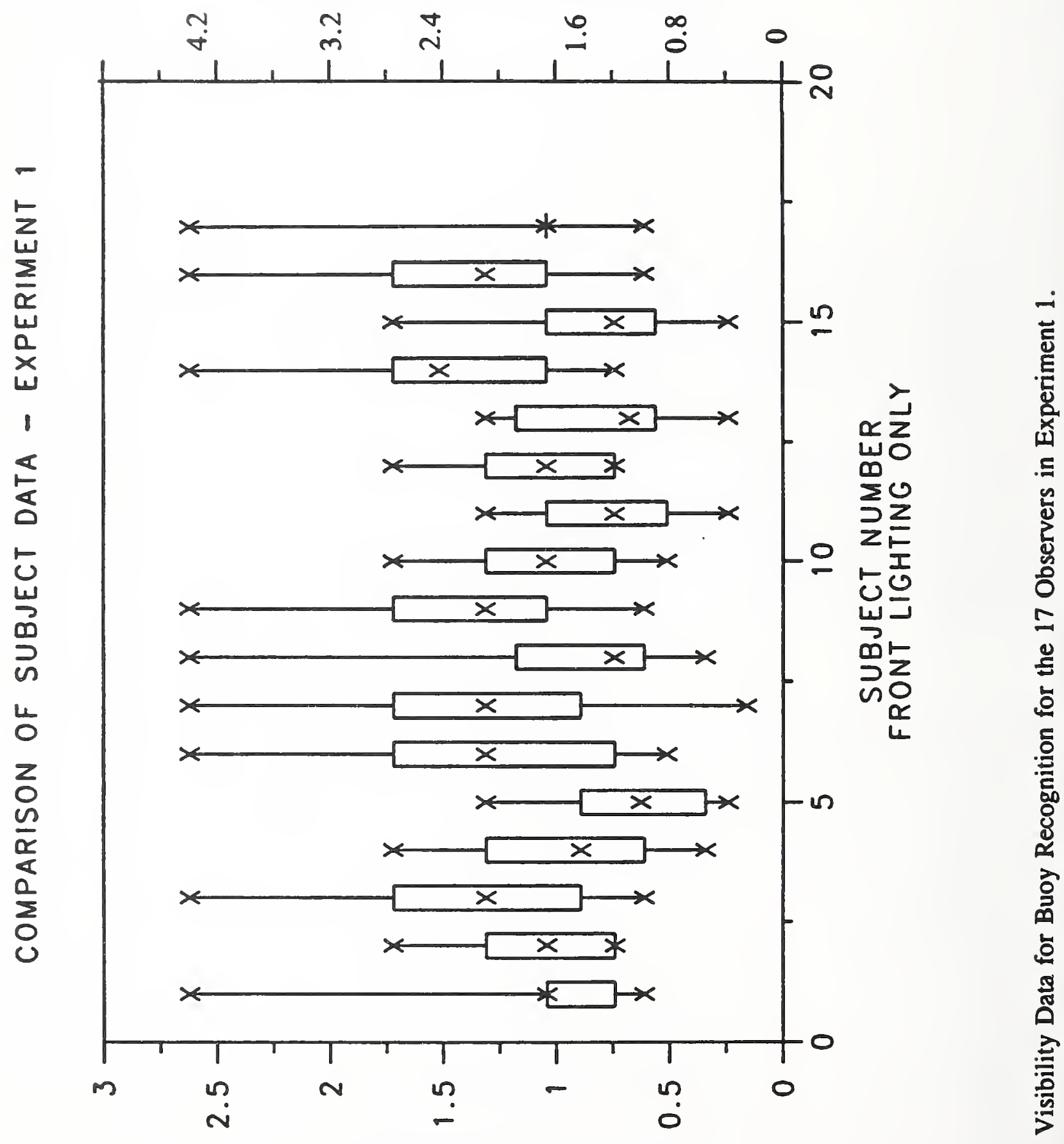

S37IW NI AIIרI8ISIA 


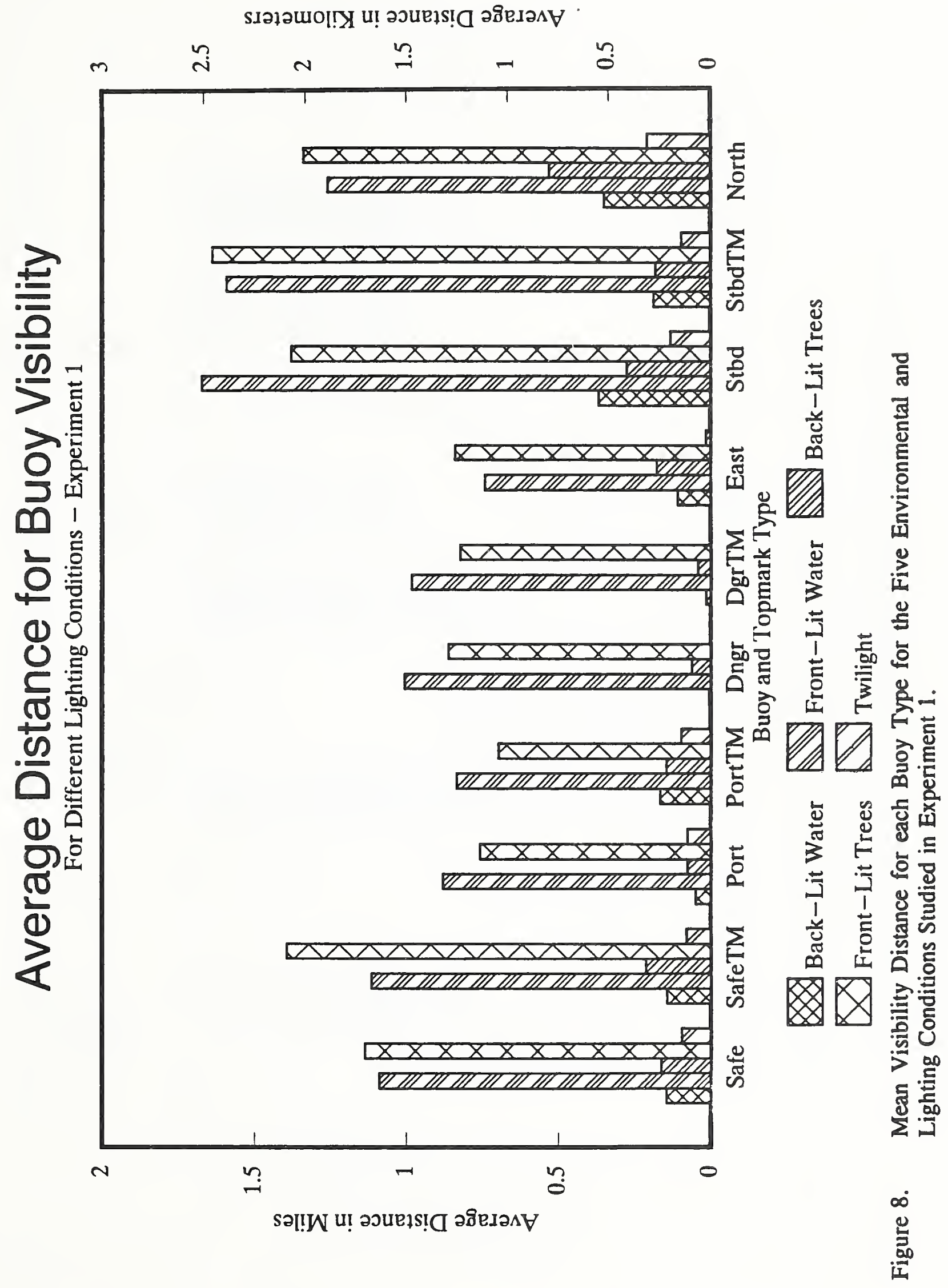




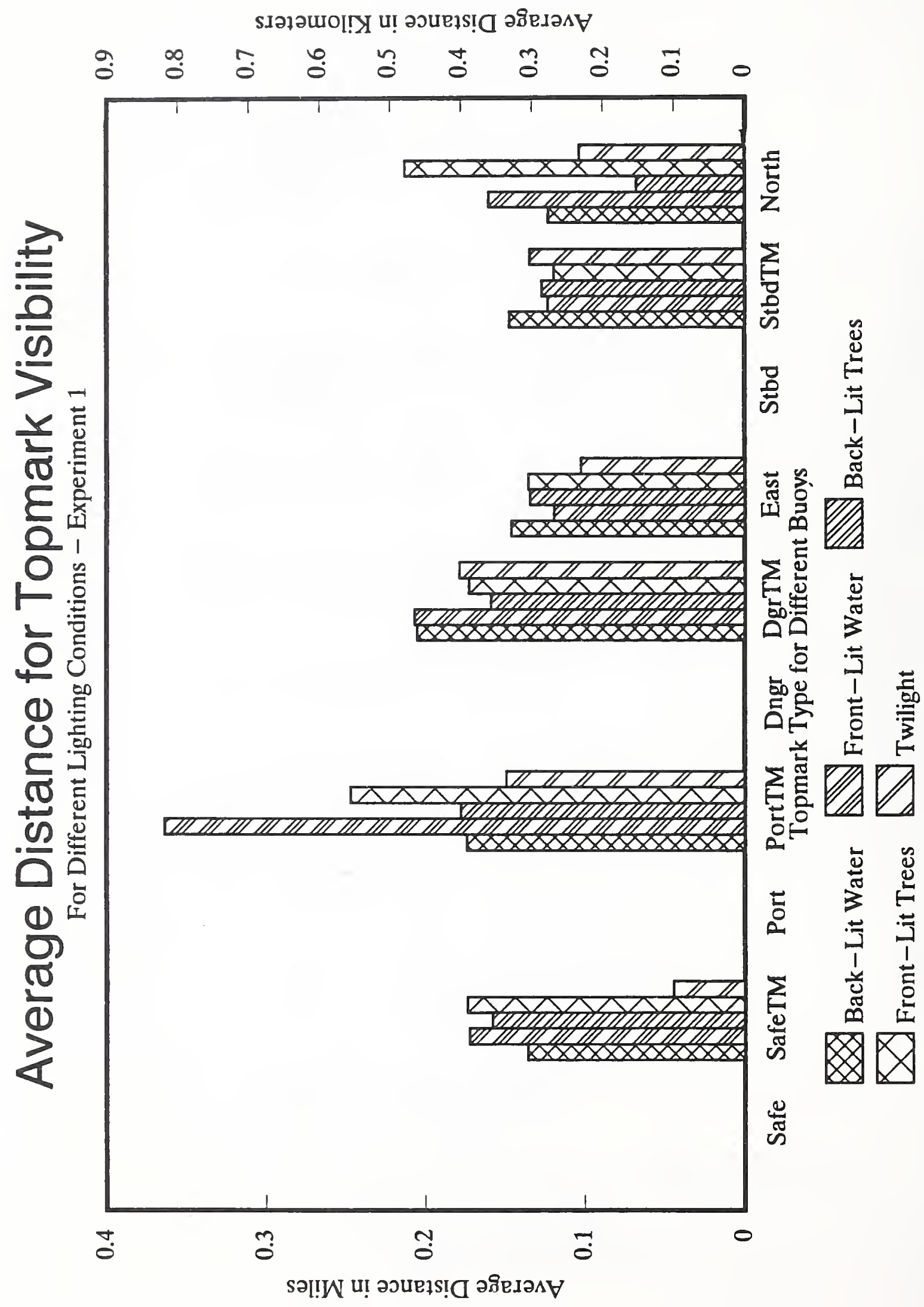

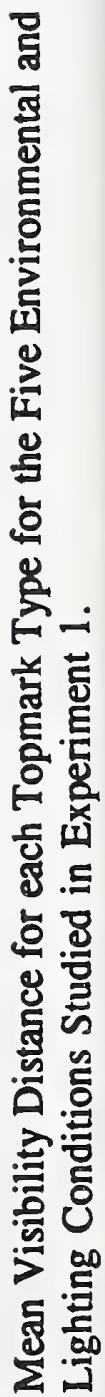




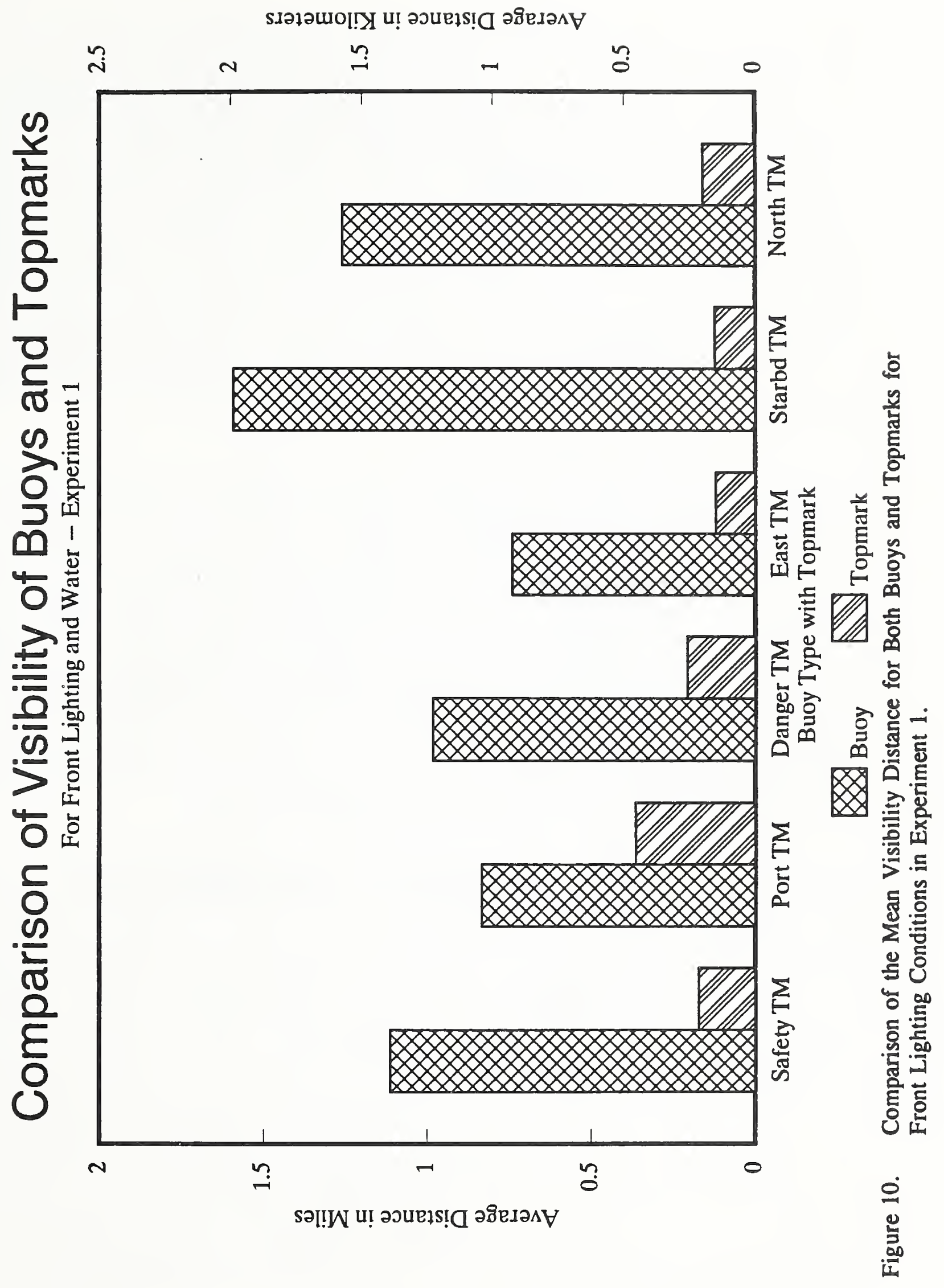


Figure 11 presents frequency counts of the number of times that each buoy configuration choice was selected in experiment 1 for all visibility distances combined. (In this figure no distinction is made between correct and incorrect choices. "No" meant that no choice was made.) The configurations are similar to those depicted in Figure 2, except that no topmark was presented. This figure reveals that for back lighting and twilight conditions buoy configuration " $\mathrm{C}$ ", a solid black buoy, was selected most frequently. The choice of this particular configuration increased dramatically for the back and twilight lighting conditions from the two front lighting conditions. Selection of the correct buoy configuration was, of course, much greater for the front lighting conditions for all buoy types. Table 6 presents the percentages of times that each configuration was selected for each buoy type presented. The buoy types presented are shown along the lefthand column and include the target buoys with and without topmarks (such as A2 and A), while all choices are shown along the top row. In this table it can be seen that " $\mathrm{C}$ " was selected less than $25 \%$ of the time in front lighting conditions, and was a major choice only for buoy type "B" - the green port buoy. The data suggest that the green buoy appeared dark or black at longer distances.

Figures 12 and 13 summarize the data for rated buoy visibility for the two distances where ratings were obtained. The ratings given by the subjects using the 7-point scale were averaged and plotted for these two figures. Figure 12 presents data for buoys which subtended a visual angle of about 32 minutes of arc (equivalent to about 0.16 mile), while figure 13 presents data for buoys subtending a visual angle of about 10 minutes of arc (equivalent to a distance of about $0.8 \mathrm{~km}$ or 0.5 miles). Data for all five lighting conditions are shown on both figures. Inspection of figure 12 indicates that buoys were generally rated highest for front lighting, particularly for front water, and lower for back lighting. Ratings for twilight were universally low. Figure 12 suggests that for front lighting conditions buoys without topmarks tended to receive very slightly higher mean visibility ratings, while some of the buoys with red color $(\mathrm{A}, \mathrm{G}, \mathrm{H})$ also tended to be rated slightly higher. In comparison with figure 12, figure 13 demonstrates a marked drop in ratings (from 5 to 3 or lower) for the longer viewing distance. Again the front lighting conditions were rated somewhat more highly.

Table 7 presents the frequency that each topmark choice was selected for different viewing conditions. In this table, the choices given in the identification chart are listed on the top row of the table with correct choices first, distractors second, and "no" responses third, while the target topmark is listed along the leftmost column. Inspection of this table reveals that distractor choices, 8,9 , and 10 were relatively rarely selected. Choice 5 , the single black ball, however, was chosen more than $15 \%$ of the time for choice 4 , the single green square. It was also selected quite frequently for topmark 2 , the single red ball under back lighting and twilight conditions. Topmark 2, the red sphere was confused with topmark 3, the red triangle, under front lighting conditions. There was also a tendency for topmark 1 , the double triangle pointing up, to be selected for both marks 6 and 7. This is a serious confusion for 7, which signifies danger, rather than a cardinal direction. Although there was a sharp decline in performance for all topmarks, the green square maintained a superior identification rate at $50 \%$ or more across viewing conditions. This superior performance can be attributed to an identification based on shape, not color, since topmark 4 was the only square presented. Comparison of tables 6 and 7 reveals that the percentage of correct choices for topmarks under comparable viewing conditions was about $20 \%$ less than for buoys, thus reinforcing the contention that topmarks are not as visible as buoys. 


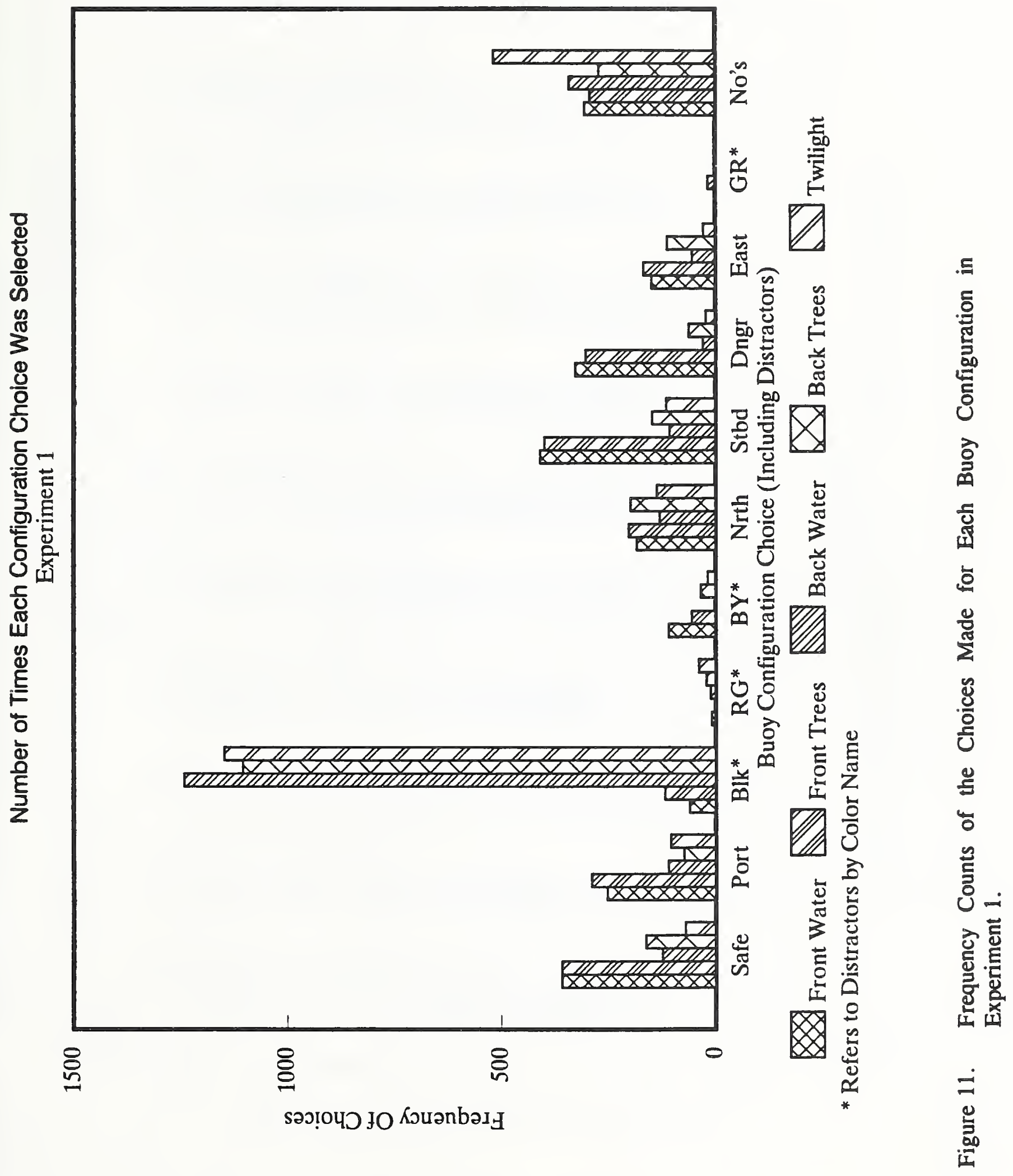




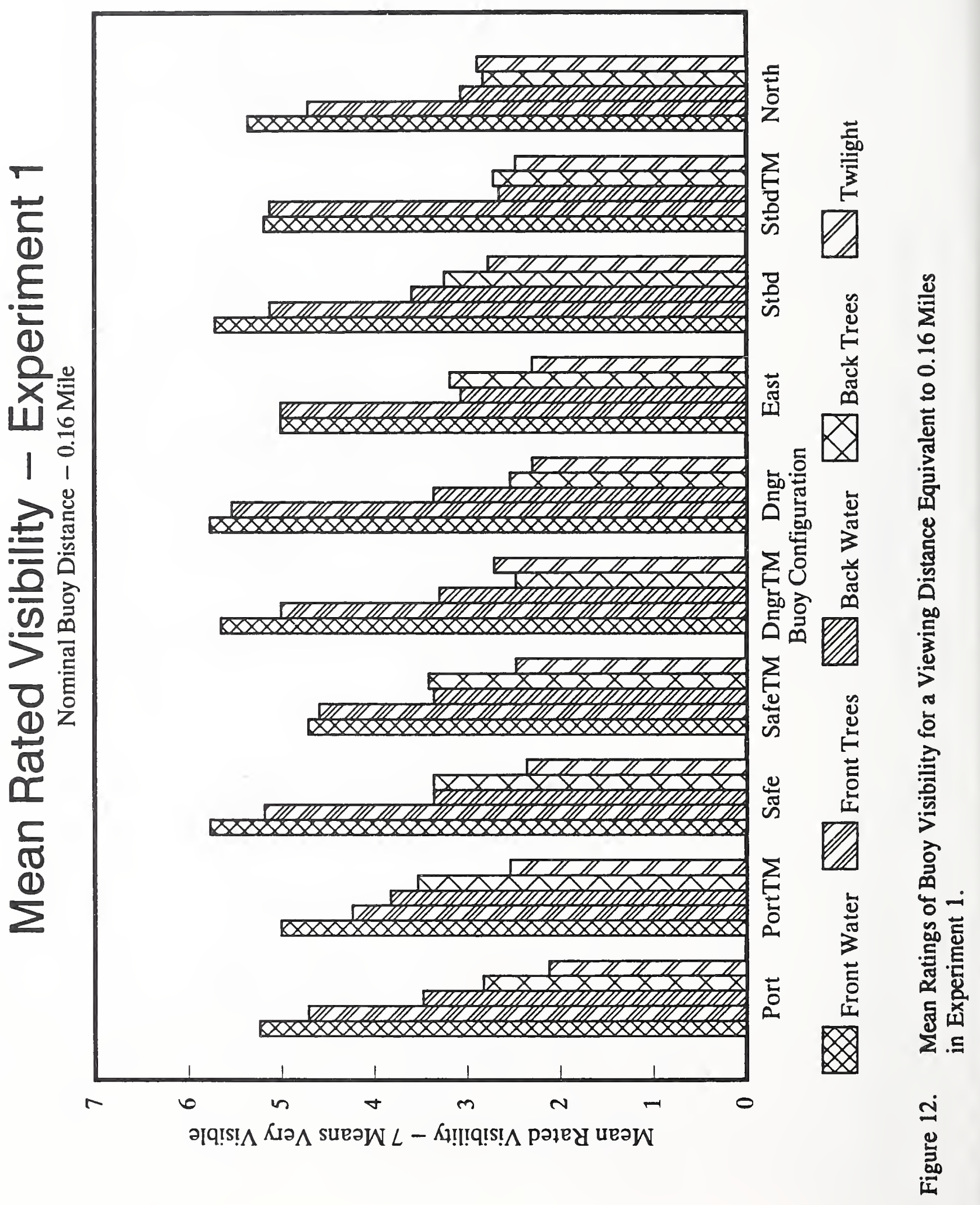




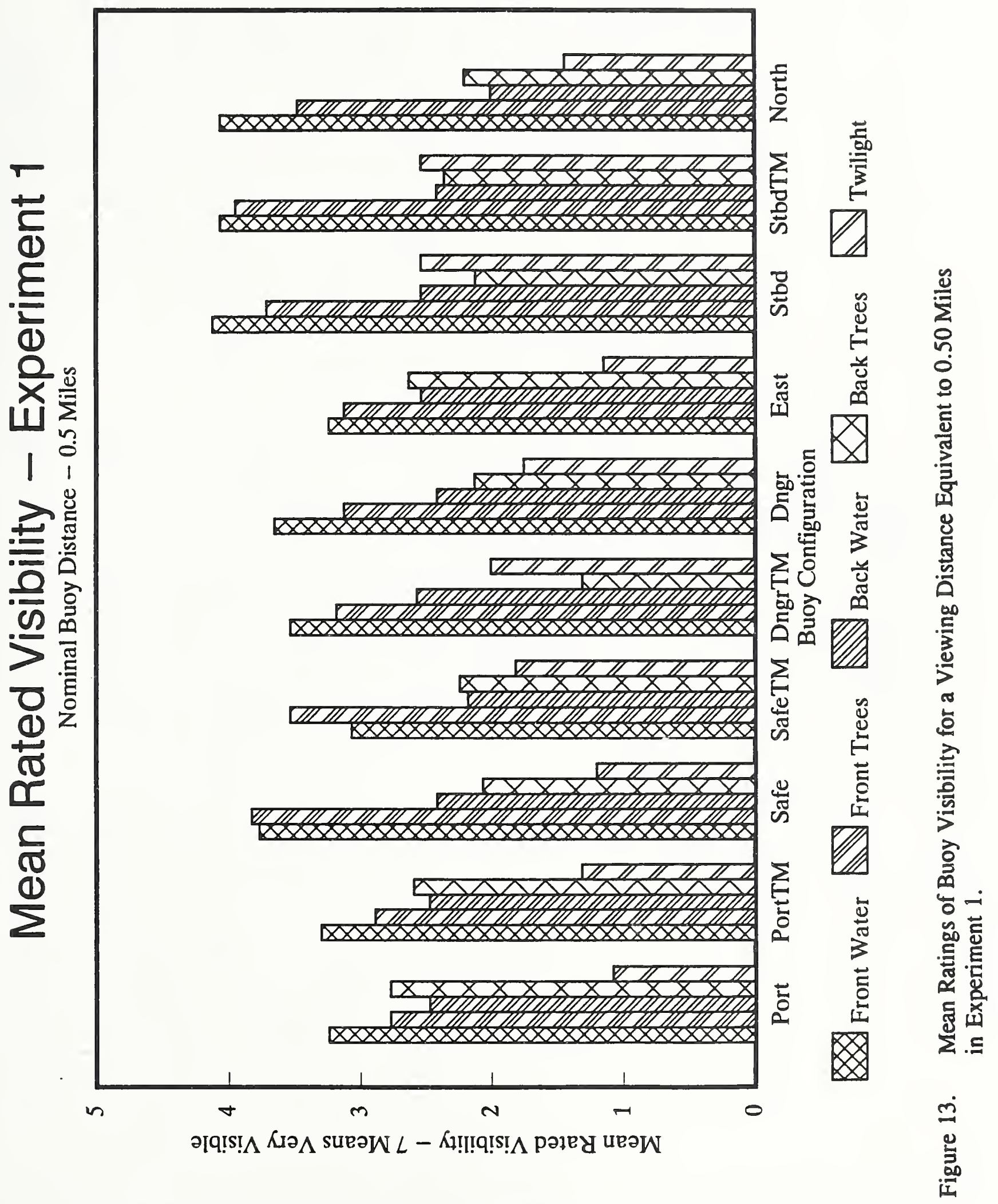


Table 6. Percentage of Times that Each Buoy Choice was Selected in Experiment 1.

Front Water Conditions

Buoy Safe Port $\mathrm{Blk}^{6} \quad \mathrm{RG}^{3} \quad \mathrm{BY}^{3}$ Nrth Stbd Dgr East $\mathrm{GR}^{3}$ NO's

\begin{tabular}{|c|c|c|c|c|c|c|c|c|c|c|c|}
\hline A & B & C & D & $\underline{E}$ & $\mathrm{~F}$ & $\mathrm{G}$ & $\underline{\mathrm{H}}$ & $\underline{I}$ & J & No & Tota \\
\hline 78 & & & 10 & 2 & & & & & & 10 & 100 \\
\hline 78 & & & 10 & 1 & & & & & & 10 & 100 \\
\hline B & 70 & 6 & & & & & & & & 25 & 100 \\
\hline B4 & 58 & 23 & & & & 2 & & & & 17 & 100 \\
\hline F1 & & & 6 & 79 & & 2 & & & & 10 & 100 \\
\hline 2 & & & & & & 89 & & & & 9 & 100 \\
\hline G3 & & 1 & & & & 89 & & & & 9 & 100 \\
\hline $\mathrm{H}$ & 1 & 3 & 1 & & & 3 & 74 & & 1 & 17 & 100 \\
\hline $\mathrm{H} 7$ & 1 & 2 & & & & 2 & 74 & & & 19 & 100 \\
\hline I6 & & & & 14 & 1 & 1 & & 66 & & 17 & 100 \\
\hline
\end{tabular}

Front Foliage Conditions

\begin{tabular}{|c|c|c|c|c|c|c|c|c|c|c|c|}
\hline A & B & C & D & E & $\mathrm{F}$ & $\mathrm{G}$ & $\mathrm{H}$ & I & $\mathrm{J}$ & No & Total \\
\hline 79 & 1 & & & 8 & 4 & & & 3 & & 5 & 100 \\
\hline 80 & 1 & 1 & & 8 & 4 & 1 & & 1 & & 3 & 100 \\
\hline B & 68 & 16 & & & & & & & 3 & 12 & 100 \\
\hline B4 & 62 & 20 & & & & & & & 1 & 16 & 100 \\
\hline $\mathrm{F} 1$ & & 1 & & 3 & 80 & & & 2 & & 13 & 100 \\
\hline G & & & 1 & & & 86 & & & & 13 & 100 \\
\hline G3 & & & & & & 88 & 1 & & & 10 & 100 \\
\hline $\mathrm{H}$ & & 7 & & & & 2 & 70 & & 2 & 19 & 100 \\
\hline H7 & & 5 & & & & 2 & 67 & 1 & 2 & 22 & 100 \\
\hline I6 & & 2 & & 6 & 3 & 1 & & 68 & & 20 & 100 \\
\hline
\end{tabular}

Back Water Conditions

\begin{tabular}{|c|c|c|c|c|c|c|c|c|c|c|c|}
\hline A & B & C & D & $E$ & $\mathrm{~F}$ & $\mathrm{G}$ & $\mathrm{H}$ & $\mathrm{I}$ & $\mathrm{J}$ & No & Total \\
\hline 26 & 2 & 47 & & & 7 & 1 & 2 & 1 & & 14 & 100 \\
\hline A2 & 2 & 49 & 1 & & 3 & & 1 & 1 & & 17 & 100 \\
\hline B & 6 & 73 & & & 1 & & 1 & 1 & & 18 & 100 \\
\hline B4 & 17 & 73 & & & & & & & & 11 & 100 \\
\hline $\mathrm{F} 1$ & 1 & 28 & & & 43 & 1 & & & & 27 & 100 \\
\hline G & 1 & 42 & 4 & & 6 & 26 & 2 & 3 & & 11 & 100 \\
\hline G3 & 6 & 57 & & & & 21 & 1 & & & 10 & 100 \\
\hline $\mathrm{H}$ & 7 & 81 & & & & & & 1 & & 11 & 100 \\
\hline H7 & 4 & 71 & & & 1 & 1 & 2 & & & 20 & 100 \\
\hline I6 & 5 & 56 & & & & & 4 & 17 & & 19 & 100 \\
\hline
\end{tabular}

6 Distractors chosen for resemblance to buoy choices. 
Table 6. Continued

Back Foliage Conditions

Buoy Safe Port $\mathrm{Blk}^{7} \quad \mathrm{RG}^{3} \quad \mathrm{BY}^{3}$ Nrth Stbd $\mathrm{Dgr}$ East $\mathrm{GR}^{3}$ NO's

$\begin{array}{llllllllllllllllllll}\mathrm{A} & \frac{\mathrm{A}}{26} & \frac{\mathrm{B}}{1} & \frac{\mathrm{C}}{36} & \frac{\mathrm{D}}{2} & \mathrm{E} & \frac{\mathrm{F}}{6} & \frac{\mathrm{G}}{10} & \frac{\mathrm{H}}{3} & \frac{\mathrm{I}}{3} & \frac{\mathrm{N}}{12} & \frac{\text { Total }}{100}\end{array}$

$\begin{array}{lllllllllll}\text { A2 } & 32 & 2 & 42 & 1 & 3 & 6 & 2 & 2 & 10 & 100\end{array}$

$\begin{array}{llllllllll}\text { B } & 8 & 76 & 1 & 2 & 1 & 1 & 10 & 100\end{array}$

$\begin{array}{lllllllll}\text { B4 } & 1 & 13 & 73 & 1 & 1 & 1 & 9 & 100\end{array}$

$\begin{array}{lllllllll}\text { F1 } & 1 & 21 & 3 & 53 & 1 & 4 & 16 & 100\end{array}$

$\begin{array}{llllllllll}\mathrm{G} & 5 & 48 & 2 & 8 & 21 & 2 & 2 & 12 & 100\end{array}$

$\begin{array}{llllllllll}\text { G3 } & 6 & 1 & 24 & 2 & 23 & 23 & 3 & 17 & 100\end{array}$

$\begin{array}{lllllllll}\mathrm{H} & 1 & 2 & 70 & 2 & 8 & 6 & 10 & 100\end{array}$

$\begin{array}{llllllllll}\mathrm{H} 7 & 1 & 2 & 61 & 4 & 1 & 5 & 6 & 20 & 100\end{array}$

$\begin{array}{llllllll}\text { I6 } & 2 & 55 & 2 & 3 & 28 & 10 & 100\end{array}$

Twilight Conditions

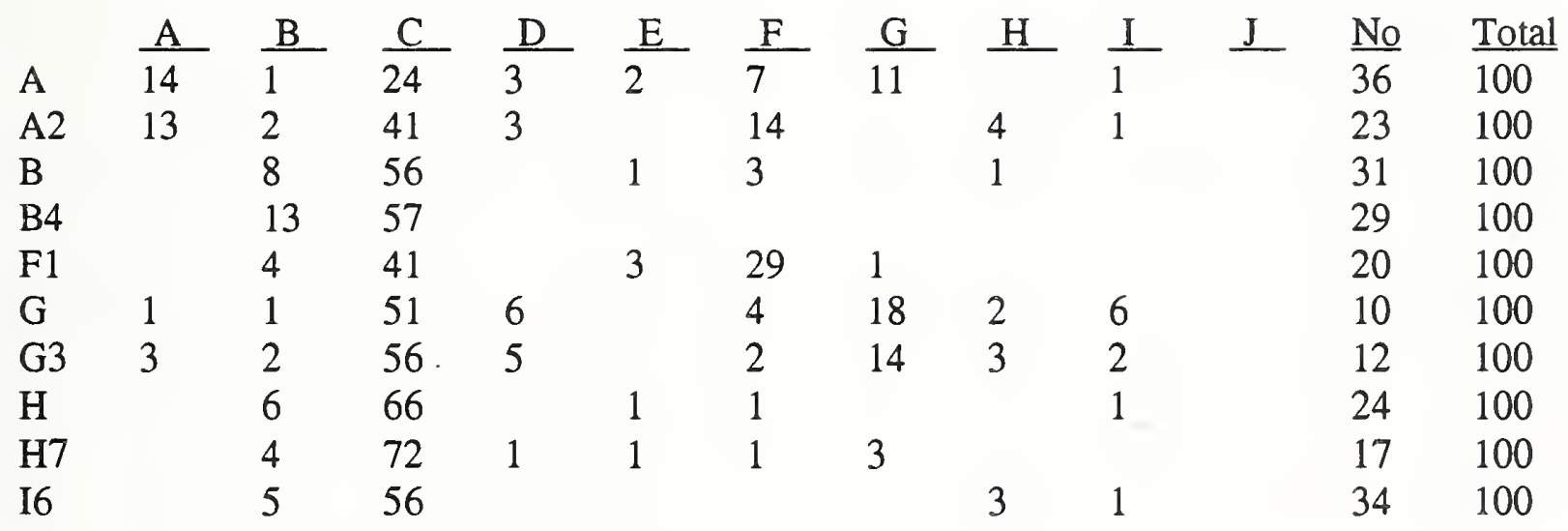

7 Distractors chosen for resemblance to buoy choices. 
Table 7. Percentage of Times that Each Topmark Choice was Selected in Experiment 1.

Front Water Condition

Topmarks

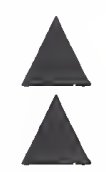

(R)
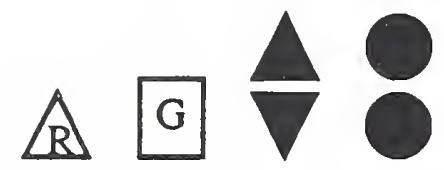

Top 1's 2's 3's 4's $\underline{\text { 6's }} \underline{\text { 7's }}$ Mark

$\begin{array}{lllllll}1 & 52 & & & & 4 & 4 \\ 2 & & 53 & 12 & 1 & & \\ 3 & & 29 & 31 & & & \\ 4 & 2 & 2 & 4 & 53 & & \\ 6 & 15 & & 2 & 1 & 37 & 12 \\ 7 & 15 & 1 & 1 & 2 & 3 & 60\end{array}$

Front Foliage Conditions

Topmarks

Top 1's 2's 3's $\underline{\text { 4's }} \underline{\text { 6's }} \underline{\text { 7's }}$ Mark

$\begin{array}{lllllll}1 & 60 & & 1 & & 4 & 6 \\ 2 & & 45 & 14 & 1 & & \\ 3 & & 25 & 36 & & & \\ 4 & 2 & 1 & 6 & 59 & & \\ 6 & 21 & & 1 & & 38 & 9 \\ 7 & 17 & 1 & 5 & 2 & 9 & 45\end{array}$

Back Water Condition

Topmarks

Top 1's 2's $\underline{\text { 3's }} \underline{\text { 4's }} \underline{\text { 6's }} \underline{\text { 7's }}$ Mark

$\begin{array}{lllllll}1 & 39 & 1 & 2 & & 7 & 6 \\ 2 & 2 & 32 & 8 & 5 & & \\ 3 & 5 & 5 & 45 & & 1 & 1 \\ 4 & 3 & & 2 & 55 & & \\ 6 & 13 & 1 & 4 & 4 & 49 & 10 \\ 7 & 15 & 1 & 2 & 1 & 1 & 60\end{array}$

Distractors

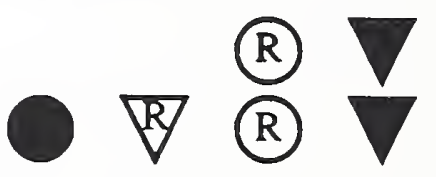

5's 8's 9's 10's No's Total

18

5

$40 \quad 100$

$33 \quad 100$

$37 \quad 100$

$22 \quad 100$

$29 \quad 100$

$\begin{array}{lllll}2 & 1 & 2 & 13 & 100\end{array}$

Distractors

5's 8's 9's $\underline{10 ' s}$ No's Total

$\begin{array}{lllll}8 & & & 21 & 100 \\ 1 & 2 & & 36 & 100 \\ & 1 & & 38 & 100 \\ 17 & & & 15 & 100 \\ 9 & 2 & 1 & 19 & 100 \\ 7 & & 2 & 12 & 100\end{array}$

Distractors

$\underline{5 \text { 's }} \underline{8 \text { 's }}$ 9's $\underline{10 ' s}$ No's Total

81

$37 \quad 100$

$\begin{array}{lll}34 & 19 & 100\end{array}$

$\begin{array}{lllll}8 & 2 & 1 & 33 & 100\end{array}$

32

$8 \quad 100$

$\begin{array}{llll}4 & 2 & 13 & 100\end{array}$

6

13100 
Table 7. Continued

\section{Back Foliage Condition}

\section{Topmarks}

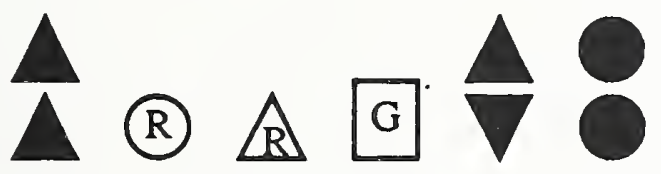

Top 1's 2's 3's 4's 6's 7's Mark

$\begin{array}{lllllll}1 & 18 & 1 & 1 & 1 & & \\ 2 & 2 & 43 & 11 & 6 & & \\ 3 & 10 & 6 & 32 & 2 & 2 & 1 \\ 4 & 2 & 3 & 4 & 53 & & \\ 6 & 20 & 2 & 2 & 4 & 43 & 9 \\ 7 & 13 & 1 & & 1 & 7 & 47\end{array}$

Twilight Conditions

Topmarks

Top 1's 2's 's 4's 6's 7's Mark

$\begin{array}{lllllll}1 & 26 & 2 & 1 & 3 & 8 & 7\end{array}$

$\begin{array}{lllllll}2 & 2 & 7 & 11 & 20 & 1 & 1\end{array}$

$\begin{array}{lllllll}3 & 8 & 3 & 40 & 2 & 1 & 3\end{array}$

$\begin{array}{llll}4 & 3 & 49\end{array}$

$\begin{array}{lllllll}6 & 7 & 1 & 4 & 4 & 29 & 6\end{array}$

$7 \quad 16$
Distractors

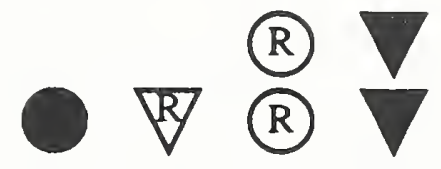

5's 8's 9's 10's No's Total

2

22

$\begin{array}{lll}16 & 2 & 2\end{array}$

$27 \quad 100$

32

9

4

21

$28 \quad 100$

$5 \quad 100$

11100

$25 \quad 100$

\section{Distractors}

$\underline{\text { 5's 8's 9's 10's No's Total }}$

$\begin{array}{llllll}8 & & 1 & 2 & 43 & 100 \\ 28 & & & & 30 & 100 \\ 8 & & & & 35 & 100 \\ 15 & & & & 33 & 100 \\ 9 & & & & 40 & 100 \\ 8 & 1 & 3 & 2 & 15 & 100\end{array}$




\subsection{Experiment 2}

The data from experiment 1 strongly suggest that the presence of a topmark did not appear to improve the visibility of buoys under any lighting condition. Furthermore, buoys were visible at a far greater distance than topmarks $(1.6-2.4 \mathrm{~km}$ or $1-1.5$ mile vs $0.3-0.6 \mathrm{~km}$ or 0.2 to 0.4 $\mathrm{m})$ for front lighting. These data do not, however, allow one to identify what feature of the buoys allows one to differentiate between buoys. As a result, in the subsequent experiment (2) subjects were asked to indicate when they could identify the color of the buoy as well as its type. They were not asked to identify the type of topmark, but only to indicate if they saw a topmark. Since experiment 1 had also indicated that back lighting significantly decreased the ability to identify a buoy accurately, only the two front lighting conditions were studied in experiment 2 . Otherwise the procedure was very similar to that followed in experiment 1 , although the 10 observers had had more experience with navigation and aids to navigation.

Thus, in experiment 2, 10 observers matched the buoy that they saw against an identification chart that contained pictures of buoys with the appropriate topmark. They indicated what color the buoy was and if they saw a topmark on the buoy. They also rated the visibility of all buoys on the 7-point visibility scale.

Figure 14 confirms the findings from experiment 1; namely that topmarks did NOT improve the visibility of buoys in experiment 2 . In this figure, box plots of buoy visibility for the four buoys tested with and without topmarks are graphed for both environmental conditions combined. An analysis of variance comparing the identification distances for buoys with topmarks and for buoys without topmarks was not significant $(p<.1)$.

Figure 15 demonstrates that as in experiment 1 , buoy type had a significant effect in experiment 2 (confirmed by a significant analysis of variance $p<.001$ ). In this figure, box plots of the visibility distances for the 10 buoy types are shown for both the front water and front foliage conditions combined. As in experiment 1 (figure 5), median visibility distance was greatest for the starboard buoys (Stbd and StbTM) followed by the safe water buoys (Safe and SafTM). Distances were shortest for danger (Dgr and DgrTM) and east (EasTM), with intermediate visibility for port (Port and PrtTM and North (NthTM). Close inspection of this figure reveals a slight tendency for the buoys with topmarks to be visible at slightly greater distances in terms of median visibility. As noted above the overall effect of topmark presence did not have a significant effect on buoy visibility. An analysis of variance revealed no effect of environment (foliage versus water) in experiment $2(p<.01)$.

Figure 16 compares the data for mean visibility distance data for topmark presence with that for color identification in experiment 2. This bar plot demonstrates vividly that colors were identified at much greater distances (sometimes 4-5 times as great) as topmarks. Furthermore, in experiment 2 , subjects were asked not to identify the type of topmark specifically but merely to indicate if they saw a topmark - a simpler task than identifying it by name. A two-way analysis of variance comparing color visibility and topmark visibility was significant $(p<.01)$. Figure 17 presents box plots of the data for color identification distance for each buoy type in experiment 2. This figure makes it clear that the red on the starboard buoy was seen at the greatest distance (median of 2.8 equivalent $\mathrm{km}$ or 1.75 miles) while the colors for the other buoys were seen at generally shorter distances, around 1.8 equivalent $\mathrm{km}$ or 1.1 miles. 
SУ31JW07IX NI AIITI8ISIN

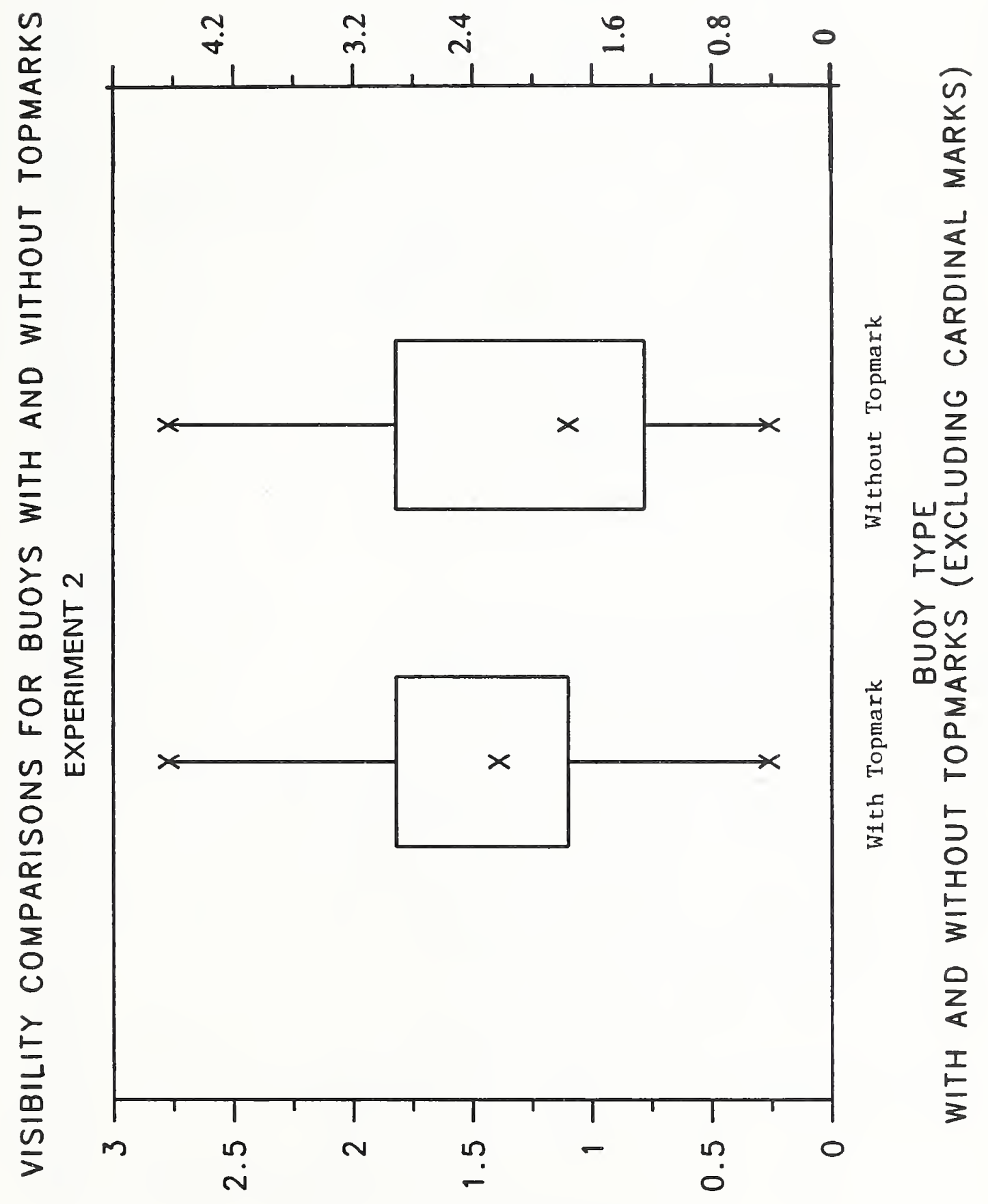

S37IW NI AIIרI8ISIA 


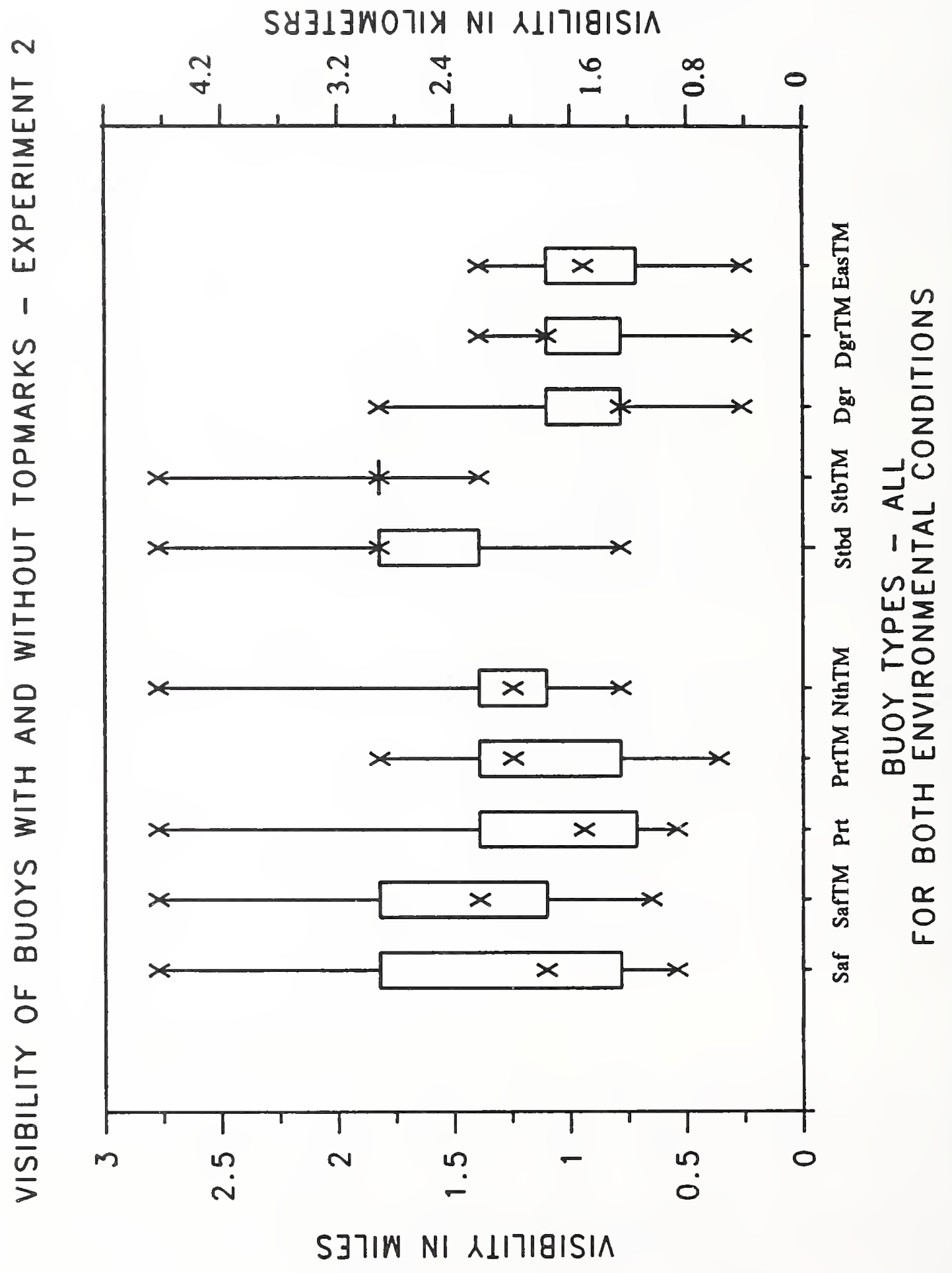




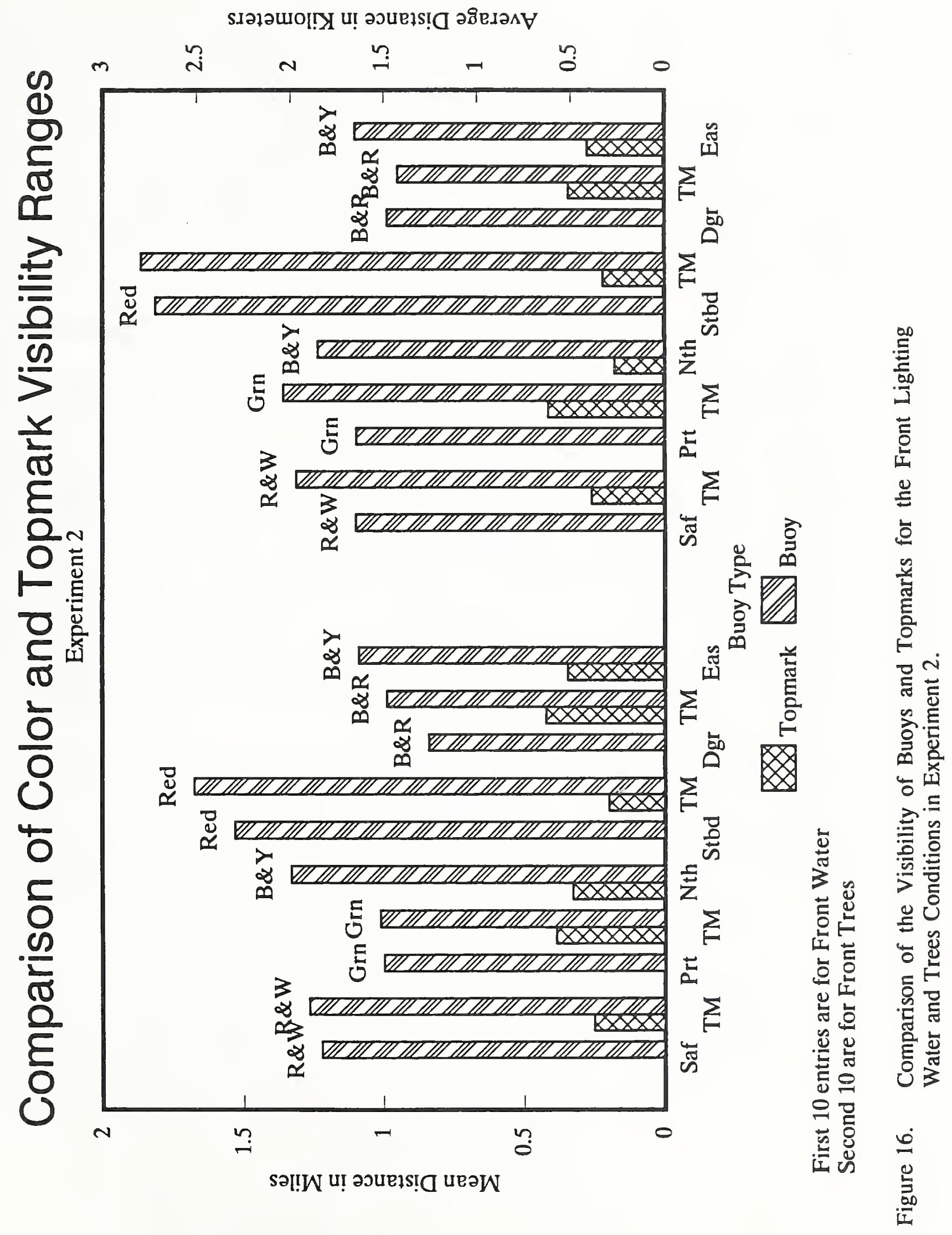




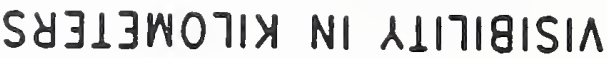
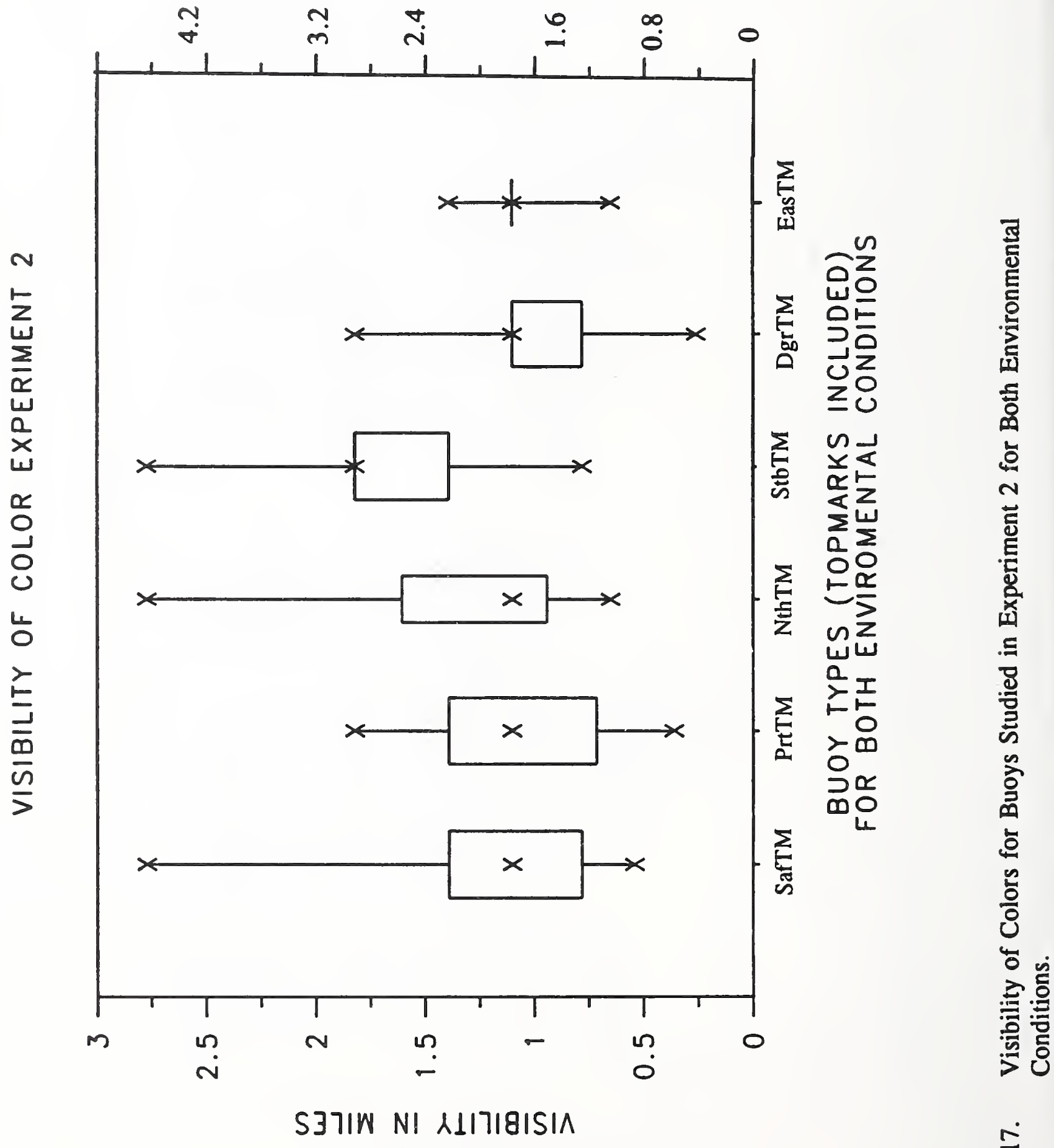

$\stackrel{ }{ \pm}$ 
Figure 18 presents box plots of the visibility distances for each topmark type for both environmental conditions combined. This figure indicates clearly that topmarks were not detectable as such beyond viewing distances equivalent to about 0.8 to $1.0 \mathrm{~km}$ ( 0.5 to 0.6 miles). The port mark, the cylindrical can, was among the most visible of the marks while the double mark for north and starboard were among the least visible. Figure 19 presents box plots of buoy visibility for each of the ten subjects. Again, an analysis of variance demonstrated a significant effect of subject with two subjects 3 and 9 (the oldest and the youngest) performing the most poorly. Across the two experiments, there was a tendency for the subjects in experiment 2 to be able to identify buoy configurations at greater distances, possibly because of their greater familiarity with sailing, detecting objects at long distances, and using aids to navigation. They were also much more familiar with current Coast Guard recommendations for buoy configuration and color.

Table 8 presents percentages of the number of times that each buoy configuration choice was selected in experiment 2 for all visibility distances combined. Again the left column refers to the buoy type actually presented, while the top row refers to configurations shown on the identification chart (Figure 2). In comparison with Table 6 from experiment 1, buoy configuration " $\mathrm{C}$ " which consisted of a black buoy with a spherical topmark, was rarely selected. (Of course the data obtained in Table 7 were restricted to front lighting conditions only.) Table 8 provides a detailed breakdown of the percentage of times that each configuration was selected for each buoy type presented. In this table it can be seen that "C" was selected relatively rarely and was not a major choice even for buoy type "B" - the green buoy. Unlike the subjects in Experiment 1 , those in experiment 2 evidently had learned, likely through experience and training that the green buoy is likely to appear dark at longer distances, but is really green since the Coast Guard no longer uses black buoys. As a result, they selected the black buoy much less frequently than did the subjects in experiment 1 . Inspection of the data in table 8 again reveals very little effect of the topmark on visibility.

Figures 20 through 22 present rating data for buoy visibility in experiment 2 . In these figures, the ratings given by the subjects using the 7-point rating scale were averaged for both the front water and foliage. Unlike experiment 1 , subjects rated each buoy for "visibility" at each viewing distance. Figure 20 presents the rating data for each buoy configuration averaged over all viewing distances and environmental conditions. This figure indicates that while the buoys tended to receive similar ratings, those for the port buoy with a topmark tended to be lowest. Figure 20 also suggests that for front lighting conditions buoys without topmarks tended to receive very slightly higher mean visibility ratings, while some of the buoys with red color $(A, G, H)$ also tended to be rated slightly higher. Figures 21 and 22 present mean rating data as a function of viewing distance for different buoy types, with figure 21 presenting data for buoys with red color; namely, safety, danger and starboard; and figure 22 presenting data for buoys with green or black colors; namely, north, east and starboard. Each figure demonstrates a marked drop in ratings (from 5 to 3 or lower) for viewing distances longer than about $0.8 \mathrm{~km}$ ( 0.5 miles), with a decline toward 1 by about $0.28 \mathrm{~km}(0.16$ miles). 


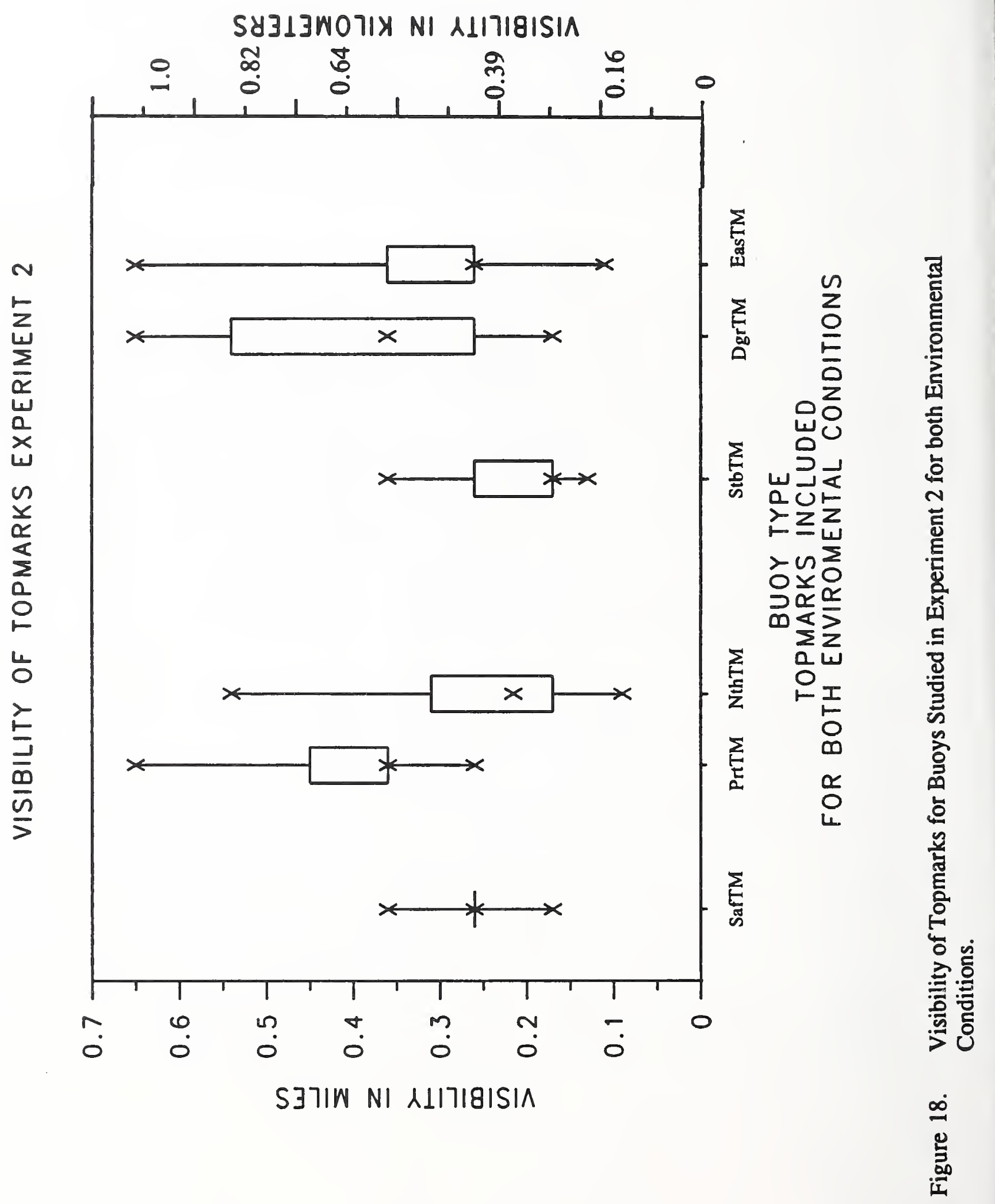




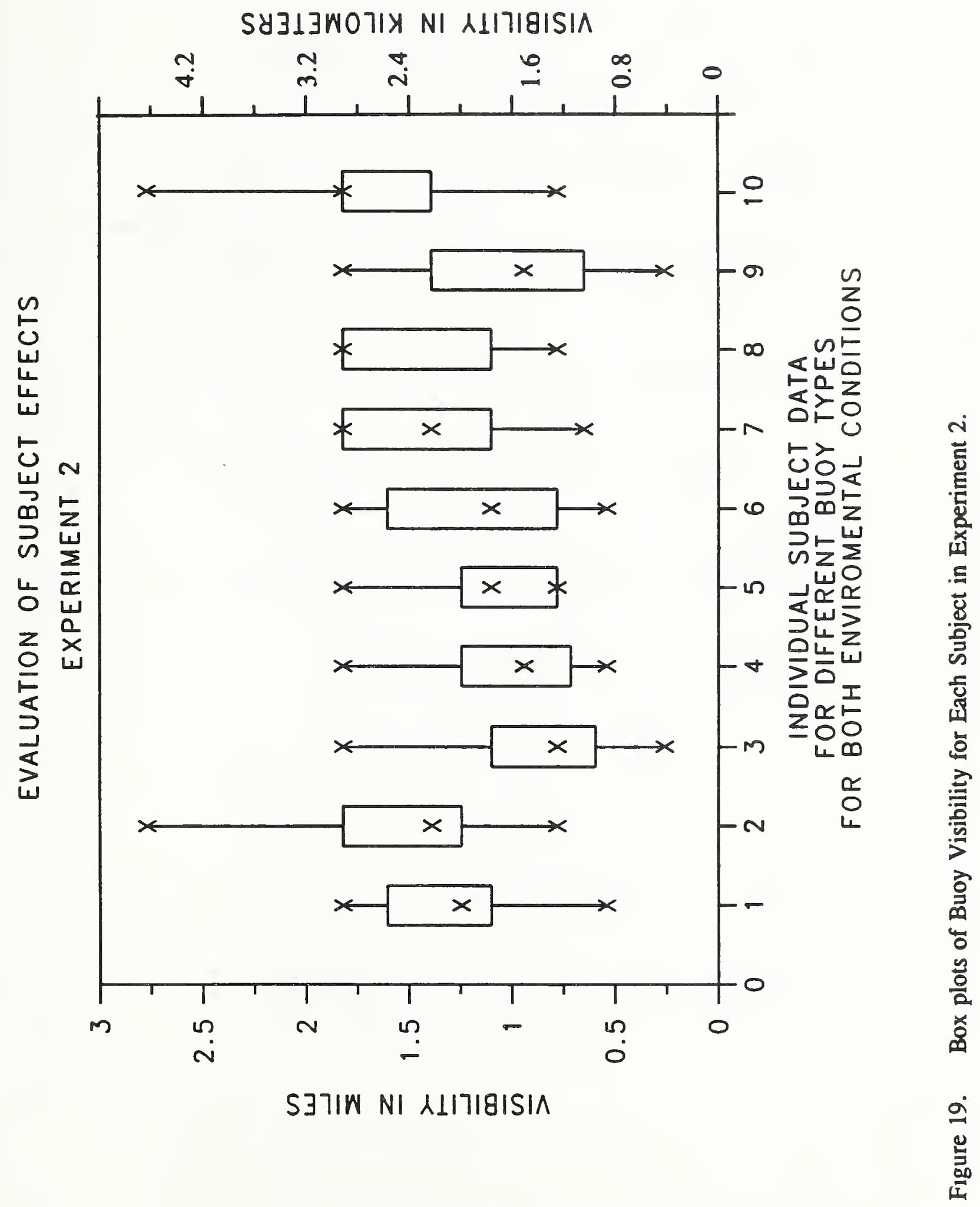


Table 8. Percentage of Times that Each Buoy Configuration Was Selected in Experiment 2.

Safe Port $\mathrm{Blk}^{8} \mathrm{RG}^{3} \mathrm{BY}^{3}$ Nrth Stbd Dgr East $\mathrm{GR}^{3}$ NO's

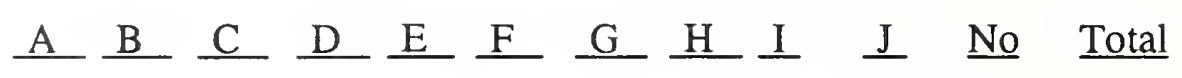

$\begin{array}{lllllllllllll}\text { A } & 81 & & & & & 4 & 1 & 1 & & & 13 & 100 \\ \text { A2 } & 84 & & & & 4 & 1 & 1 & & & & 10 & 100 \\ \text { B } & & 77 & 3 & & & & 4 & & & 4 & 20 & 100 \\ \text { B4 } & & 66 & 5 & & & & & & 4 & & 29 & 100 \\ \text { F1 } & & 1 & & & 8 & 82 & & & 2 & & 14 & 100 \\ \text { G } & 1 & & & & & & 90 & & & & 9 & 100 \\ \text { G3 } & & & & & & & 92 & & & & 9 & 100 \\ \text { H } & & & 3 & 2 & & & 2 & 71 & & 1 & 22 & 100 \\ \text { H7 } & & 8 & 4 & 4 & & & 1 & 65 & & 3 & 26 & 100 \\ \text { I6 } & & & 2 & & 6 & 1 & & & 67 & & 23 & 100\end{array}$

8 Distractors chosen for resemblance to buoy choices. 


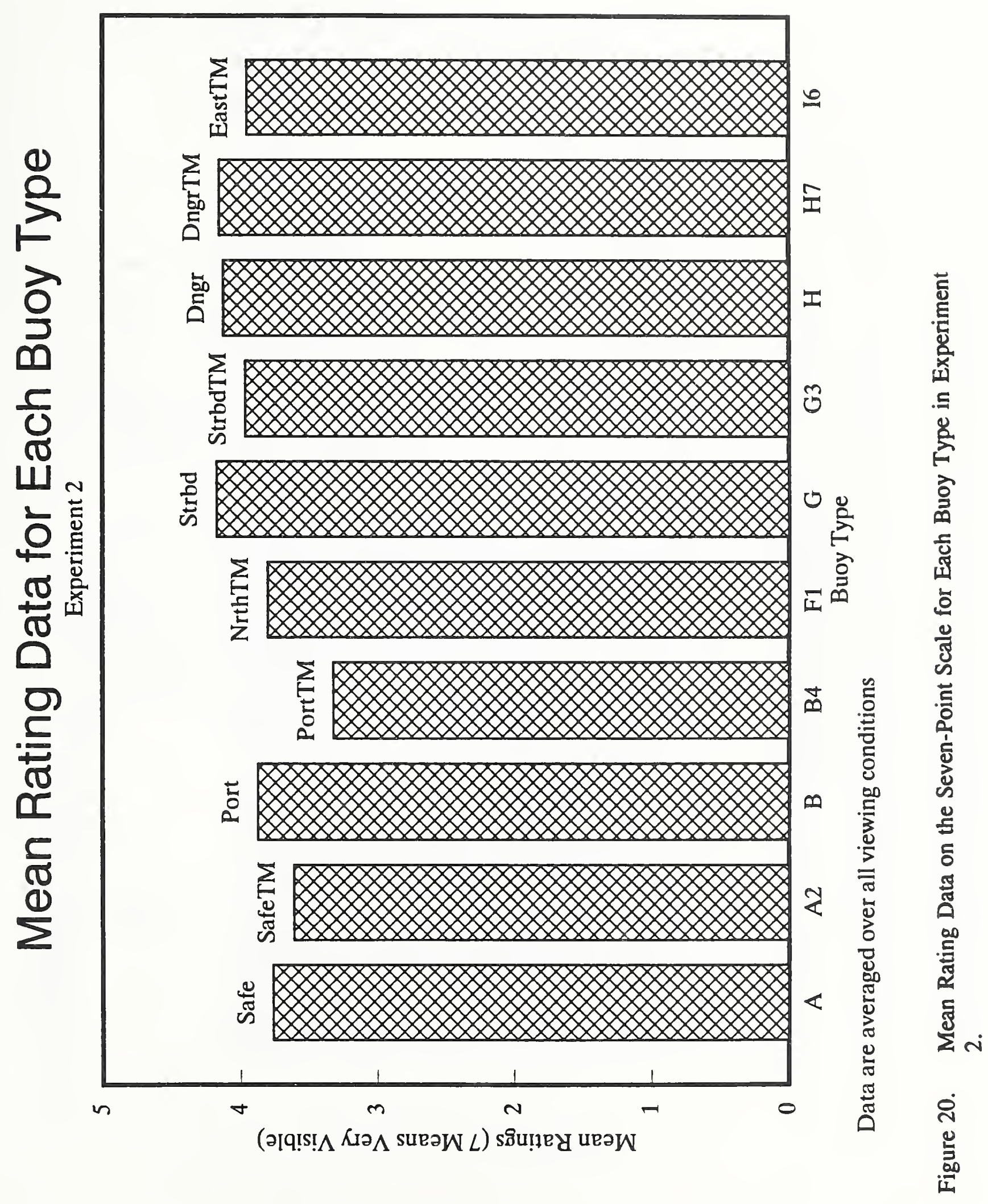




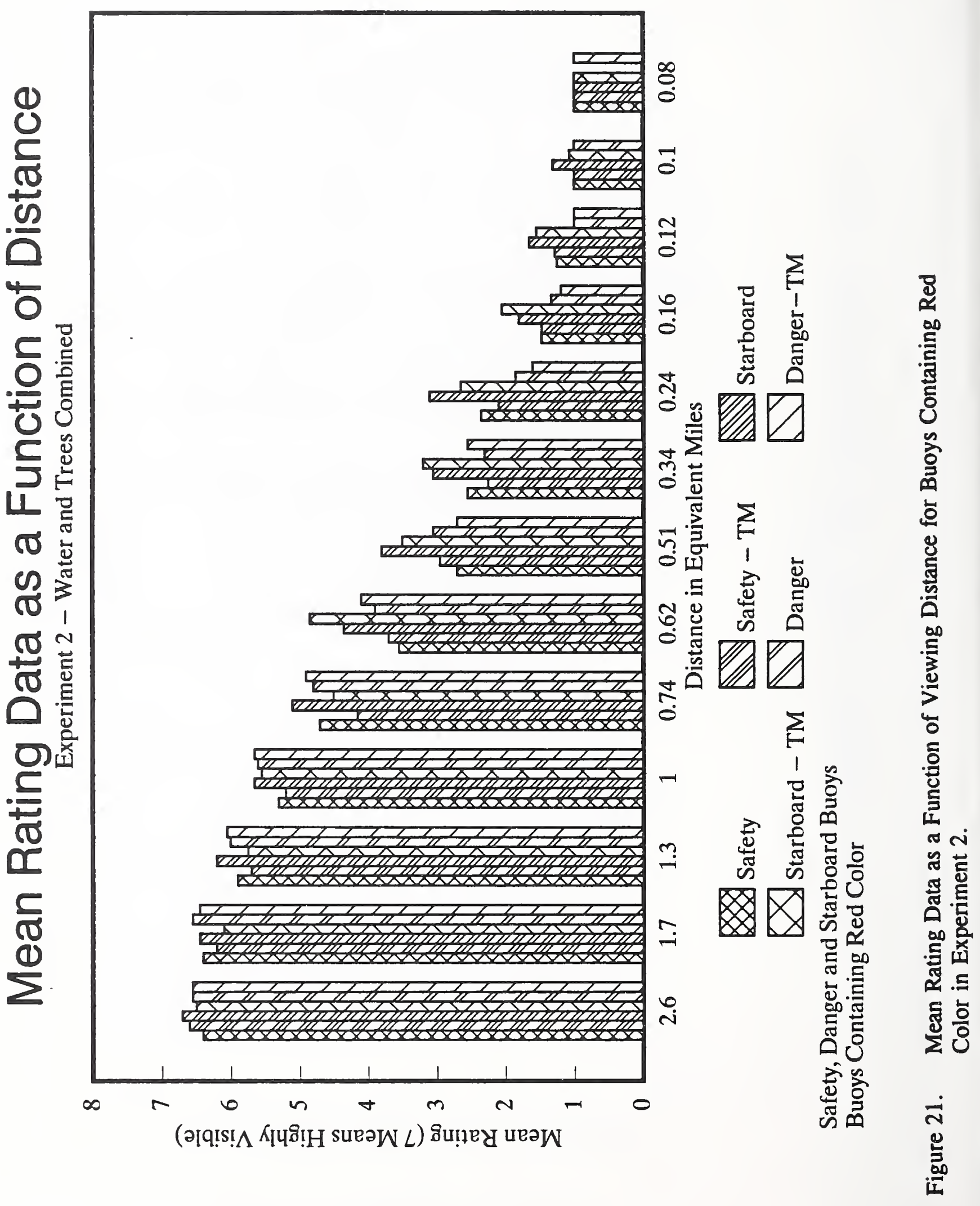




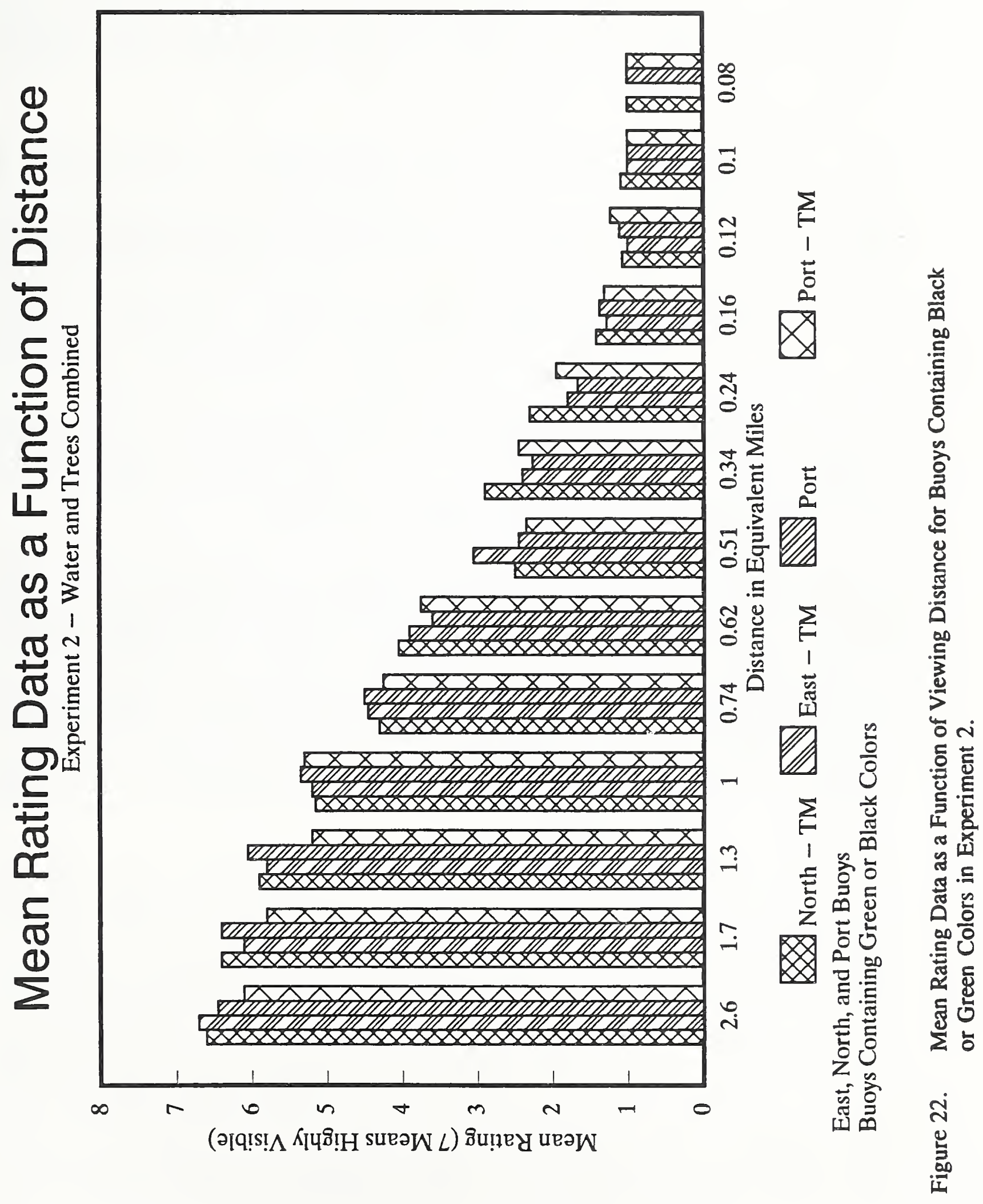


The visibility of ten different buoy/topmark configurations was assessed for five viewing conditions. Four of the buoys, including safe water, danger, port and starboard were shown with and without topmarks, while two buoys, the cardinal marks north and east, always had topmarks. The results for these four buoys were compared to determine the effect of topmarks on buoy identification and visibility distance.

Analysis of the data from both experiments indicates clearly that the presence of a topmark did not increase the visibility of a buoy at distances beyond 0.8 equivalent $\mathrm{km}(0.5 \mathrm{miles})$. Rather, experiment 2 suggests that color was the critical cue in detecting and identifying a buoy for front lighting conditions. Data from experiment 1 indicate that both the back lighting and twilight condition severely reduced the visibility of the buoys, with no significant improvement in visibility attributable to the presence of a topmark. Data from both experiments revealed significant differences in the detectability of the different buoys with the two red buoys, starboard and safe water, detected at the greatest distance, and the green buoy, port detected at the shortest distance. Comparison of the effects of foliage and water for front lighting conditions showed little effect in either experiment, probably because of some confounding in the photography. It was difficult to get purely water or purely foliage conditions at all distances. The major environmental effect, however, was that of lighting geometry, with front lighting being far superior to back lighting. Interestingly, the use of topmarks did not appear to improve buoy visibility even at short distances in back lighting conditions.

The data obtained in the present experiment are in accord with previously reported research. For example, Blaise (1971) found that the use of back lighting markedly reduced all color recognition, with the greatest impact on the reds. Under more satisfactory lighting conditions, red was the most satisfactory color, with the longest identification range and the fewest confusions with other colors. Blaise (1971) also found that lighting and background contrast did not particularly affect shape recognition with shapes subtending 2.64' visual angle being recognized at distances of $250 \mathrm{~m}$. Colors, especially reds, were recognized well beyond this for front lighting conditions, while blacks tended to disappear into the background. When objects were back lit, against the sky (silhouetted) color tended to disappear as a cue, a finding confirmed in the present experiment.

Walraven's data provided valuable information on the optimal angle for the apex of cardinal marks as well as on possible confusions between the double marks for danger and cardinal indication. He found that the mark for east was identified correctly the most frequently, regardless of angle, followed by the mark for west. These two marks were the only ones which were identified correctly more than $50 \%$ of the time, regardless of apex angle. At $60^{\circ}$, both marks were identified correctly $80 \%$ of the time. If the viewing distance were reduced to $9 \mathrm{~m}$, identification frequency went up to $90 \%$. Walraven commented that the identification distance would translate into an effective viewing distance of $700 \mathrm{~m}$ (for observers with good eyesight). As a result, Walraven concluded that an apex angle of $60^{\circ}$ and a separation distance of $66 \%$ cone height was practicable. These configurations were used in the present experiment. Finally, Walraven suggested that the incompatibility between the ability to detect objects and recognize colors is almost insurmountable for green. Walraven presented data which suggests that a very dark green object could be visible at about $27 \mathrm{~m}$ for a light background but that its color would 
be detected as such at only between 1 and $4 \mathrm{~m}$. He noted further that because red is more conspicuous than green, particularly against a green-shaded sea, perhaps the best that can be hoped for green is a perception of "not red". As a result, he recommended a darker green to maximize contrast with the sky and sea. In the present experiment, of course, green was confused with black suggesting that darkening green may not increase its visibility.

Evaluation of the data reported by JAPMA for recognition of the color configurations for the cardinal and isolated danger marks revealed that size and number of the horizontal bands used on the buoys played an important role in their recognizability. Analysis of the data on the recognizability of the colors and shapes of topmarks for lateral, safe water, and special marks indicated serious problems with the recognizability of these shapes even at $500 \mathrm{~m}$. At $300 \mathrm{~m}$ the green square, red triangle, and red sphere were all distinguished readily, while only the cross of the yellow cross could be distinguished. By $500 \mathrm{~m}$, while the red and green colors were recognized accurately, their shapes were not. At $800 \mathrm{~m}$, no color or shape could be recognized correctly. These data support those of the present experiment in indicating that color was identifiable at a substantially greater distance than geometrical shape.

The data from the present two experiments strongly suggest that the critical cue in determining buoy type is surface color, not topmark type. Furthermore, these colors are detectable at significantly greater distances if the buoy is lighted from the front. Under back lighting conditions, both color and topmark appear to be ineffective. Although topmarks are intended to enhance the visibility of buoys in less than perfect viewing conditions, the present data do not support this intent. Rather, the data indicate that the topmark (as sized in the present experiment) is ineffective at distances greater than 0.3 to $0.6 \mathrm{~km}$ (0.2 to 0.4 miles). This effect likely occurs because the size of the topmark is beyond the capability of the visual system to resolve it. While training might have improved the overall accuracy for the different viewing conditions examined in experiment 1 the effects of the training would be limited to distances below $0.8 \mathrm{~km}(0.5$ miles), and would not likely improve the viability of topmarks as an effective aid to navigation. The only way in which topmark visibility can be increased is by increasing their size. The data suggest that they would have to be doubled in size to increase their visibility to $0.8 \mathrm{~km}$ ( 0.5 miles) consistently. The impact of such an increase on the logistics of implementing and maintaining buoys is likely to be sizeable. 
6. Bibliography and Additional References of Interest

ANSI, ASC Z535.1, American National Standard Safety Color Code. Approved 1991 for Publication by the American National Standards Institute. Now in Press, 1992.

Blaise, P. Color and Colorimetry. Bulletin of the International Association of Lighthouse Authorities, No. 35, Jan 1968, Pp. 10-25.

Blaise, P. Daymarks as aids to marine navigation. Bulletin of the International Association of Lighthouse Authorities, No. 47, Apr 1971, Pp. 1-29.

Blaise, P, and Pétry, P. The colours of signals and some comments on the shapes of daymarks. Bulletin of the International Association of Lighthouse Authorities, No. 42, Oct 1969, Pp. 5-25.

Burns, S.A., Smith, V.C., Pokorny, J., and Elsner, A.E. Brightness of equal luminance lights. Journal of the Optical Society of America, 1982, 72, Pp.1225-1231.

Clark, G.P. Recognition characteristics study for buoys. U.S. Coast Guard, Washington, D.C. Report No. 503, Jan, 1970.

Colburn, W.E., and Thompson, W.R. Lightweight lighted buoy development for use as discrepancy NAVAIDS. U.S. Coast Guard, Groton, CT., CG-D-2-77, Dec, 1976.

Filliben, J.J. Dataplot - An Interactive High-Level Language for Graphics, Non-Linear Fitting, Data Analysis and Mathematics. Computer Graphics, 1981, 15, Pp. 199-213.

Forbes, T.W. Luminance and contrast for sign legibility and color recognition. Transportation Research Record N611, Pp. 17-24.

Halsey, R.M. Identification of signal lights. I. Blue, green, white, and purple. Journal of the Optical Society of America, 1959a, 49, Pp.45-55.

Halsey, R.M. Identification of signal lights. II. Elimination of the purple category. Optical Society of America, 1959b, 49, Pp.167-169.

Henderson, D. and May, B. Marine visibility research and development initiatives of the U.S. Coast Guard. Transportation Research Record 1149, Pp. 31-31.

International Association of Lighthouse Authorities (IALA). Maritime Buoyage System. Paris France, Sept 1983 (a).

International Association of Lighthouse Authorities (IALA). The IALA Maritime Buoyage System Guidelines. Paris, France, 1983 (b). 
International Association of Lighthouse Authorities (IALA). Recommendations for the surface colours used as visual signals on aids to navigation. Extract from the IALA Bulletin, No. 84 1980/4, May 1980.

Japan Association for Preventing Marine Accidents. Research study on the introduction of the international maritime buoyage system: Report on field test performance. 1981, Ref 6.10

Jenkins, S.E. and Cole, B.L. Daytime conspicuity of road traffic control devices. Transportation Research Record 1093, P. 74-80.

Nagy, A.L. Sanchez, R.R. Critical color differences determined with a visual search task. Journal of the Optical Society of America A , 1990, 7, Pp. 1209-1217.

Niemiller, M.K. Comparative evaluation of visual distress signals. U.S. Coast Guard, Groton, CT., CG-D-47-76, Aug, 1976.

Sivak, M., and Olson, P. L. Optimal and minimal luminance characteristics for retroreflective highway signs. Transportation Research Record 1027, Pp. 53-57.

U.S. Coast Guard. Aids to Navigation. COMDTINST.M16500.3A. 1991.

Walraven, J. The marking of buoys in the combined cardinal and lateral system. Instituut voor Zintuig Fysiologie TNO, Soesterberg, Netherlands, 1978 Report No IXF 1978-18.

Wickens, C.D. and Andre, A.D. Proximity compatibility and information display: Effects of color, space, and objectness on information integration. Human Factors, 1990, $\underline{32}$, Pp.61-77. 
The U.S. Coast Guard uses buoys to mark different conditions in the water such as safe water, danger, channels, and directions. Currently these conditions are indicated by different colors on the buoys. The Coast Guard is now considering some changes to the existing buoys. These include the use of different combinations of colors on the buoys themselves and the use of geometric shapes known as "topmarks" on top of the buoys.

We would like your help in evaluating the visibility of these proposed changes to determine their effectiveness for mariners. This experiment is a simulation of conditions that you might actually see in the water as you approach or leave land. The purpose is to evaluate the visibility of different configurations and markings for buoys proposed for use by the U.S. Coast Guard. You will see a variety of marks, buoys, and colors during the experiment.

During the experiment, we will show you a series of slides which simulate buoys that you might see from a boat in the water. Your task is to evaluate the visibility of the buoy as it is presented to you. Attached is one chart of proposed buoy colors and another of proposed topmarks for your guidance during the experiment.

We would like you to indicate when you first see something in the slide, other than water and sky. Please use the number shown on the slide. Next, we would like you to indicate when you can identify the object that you saw as a buoy. We would like to know any colors, color combinations, or topmark shapes that you can identify on this object. Please indicate when you see each of these elements by pointing to them with this laser pointer. Finally, we would like you to rate the buoy's overall visibility, using a scale of $1-7$, where 1 means not very visible and 7 means very visible. We will tell you when to make this rating.

Do you have any questions? Thank you very much for your participation. 
Appendix B. Configuration of Buoys Studied

Table B1. Dimensions of Buoy and Topmark Models

Tower Height $=171.5 \mathrm{~mm}(6.75 \mathrm{in})(152.4 \mathrm{~mm}$ or 6.0 in to top of tower $)$

Tower plus base height $=215.9 \mathrm{~mm}(8.5 \mathrm{in})$

Base Diameter $=120.6 \mathrm{~mm}(4.75 \mathrm{in})$

Topmark configurations

Safe Water - One red ball -

For $508 \mathrm{~mm}(20 \mathrm{in})$ topmark - Height $=15.7 \mathrm{~mm}(0.62 \mathrm{in})$, Width $=7.9 \mathrm{~mm}(0.31 \mathrm{in})$, Mount $=9.4 \mathrm{~mm}(0.37 \mathrm{in})$

Danger - Two black balls

For $508 \mathrm{~mm}$ (20in) topmark - Height $=19 \mathrm{~mm}(0.75 \mathrm{in})$, Width $=19 \mathrm{~mm}(0.75 \mathrm{in})$, Space $=$ $12.7 \mathrm{~mm}(0.50 \mathrm{in})$, Mount $=12.7 \mathrm{~mm}(0.50 \mathrm{in})$

Port - One green can

For $508 \mathrm{~mm}(20 \mathrm{in})$ topmark - Height $=25.4 \mathrm{~mm}(1.0 \mathrm{in})$, Diameter $=22.2 \mathrm{~mm}(0.875 \mathrm{in})$,

Mount $=12.7 \mathrm{~mm}(0.50 \mathrm{in})$

Starboard - One red cone

For $508 \mathrm{~mm}(20 \mathrm{in})$ topmark - Height $=17.8 \mathrm{~mm}(0.70 \mathrm{in})$, Width $=203 \mathrm{~mm}(0.8 \mathrm{in})$, Mount $=$ $12.7 \mathrm{~mm}(0.50 \mathrm{in})$

Cardinal Marks (2) - Two black triangles - four positions

For $508 \mathrm{~mm}(20 \mathrm{in})$ topmark - Height $=19 \mathrm{~mm}(0.75 \mathrm{in})$, Width $=19 \mathrm{~mm}(0.75 \mathrm{in})$, Mount $=$ $12.7 \mathrm{~mm}(0.50 \mathrm{in})$, Spacing $=12.7 \mathrm{~mm}(0.50 \mathrm{in})$

North - Two triangles, both pointing up

East - Two triangles, upper pointing up, lower pointing down

Buoy Colors in the IALA system

Red and White Stripes

Safe Water

Black and Red Stripes

Danger

Red

Starboard

Green Port

Black and Yellow Cardinal

Topmark Colors in the IALA system

Cardinal Topmarks Double Cones - Color Black

North

East

Points upward

South

Base to Base

West

Points downward

Point to Point

Lateral Topmarks Cone or Cylinder

Starboard

Port

Single cone - Color Red

Isolated Danger Topmark Two Black spheres, one above the other

Safe Water Topmark Single Red sphere

Special Topmark Single Yellow "X" 


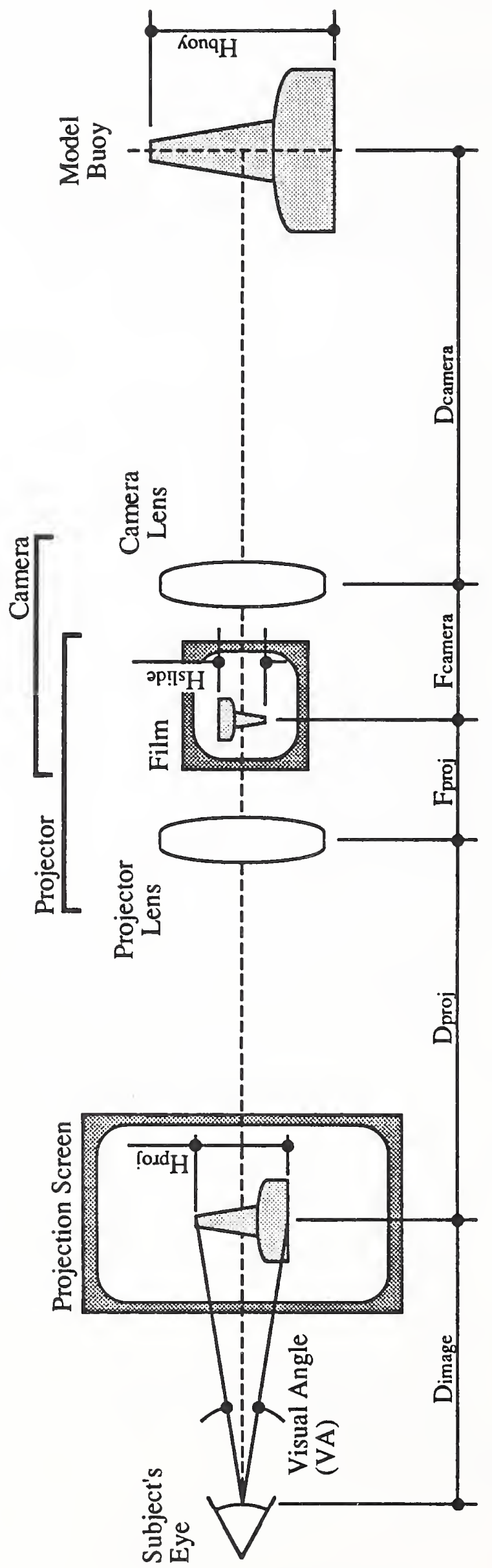

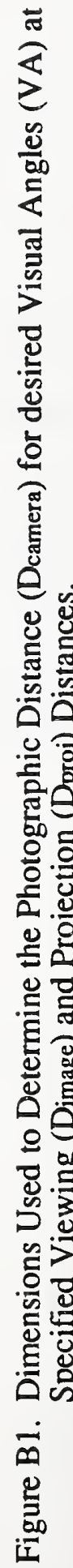


Appendix C. Replies to Query about Topmarks

1. Pintsch-Bamag

As master of ocean going vessels, believe topmarks are a must for marking wrecks, for situations in which color coding of buoys has been obscured through poor maintenance (e.g. bird droppings, etc.), and for orientation regarding ship's position.

2. Gakuyo Toki Kogyo

Had problems of some breakage on supporting center rods of some top marks on first application. Since a redesign have had no further troubles.

3. Trinity House Lighthouse Service

Now use GRP moldings which are very durable for Cardinal buoys with double-cone topmark, because of early problems. Had no problems initially with spherical, can, conical, and cross topmarks.

"View topmarks as part of the 'whole' buoy message provided by shape, colour and light character". Note that visibility is fairly subjective matter, particularly in the prevailing weather conditions around the U.K..

4. Seezeichenversuchsfeld

Conducted sea trials in Baltic Sea off Fehmarn Island in Dec 1975. Attended by own Aids to Navigation people, but also by IALA Buoyage committee. Included comments of all attendants. Also had knowledge of scientific work done by TNO at Soesterberg by Walraven.

Developed class 2 ball topmark of $360 \mathrm{~mm}$ instead of $400 \mathrm{~mm}$. Did not need class 1 ball topmark so left it out of catalogue. Special mark topmarks were rarely needed.

All other topmarks made of rotational molded and dyed-in polythene which are fixed to their support posts with sockets.

Use more and more class 2 topmarks on cardinal and isolated danger buoys (with "double" topmarks) because of wind impact and stability problems.

No complaints about visibility - believe everybody is content with IALA topmarks.

Damaged topmarks are thrown away so that there is no maintenance at all. Problems due to weather were diminished by fixing each individual socket or sleeve with bolts or clamps to the support post. In some cases even support posts buckled which is why they went over to the class 2 double topmarks on the standard lighted buoy. 
Also use unlighted buoys on inland waterways which have superstructures in either "can" or "cone" shape. Here the silhouette is accomplished by crossed aluminum plates which can serve as a radar reflector.

5. Gilman - phone conversation

Every inch of elevation important. The higher the object is against the horizon or the sky, the better. As such the topmark could be very helpful to the mariner. Visibility changes every day, with rain, storm, high seas, and no road signs. Often foggy or hazy. Any information can help. See study on day marks.

6. Grewal - ANA NAVAIDS LTD

Believes top marks have proved very useful and effective as an aid to navigation. Have not supplied a single buoy without topmarks, even lateral buoys. Customers very particular about always having topmarks on buoys. Topmarks made of Glass Reinforced Plastic (GRP) for weight reasons. Designed and synchronized (?) per IALA specs. Normal life is about 5-6 years. Color is impregnated, so there is no maintenance work required.

Visibility very satisfactory although it depends on dimensions of marks and height above sea level. Experience is that topmark/combination of "top marks of 1 meter base diameter at a height of 5 meter from the sea level, would be very easily visible from about 5 nautical miles or so. In fact we could pick up the top mark first then the Pillar Daymark. At another place, daymark with $0.6 \mathrm{M}$ diameter base, we could easily see the top mark from $3.0 \mathrm{n}$ miles". In general have found top marks on buoys to be quite useful. 
NIST-1144

(REV. 3-0)
U.S. DEPARTMENT OF COMMERCE NATIONAL INSTITUTE OF STANDARDS AND TECHNOLOGY

BIBLIOGRAPHIC DATA SHEET
1. PULLCATIOH OR REPORT MUMBEA

NISTIR 4756

2 PERFORMIMO ORCAMIZATION REPOAT MUMEER

3. MUEUCATIOM DATE

MARCH 19.92

4. TITLAND SUDTITE

Evaluation of the Visibility of Buoys and Topmarks

5. AVTHOT(S)

Belinda L. Collins and Phllip Sanders

6. PERFORMIMO ORQNMEZTION (IF JOINT OR OTHER THAN MIST, SEE IMSTRUCTIONS)

U.S. DEPANTMETT OF COMMERCE

MATIONAL INSTITUTE OF STAHDARDS AMD TECHHOLOQY

cartmensLURG, MD 2000

7. CONTRACT/ORANT MULEER

Q. TYPE OF REPORT AND PEAIOD COVERED

9. SPONSOANG ORCANIZATION MAME AMD COMPLTE ADDRESS (STREE, CTV, STATE, ZTP)

U.S. Coast Guard

Washington, DC 20593

\section{SUPPLEMETANYMOTES}

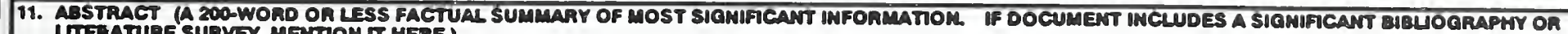
UTERATURE SUAVEY, MENTOM IT HERE)

The research literature on the visibility of colors and topmarks used to code information used on buoys and other aids to navigation was reviewed. Although several studies suggested that color may be recognizable at greater distances than topmarks, it is difficult to draw conclusions about the relative effectiveness of different topmark, color, and buoy configurations because they used small numbers of observers and tested different aspects of aids to navigation. Consequently, two experiments were conducted to determine the distance at which buoy topmark configurations could be correctly identified for different lighting geometries and background conditions. In experiment 1 , the visibility of buoys and topmarks as separate entities was evaluated for ten different buoy configurations in simulated waterway viewing environments. Four buoys, including safe water, danger, port and starboard, were shown with and without topmarks, while two buoys, the north and east, always had topmarks. Front and back lighted buoys were presented in both water and foliage environments, as well as in a "twilight" condition. In experiment 2 the visibility of buoys with integral topmarks was evaluated only for front lighting conditions. Analysis of the data from both experiments suggests strongly that topmarks did not increase the visibility the buoy configurations studied. It appears that the topmark is too small to be effective beyond $0.8 \mathrm{~km}(0.5$ mile $)$ - near the limit of visual resolution. The data indicated that color is a critical cue in determining buoy type, with significant differences in buoy detectability between red and green buoys. Front lighting also increased visibility distance significantly. Even under back lighting conditions, however, the presence of a topmark did not increase buoy visibility. While it is possible that training could have improved accuracy, this effect would likely be limited to distances shorter than $0.8 \mathrm{~km}$ ( 0.5 miles).

12. KEV WOADS (6 TO 12 ENTAIES: ALPLABETICAL ORDER; CAFTALEE OMLY PAOPEA MAMES; AMD SEPARATE KEY WORDS BY SEMICOLOMS)

Keywords: Buoy, color, detection, lighting, mark, navigation aid, shape, topmark, visibility 


